Universidad de Salamanca

Facultad de Medicina

Departamento de Anatomía e Histología Humanas

Laboratorio de Microscopía Electrónica

\title{
Estudio a \\ microscopía \\ electrónica de \\ ciertas especies \\ de dermatofitos \\ zoofílicos
}

Pablo Martín Clavijo

2009 
José Manuel Riesco Santos, Catedrático Acreditado de Anatomía Humana y Profesor Titular de Anatomía Humana de la Facultad de Medicina de la Universidad de Salamanca, Agustín Martín Pascual, Prof. Emétrito de la Universidad de Salamanca y Ricardo Vázquez Rodríguez Catedrático de Anatomía Humana de la Facultad de Medicina de la Universidad de Salamanca, en su calidad de Directores del Trabajo de Tesis Doctoral

\section{HACEN CONSTAR:}

Que el trabajo titulado:

ESTUDIO A MICROSCOPÍA ELECTRÓNICA DE CIERTAS ESPECIES DE DERMATOFITOS ZOOFÍLICOS

ha sido realizado bajo nuestra dirección por Don Pablo Martín Clavijo, en los Laboratorios Microscopía Electrónica del Departamento de Anatomía Humana y en el Servicio Central de Microscopía Electrónica de la Universidad de Salamanca y que a nuestro entender, el trabajo reúne los requisitos suficientes de experimentalidad, originalidad e interés científico y aplicativo, como para ser presentado y defendido como trabajo de Tesis Doctoral

Y para que así conste firmamos la presente en Salamanca a 30 de Junio de 2009

José Manuel Riesco

Agustín Martín

Ricardo Vázquez 


\section{Indice}

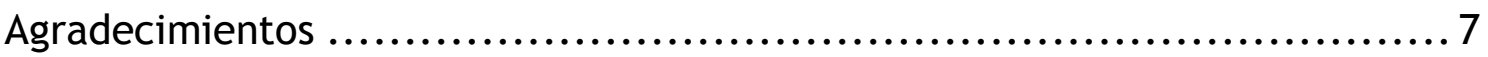



Introducción .......................................................... 15

Dermatofitos y dermatofitosis ....................................... 17

Generalidades................................................. 19

Taxonomía de los hongos .......................................... 19



Clasificación ecológica ............................................ 26

Clasificación taxonómica ......................................... 27



Rasgos generales de las tres especies estudiadas .................... 32

T. mentagrophytes ( $v$. mentagrophytes) ........................ 32



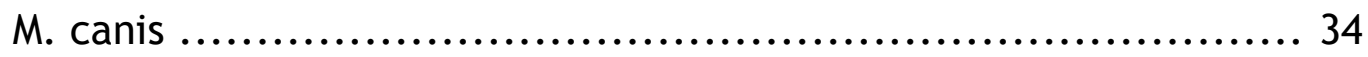

Repercusiones; epidemiológicas y económicas........................ 35

Hipótesis del trabajo .................................................... 37

Objetivos: ........................................................ 40

Como objetivos concretos, consideraremos: ........................ 40

Material y Métodos.................................................... 43

Muestras analizadas.................................................. 45 
Siembra de las muestras.

Procesado de las colonias para su estudio ultraestructural (MET y MEB) ... 47

Microscopía electrónica de transmisión. ............................ 47

Microscopía electrónica de barrido. ................................. 48

Tratamiento de texto e imágenes. Edición final........................ 51

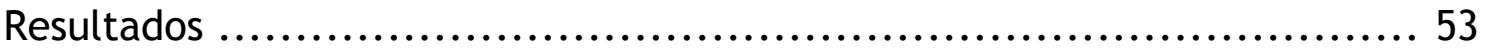

T. mentagrophytes (v. mentagrophytes) ............................. 55

Microscopía Electrónica de Barrido ................................. 55

Microscopía Electrónica de Transmisión .............................. 79

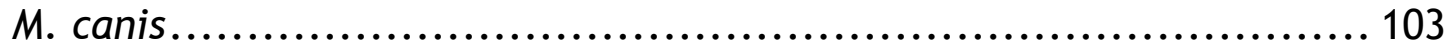

Microscopía Electrónica de Barrido ................................. 103

Microscopía Electrónica de Transmisión ............................. 109

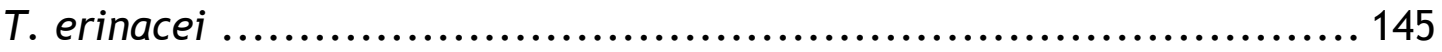

Microscopía Electrónica de Barrido ................................. 145

Microscopía Electrónica de Transmisión .............................. 171








Agradecimientos 
En primer lugar, expresar mi más profundo agradecimiento a mi padre, el Dr. D. Agustín Martín Pascual que, sin su ayuda, su estímulo, su paciencia y sus valiosos consejos esta tesis no hubiera sido posible. Pero además, le agradezco el ejemplo de amor al trabajo y el modelo de integridad moral que representa para mí y ello ha jugado un papel insustituible en mi enriquecimiento personal.

Tengo una gran deuda con el Dr. D. Ricardo Vázquez Rodríguez, por haber insistido de forma reiterada en la realización de este trabajo, considerándome capaz de emprender y finalizar tan largo camino, por su ejemplo, su continua enseñanza, su gran paciencia y su especial modo de transmitir comprensión y seguridad. Sincero agradecimiento y admiración.

Al Dr. D. Jose Manuel Riesco Santos por sus efectivos consejos en la dirección de este trabajo.

Al Prof. Carretero González también por sus consejos y, además, por su ayuda desinteresada en la maquetación del trabajo.

Agradezco también a los Profesores Blanco Barco, Rubio Sánchez y Juanes Méndez, miembros del Departamento de Histología y Anatomía Humanas de la Facultad de Medicina de la Universidad de Salamanca, por ofrecerme su ayuda desde el primer momento y por la confianza que me han dado; por supuesto, también a Concha, Damián y Marisa por su paciencia, buena disposición e inestimable ayuda.

A todos aquellos que de una manera u otra han contribuido a que este trabajo de Tesis Doctoral haya sido realizado, compañeros, familiares y amigos.

Aún sigo pensando en cómo darles las gracias a mi mujer y a mi hija, por su cariño y apoyo incondicional que me ha permitido llegar a ser todo lo que soy ahora. 
Prólogo 
Lo que aparentemente significa un final, en realidad, puede ser el inicio de algo nuevo. De esta manera, cuando finalicé la licenciatura en veterinaria, se iniciaba la obtención del diploma de estudios avanzados y una vez finalizado éste, la realización de la Tesis Doctoral.

Varios años atrás, los Profesores Agustín Martín Pascual y Ricardo Vázquez Rodríguez publicaron un novedoso y aún actual Atlas con los aspectos ultraestructurales de los dermatofitos. Este sería el punto de partida de esta Tesis doctoral. Otra vez, algo que había concluido, era el inicio de algo nuevo.

Pero hay algo más que motivó la realización de esta trabajo y éste no es más que el saber apreciar en el trabajo de estos dos profesores, que hicieron las cosas por el gusto de hacerlas, por sentar bases en el estudio de los dermatofitos y dermatofitosis para futuras generaciones, sin pensar obsesivamente en los resultados de beneficios obtenidos.

Por mi condición de veterinario, me gustó la idea de iniciar la tesis doctoral sobre los dermatofitos con la premisa de proseguir e incidir un poco más en el análisis morfológico de este tipo de hongos, comunes en los animales y en el hombre; ahora, una vez terminada, creo que todo el esfuerzo valió la pena, porque me sirvió para entender que no hay nada mejor que seguir los caminos que uno ha de recorrer sin pensar únicamente a donde nos llevan. He tenido buenos referentes y ello me ha hecho sentir que no estaba sólo ni perdido, he intentado ir un poco más allá en ese camino trazado. 


\section{Introducción}

Raymond Sabouraud 



\section{Dermatofitos y dermatofitosis}

La primera rama de la Microbiología que se desarrolló fue la micología; las micosis superficiales ya eran conocidas por los griegos y los romanos, si bien, hasta el siglo XIX no aparece la Micología Médica y se debe a Agostino Bassi que, en 1835, describió que la muscardina del gusano de seda era producida por un hongo (Beauveria bassiana). A partir de esta fecha es cuando se inician los grandes descubrimientos sobre los hongos en general y sobre los dermatofitos en particular (citado por Arenas, 2008).

Dentro de la Micología, las dermatofitosis son micosis superficiales y, como hemos dicho anteriormente, ya eran conocidas por los griegos, que las denominaron herpes por su forma circular y por los romanos, que las denominaron tinea que significa larva o polilla. Son producidas por los dermatofitos que agrupan un conjunto de hongos filamentosos, con capacidad para producir infecciones en la piel, pelo y uñas, tanto en el hombre como en animales.

Las tiñas fueron una de las enfermedades más frecuentes y, como cita Arenas (2008), entre los años 1807 y 1828 en París se presentaron 25.000 casos de Tiñas de la cabeza.

En el siglo XIX, Remak apreció la existencia de filamentos en el favus y llamó a este hongo Achorion schonleinii y concluyó en sus estudios que el favus tenía su origen en las plantas (Remak, 1842).

Un poco más tarde, en 1840, el dermatólogo A. Cazenave observó una epidemia de Tiña de la cabeza y propuso el término de Herpes tonsurans 
capilliti, quizás por la presencia concomitante de lesiones anulares de Herpes circinatus (citado por Arenas, 2008)

David Gruby en 1841 describió la tiña microspórica y cultivó el Microsporum audouini; estos hallazgos y otros muchos le hicieron que fuera muy controvertido en su época y prácticamente ignorado.

En un suplemento del Oxford English Dictionary en 1882 aparece el término dermatofito, sin que se conozca a quién debe ser atribuido ni cuando se acuñó. Proviene de los términos griegos dern (piel) y phyle (planta) y, aunque se consideró que los dermatifitos estaban relacionados con las plantas, hoy día esta relación no es exacta.

Fue el francés Sabouraud (1864-1938) uno de los micólogos más famosos de los últimos años del siglo XIX y de principios del XX. Escribió el primer libro de micología dermatológica y el tercer libro de la enciclopedia del cuero cabelludo, estaba dedicado al análisis de las Tiñas. Clasificó a los dermatofitos en cuatro géneros, Trichophyton, Microsporum, Epidermophyton y Achorion (Sabouraud, 1910).

Una detallada evolución de nuevos conceptos y nuevos dermatofitos se encuentra en el libro Micología Médica ilustrada (Arenas, 2008) que le dedica un capítulo a las dermatofitosis, destacando que, en 1934, se clasificaron los dermatofitos en sólo tres géneros: Trichophyton, Microsporum y Epidermophyton.

En 1954, se intentó realizar una clasificación de los dermatofitos teniendo en cuenta las características morfológicas de las colonias y, un poco más tarde, se describió el Trichophyton ajelloi como el primer hongo teleomorfo de un microorganismo queratinófilo. En 1961 y 1963 se describieron la Nannizzia incurvata y la Nannizzia gypsea. 


\section{Generalidades}

Durante mucho tiempo los hongos fueron considerados como miembros primitivos o degenerados del reino vegetal, pero en la actualidad se les reconoce como un género independiente con características propias.

Los hongos son incapaces de fotosintetizar sus necesidades de alimentación orgánica a partir de $\mathrm{CO}_{2}$ y el agua, por lo que tienen que alimentarse de materia orgánica preformada (son heterótrofos); ello obliga a que tengan que existir como saprofitos o parásitos. La mayoría de los hongos son saprofitos, devolviéndole al suelo los nutrientes extraídos por las plantas superiores, desempeñando un papel fundamental en la naturaleza (Roberts y Mackenzie, 1986).

Los hongos se diferencian con claridad de las plantas superiores por su estructura, nutrición y reproducción. El citoplasma fúngico está rodeado por una pared celular rígida formada por polisacáridos, polipéptidos y una sustancia similar a la quitina. Por la rigidez de su pared no puede fagocitar alimentos, sino que absorben nutrientes simples y solubles mediante enzimas extracelulares llamadas despolimerasas (Arenas, 2008).

\section{Taxonomía de los hongos}

Hasta la época actual, la clasificación de los hongos se ha basado en criterios morfológicos y en las características de las estructuras de reproducción sexuada y, sólo en el caso de las levaduras, se requirió el análisis de detalles bioquímicos o fisiológicos por tratarse de atributos importantes para estos hongos. Las primeras clasificaciones tuvieron en cuenta el estudio morfológico de las esporas y, más tarde, los mecanismos de su formación, ya que los mecanismos de esporulación permiten distinguir familias de hongos.

En la taxonomía fúngica se mantienen categorías, niveles o jerarquías que agrupan a los especímenes desde grupos que comparten características muy generales (Reino), hasta características muy específicas que los distribuye en distintos niveles, como grupo o phyla, clase, orden, familia, género, especie, variedad, etc. De acuerdo con el diccionario de Hongos (Hawksworth y col., 
1995) los hongos pertenecen al reino Fungi, divididos en cuatro grupos o "phyla" (Ascomycota, Basidiomycota, Chytridiomycota y Zygomycota). El reino Fungi tiene aproximadamente 103 órdenes, 484 familias, 4.979 géneros y unas 80.000 especies descritas.

La nomenclatura en micología establece reglas que se aceptan universalmente en el lenguaje de los hongos. La forma habitual de denominar a los hongos es mediante un binomio de palabras en latín y ambas escritas en cursiva: el género, con mayúscula la primera letra y la especie escrita en minúsculas. Cuando se mencionen varias especies del mismo género se recomienda escribir la palabra completa del género la primera vez y en las sucesivas sólo la letra inicial (p. ej.: Microsporum canis; M. gypseum; M. audouinii, etc.) y para referirse a una $o$ varias especies sin determinarlas se utiliza las abreviaturas sp. y spp. (p. ej.: Aspergillus spp.).

Debe ternerse en cuenta en la taxonomía de los hongos, la posibilidad de denominaciones diferentes para un mismo organismo, ya que ciertos hongos se pueden presentar, con características morfológicas distintas, en su forma sexuada (hongos teleomorfos), asexuada (hongos anamorfos) o en ambas modalidades (hongos holomorfos), o presentar varios tipos independientes de propagación anamorfa (hongos sinanamorfos), de manera que aparezcan dos 0 tres denominaciones distintas para el mismo hongo (p. ej.: Petriellidium boydii, se conoce también con los nombres sinanomorfos de Graphium eumorphum y Scedosporium apiospermum). Por eso, en la actualidad, para el análisis taxonómico, de identificación y de diagnóstico se hace impresindible la utilización de la biología molecular que permite analizar el ADN de los hongos en su fromas parasitarias o en cultivos (Arenas, 2008). Las técnicas de biología molecular que estudian el ADN genómico, nuclear o mitocondrial, se emplean actualmente para lograr una clasificación natural y tratar de solucionar el problema de la definición taxonómica de grupos separados por características fenotípicas (Kohn, 1992; Hopfer y col., 1993; Li y col., 1994; Kawasaki y col., 1995; Palumbi, 1996; Pereiro y col., 1999). 


\section{Estructura de los hongos}

Los hongos poseen un auténtico núcleo por lo que se denominan eucarióticos. A diferencia de las bacterias los hongos tienen un tamaño y una complejidad citoplasmática y morfológica muy superiores. Los hongos pueden ser unicelulares (levaduras) o bien las unidades celulares pueden unirse formando unos largos filamentos (hifas) constituyendo una estructura compleja denominada micelio o talo.

\section{HIFA}

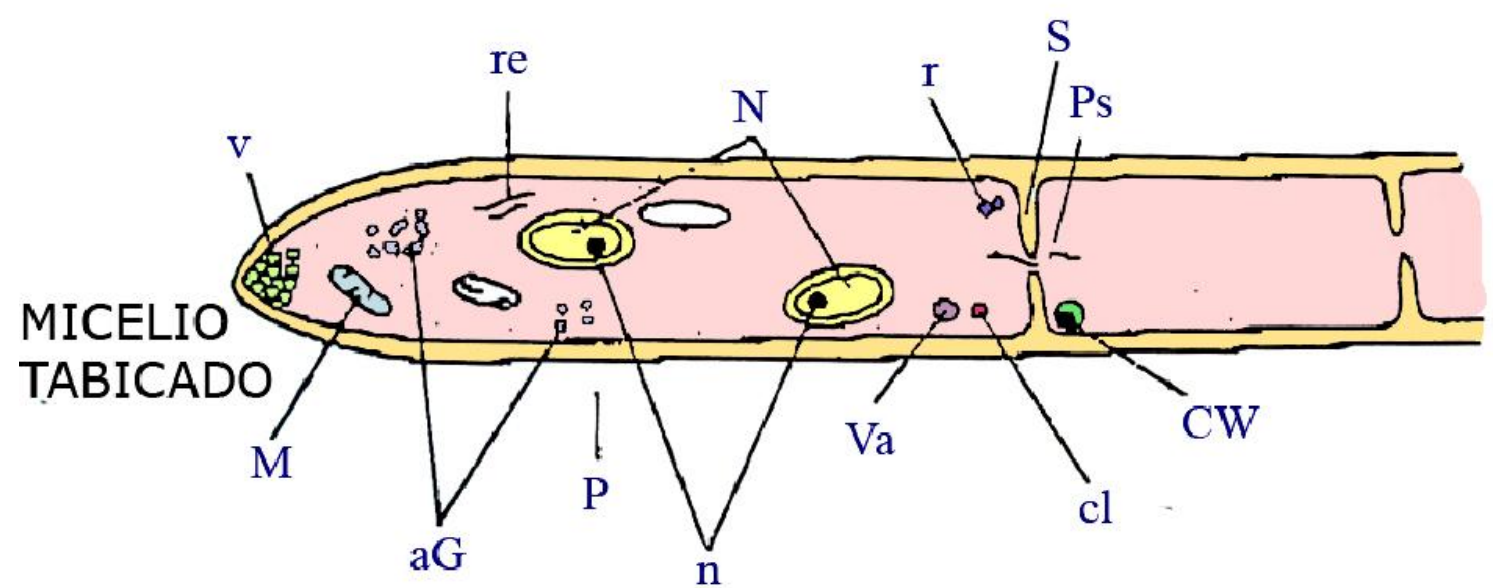

Esquema 1.- Ultraestructura de un micelio tabicado. Modificada de Arenas P. En: Micología médica ilustrada. McGraw-Hill, 2008. N: Núcleo; n: nucléolo; Va: vacuola; cl: cuerpo lipídico; CW: Cuerpos de Woronin; Ps: poro septal; S: septo; r: ribosoma; re: retículo endoplasmático; v: vesículas. M: mitocondrias: aG: aparato de Golgi; P: Pared.

El micelio, a su vez, está formado por dos partes distintas: A) micelio vegetativo que asegura el desarrollo, la nutrición y el soporte para la formación de la parte B) o micelio reproductor donde se forman los órganos reproductores. En el micelio pueden originarse diferentes estructuras vegetativas, como los clamidosporos, con una gruesa pared resistente a las condiciones adversas; pueden formarse aislados o en grupos, en una posición intercalada o terminal. Otras esporas vegetativas unicelulares son las artrosporas, constituyendo ca- 
denas de pequeñas esporas cúbicas. La producción de artrosporas es una característica de la fase parasitaria de los dermatofitos.


a

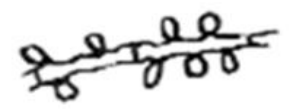

b


Esquema 2.- Representación esquemática de algunos tipos de macroconidios (a) microconidios (b) clamidosporas (c) e hifas (d). Esquema tomado de Cabañes (2001).

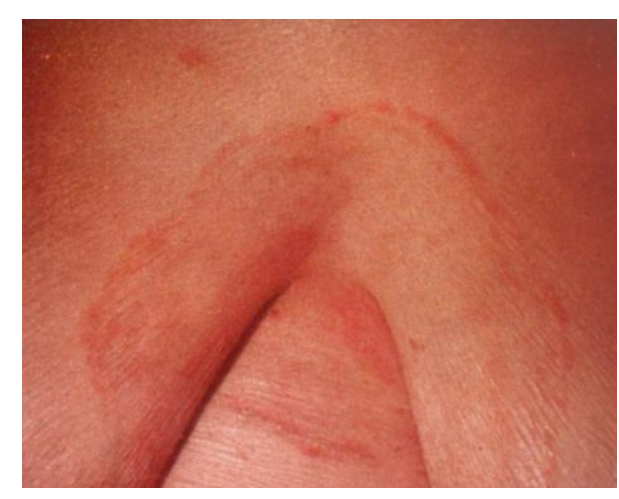

Figura I-1.- Herpes circinado producido por $T$. rubrum. Lesión anular de gran tamaño, con bordes de crecimiento visible, mínima reacción inflamatoria y evolución muy crónica.
En el micelio reproductor, a diferencia de las esporas vegetativas (clamidosporos y artrosporos), presentan una gran variación en cuanto a número, forma, tamaño y complejidad, pero estos rasgos son constantes para una misma especie. Un hongo puede producir más de un tipo de esporas asexuales que, en general, se denominan microsporas (microconidios) y macrosporas (macroconidios). A su vez en el micelio reproductor, las hifas 
pueden presentar diversas estructuras, como hifas en "espiral” o "tirabuzón",

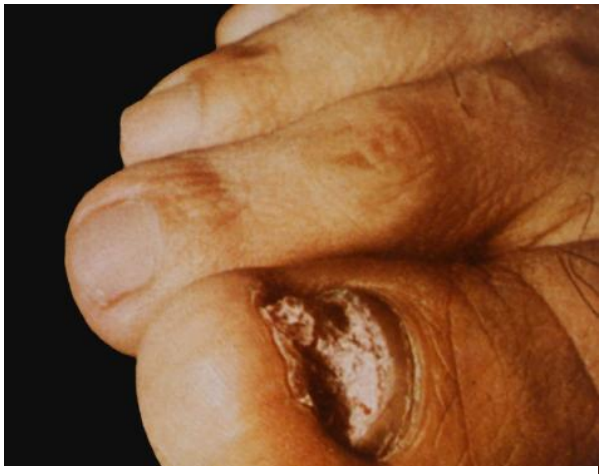

Figura I-2.- Onicomicosis (Tinea unguium) por T. rubrum. La lámina ungueal aparece destruida casi en su totalidad. Estas alteraciones y su cronicidad son los rasgos que caracterizan a las onicomicosis. hifas en "raqueta", "hifas pectinadas" "candelabros fávicos", etc. (ver figuras. I-18 e I19).

La estructura de la hifa es un tubo de longitud variable, formado por una pared celular rígida que contiene el protoplasma; su diámetro, varía de 1 a $30 \mu \mathrm{m}$. Los hongos superiores muestran tabiques transversales, que se denominan septos. Estos tabiques tienen unos orificios, poros, que permiten el paso del contenido citoplasmático, incluyendo el núcleo, a uno y otro lado. Por ello las hifas no constituyen células, sino compartimentos. En el citoplasma, además del núcleo, encontramos mitocondrias, aparato de Golgi, vacuolas, cuerpos lipídicos, etc., así como una estructura propia, los cuerpos de Woronin, que se sitúan en la proximidad del poro regulando, posiblemente, su función. (Esquema 1, tomado y modificado de Arenas, 2008).

A diferencia de estos, los hongos inferiores tienen un micelio continuo (micelio cenocítico), sin tabiques (aseptados), pero que en determinadas circuns-



Figura 1-3.- Tiña (Herpes) en un becerro por T. verrucosum.- Lesiones múltiples, en impacto, que se inician con una placa grande central y posteriormente múltiples lesiones alrededor. Generalmente localizadas en la cabeza y con escaso componente inflamatorio, recuerdan a las tiñas tonsurantes humanas. tancias pueden presentarlos para aislar las partes viejas (hifas muertas) o las reproductoras.

Los dermatofitos son un grupo amplio de hongos, que dan lugar a lesiones tanto en el hombre como en los animales. De forma amplia el término dermatofitos podría incluir a todos aquellos hongos que provocan enfermedades en la piel del hombre y distintas especies animales. De forma más restringida puede limitarse a aquellos hongos capaces 
de provocar lesiones cutáneas denominadas tiñas.

Los dermatofitos son hongos queratinolíticos o lo que es lo mismo, son hongos

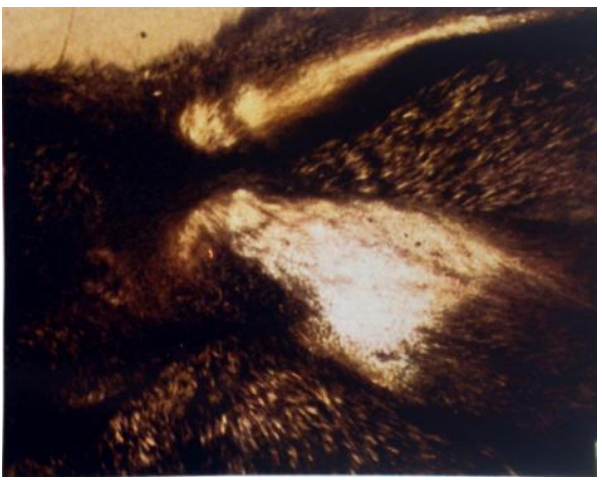

Figura I-4.- Tiña en un conejo por $T$. mentagrophytes ( $v$. mentagrophytes). La lesión localizada en la oreja aparece como una placa, redondeada, irregular, con tonsura del pelo a su nivel, descamación y mínimo componente inflamatorio. que digieren la queratina. La afección que producen se denomina dermatofitosis 0 comúnmente denominadas tiñas. Las lesiones de la piel tienen forma anular y/o de serpentina, dando lugar a lesiones en las que da la impresión de ser un gusano debajo de la piel (Kane y col., 1997).

Los dermatofitos (y otros hongos filamentosos) pese a ser tabicados pueden considerarse como cenocíticos pues en la fase de desarrollo activo, el contenido citoplasmático puede circular libremente entre los diferentes segmentos de la hifa a través del poro septal; pero, en ocasiones, pueden adoptar una organización pseudocelular para evitar efectos dañinos en el micelio (envejecimiento, trauma, lisis, etc.) por la oclusión parcial o completa del poro septal. Los cuerpos de Woronin parece ser que actúan como obturadores de los poros para aislar los compartimentos de las hifas cuando envejecen o se diferencian (Trinci y Collinge, 1974; Vannini y col., 1975; Markham, 1994; Calvo y Agut, 2001; Maruyama y col., 2005).



Figura l-5.- Tiña tonsurante microspórica (Tinea capitis), producida por M. canis en el cuero cabelludo de un niño. Las lesiones forman placas grandes e irregulares, de superficie escamosa, con tonsura o ruptura de los pelos a su nivel.
Taxonómicamente se engloban en el reino Fungi, grupo o phylo Ascomycota, clase Plectomycetes, orden Onygenales, en los que se integran varias familias y numerosas especies.

Esta proliferación de especies dentro de un grupo de hongos, con posibilidad de producir infecciones en el hombre y en animales, es un caso único en micología médica. Consideremos, por ejemplo, el grupo cándida, con 
varias especies de las cuales prácticamente sólo una ( $C$. albicans) produce, en determinadas circunstancias, infecciones en el hombre (Hildick-Smith y col. 1964).



Figura l-6. - Tiña inflamatoria de la barba (Kerion) producida por $T$. mentagrophytes ( $v$. mentagrophytes).- Intensa foliculitis y perifoliculitis de la barba con exudación purulenta y restos de pomadas.
Los dermatofitos parasitan estructuras queratinizadas (capa córnea, pelos y uñas) y los cuadros clínicos a que dan lugar (dermatofitosis) se denominan genéricamente tiñas, con diferentes nombres según la región anatómica o estructura que parasitan: tinea corporis (herpes circinado), tinea cruris (eczema marginado), tinea capitis (tiñas tonsurantes), tinea ungium (onicomicosis), tinea pedis (pie de atleta), etc. (Roberts y Mackenzie, 1986).

Los dermatofitos, en su forma asexuada o imperfecta (dermatofitos anamorfos) se clasifican desde el punto de vista botánico y dependiendo de sus características morfológicas, ecológicas y genotípicas, en tres géneros: Tricophyton, que comprende diecinueve especies; Microsporum con trece especies diferentes y Epidermophyton, del que sólo se conoce una ( $E$. floccosum, Fig. I.8). No obstante, estudios recientes han indicado que los tres géneros clásicos son artificiales (Gräser y col., 2000).

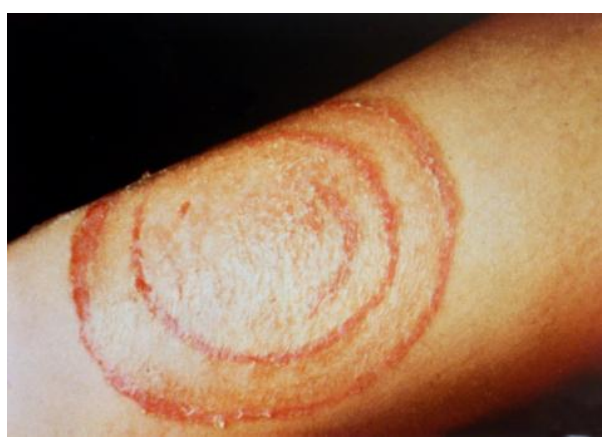

Figura 1-7.- Herpes circinado (Tinea corporis) de anillos concéntricos producida por $T$. verrucosum. Reacción inflamatoria eczematiforme aguda que se extiende radialmente en ondas 0 anillos concéntricos. Estas lesiones son características del $T$. verrucosum.
También se ha descrito un cuarto género, Keratinomyces (De Hoog y col., 2000b), que solo incluye una especie no patógena (ceratinacus) que solo crece a temperaturas de $15-17^{\circ} \mathrm{C}$.

Algunas especies de Trichophyton y de Microsporum son capaces de reproducirse sexualmente (dermatofitos teleomorfos, género Arthroderma y Nannizzia), produciendo ascos y ascosporos (Weitzman y col., 
1986). Para más detalles de la clasificación ver, Weitzman y Summerbell (1995) y Cabañes (2001).

Los dermatofitos del género Trichophyton pueden parasitar todas las estructuras queratinizadas (capa córnea, pelos y uñas); los del género Microsporum parasitan la capa córnea y el pelo, pero no las uñas y el Epidermophyton parasita la capa córnea y uñas, pero no el pelo. Los datos morfológicos están, basados en las características de los conidios, como podemos observar en el esquema 2, como ya describió Emmons, en 1934.

\section{Clasificación ecológica}

Desde el punto de vista de su epidemiología, los dermatofitos se han clasificado en tres grupos (Georg, 1960; Ajello, 1962; Hildrick-Smith y col., 1964; Velasco y col., 1979; Pereiro, 1979, 1982, 1985): Antropofílicos, zoofílicos y geofilicos. Las especies más comunes en cada uno de ellos las recogemos en el esquema 3.

\begin{tabular}{|l|l|l|}
\hline \multicolumn{3}{|c|}{ Esquema 3 } \\
\hline \multicolumn{1}{|c|}{ Antropofílicos } & \multicolumn{1}{|c|}{ Zoofílicos } & \multicolumn{1}{c|}{ Geofílicos } \\
\hline M. audouinii & M. canis & M. gypseum \\
T. violaceum & T. verrucosum & T. agelloi \\
T. tonsurans & T. mentragrophytes & M. cookei \\
T. schonleinii & (v. mentagrophytes) & M. fulvum \\
T. mentagrophytes & T. mentragrophytes & \\
(v. interdigitale) & (v. erinacei) & \\
T. rubrum & T. equinum & \\
E. floccosum & & \\
\hline
\end{tabular}

Esquema 3.- Especies de dermatofitos comprendidas en los tres grupos según la clasificación ecológica (tomado de Matsumoto y Ajello, 1987; Weitzman y Summerbell, 1995).

- Antropofílicos, que parasitan al hombre, el cual constituye su reservorio, infectando de persona a persona y con posibilidad de producir brotes epidémicos locales (escuelas, cuarteles, etc.). Los cuadros clínicos a que dan lugar son de evolución crónica, con escasa reacción inflamatoria (Figs. I-1 e I-2). 
- Zoofílicos, aquellos que parasitan a diferentes especies animales (gatos, perros, terneros, cerdos, caballos, ratones, erizos, etc.), donde producen con frecuencia zoonosis en granjas, peleterías o cebaderos (Georg 1960; Connole 1965; Vanbreuseghem 1966; English 1972). En estos animales, que constituyen su reservorio, las lesiones suelen ser de evolución crónica con poca reacción inflamatoria (Figs. I-3 e I-4). A partir de estos animales infectan al hombre originando lesiones con importantes fenómenos inflamatorios (tiñas inflamatorias, kerion) como puede apreciarse en las Figs. I-5, I-6 e I7.

Del mismo modo, cuando una especie antropofílica infecta, excepcionalmente, a un animal, origina en éste lesiones con intenso componente inflamatorio (Hildrick-Smith y col., 1964). En líneas generales, puede decirse que están bien adaptados a la especie a la que parasitan habitualmente sin inducir en ella fenómenos inflamatorios agudos; de ahí la cronicidad de las lesiones constituyendo su reservorio.

- Geofílicos, aquellos que parasitan estructuras queratinizadas en el suelo (pelos, plumas, cuernos, etc.). Algunas especies, ocasionalmente, pueden parasitar al hombre y animales induciendo en ambos fenómenos inflamatorios agudos (Chmel y Buchvald., 1970). El reconocimiento de estas especies tiene abiertas amplias expectativas para el mejor conocimiento de los hongos. Mediante la técnica del "pelo de cebo" (Fig. I-9) se han podido aislar del suelo numerosos hongos morfológicamente similares a los dermatofitos, pero no patógenos (Ajello y Georg, 1957). Se especula con la hipótesis de que los dermatofitos procederían filogénicamente de hongos sexuados existentes en el suelo (ascomicetos) a partir de los cuales algunas especies se habrían adaptado a parasitar estas mismas estructuras queratinizadas (capa córnea, pelos, uñas) en el hombre y algunos animales, modificando para ello su morfología y forma de reproducción (asexuada). Se ha demostrado que algunas especies de dermatofitos desarrollan su estado perfecto (teleomofo o sexual), cuando se cultivan en tierra estéril sobre pelos (géneros Nannizzia y Arthroderma para especies de Microsporum y Tricophyton respectivamente) según Dawson y col., 1964; Takashio 1972 y Gräser, 2008 (Figs. I-10, I-11, I-12, I-13 e I-14).

\section{Clasificación taxonómica}

La identificación y clasificación taxonómica de los dermatofitos se hace mediante siembra y cultivos en medios artificiales (a partir de material clínico) sobre los cuales desarrollan un micelio aéreo, reproductor, formando órganos reproductores muy diversos (macro y microconidios) que nos permiten su identificación taxonómica (Ajello, 1968; Rebel y Taplin, 1974). A nivel de las 


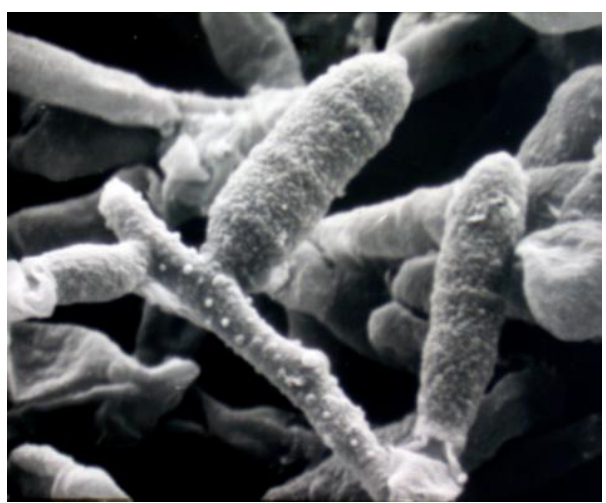

Figura I-8.- E. floccosum. Aspecto caraterístico del micelio y macroconidios que permiten su identificación. Tomada de Martín Pascual y Vázquez, 1979.

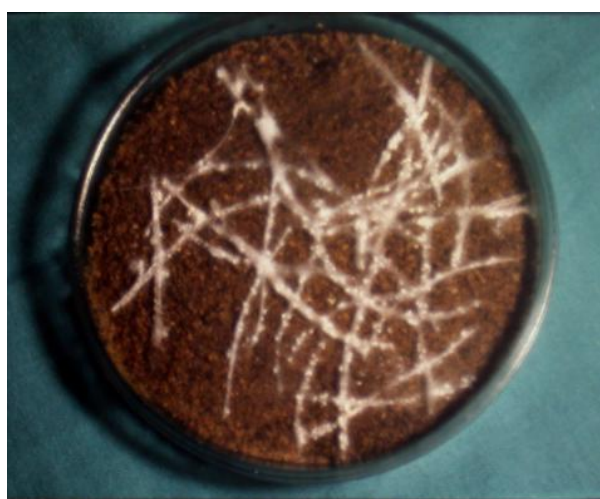

Figura 1-9.- Técnica del "pelo cebo" o anzuelo. En una placa de Petri con tierra húmeda se depositan pelo estériles, sobre los cuales se desarrollan los hongos queratinófilos del suelo, en donde podemos estudiar sus formas sexuadas (ascomicetos).

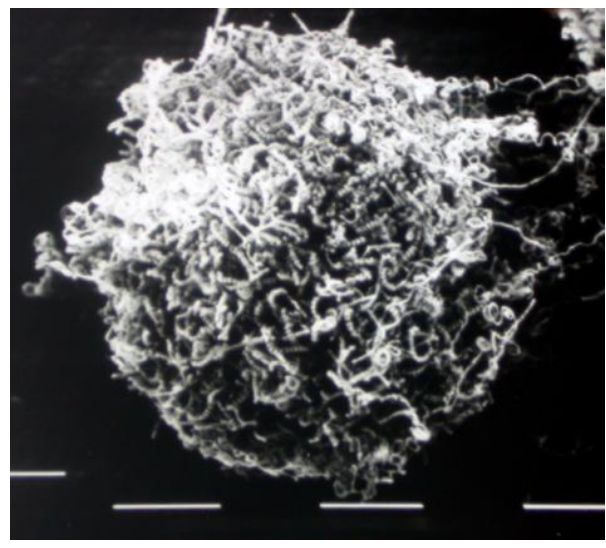

Figura I-10.- Arthroderma benhamiae. Cleistotecio rodeado de hifas peridiales que ocultan el asco o saco donde se encuentran los ascosporos. Tomada de Martín Pascual y Vázquez, 1979. lesiones clínicas los dermatofitos son muy similares (micelios más o menos tabicados en capa córnea, macro o microsporas en disposición endotrix o ectotrix en pelo, etc.), datos que, en la mayoría de los casos, no permiten su identificación.

De este modo, los dermatofitos pueden presentar tres variantes morfológicas distintas en función del medio en el que se desarrollan:

1. Micelios ramificados y esporos (de diferentes formas y disposición) a nivel de lesiones clínicas (Figs. I-15, l-16 e l-17).

2. Órganos reproductores y micelio aéreo, diferentes en las distintas especies y que permiten su identificación y clasificación taxonómica, cuando los observamos en cultivos artificiales (Figs. I-18, I-19 e I20).

3. Desarrollo de estructuras complejas sexuadas, (ascomicetos) cuando los cultivamos sobre pelos en la superficie del suelo, con tierra estéril (Figs. I-9, I-10, I$11, \mathrm{l}-12, \mathrm{I}-13$ e I-14).

Las especies del género Microsporum producen más macroconidios que microconidios; los macroconídios son, generalmente, fusiformes, multiseptados, a veces con más de quince septos. Su pared celular puede ser delgada o gruesa y lisa o rugosa. Los microconidios son piriformes y se disponen a uno y otro lado de la hifa o bien aisladamente.

El género Trichophyton produce más microconidios que macacroconidios, si lo compa- 




Figura I-11.- Aspecto de las hifas peridiales de $A$. benhamiae. Tomada de Martín Pascual y Vázquez, 1979.
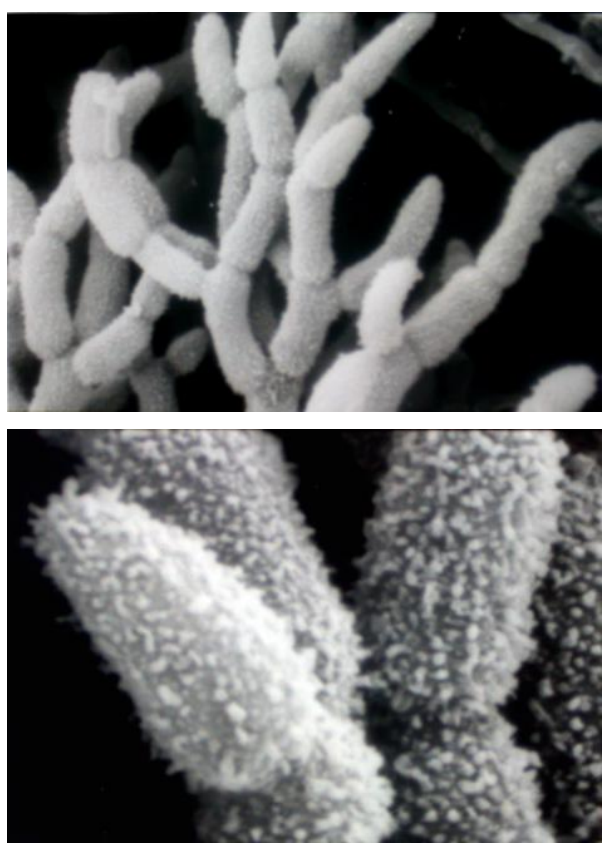

Figuras I-12 (superior) y I-13 (inferior).- Hifas peridiales de Nannizzia (N. incurvata). Tomada de Martín Pascual y Vázquez, 1979.

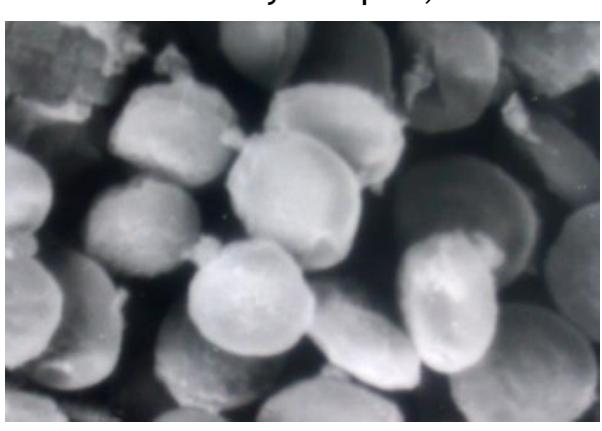

Figura I-14.- Ascosporos en el interior del asco que caracteriza a los ascomicetos o formas sexuadas de los dermatofitos. Tomada de Martín Pascual y Vázquez, 1979. ramos con el género Microsporum. Los macroconidios tienen forma cilíndrica o alargada, son lisos, de pared delgada, con un número menor de septos. Los microconidios son piriformes o claviformes y pueden disponerse en forma de racimos.

Las especies del género Epidermophyton poseen macroconidios con aspecto de maza, son multicelulares y sus paredes son lisas y delgadas (Fig. I-8). No produce microconidios pero tiene muchas clamidosporas.

El género Arthroderma (estado perfecto del Trichophyton) se caracteriza por presentar hifas peridiales en forma de yugo o ramificadas dicoronicamente. Presentan también ascos esferoidales $\mathrm{u}$ ovales $\mathrm{y}$ en su interior poseen hasta 8 ascosporas (Maibach y col., 2002).

El género Nannizzia (estado perfecto de $M i$ crosporum) se caracteriza por presentar hifas peridiales con estrangulaciones más o menos pronunciadas, de superficie con verrucosidades redondeadas o alargadas como se aprecia en las figuras adjuntas, pertenecientes a Nannizzia incurvata. Los ascosporos son de superficie lisa y de forma redondeada o lenticular.

En la actualidad, el caballo de batalla con el que se intenta resolver los problemas taxonómicos de los hongos, en general, y de los dermatofitos, en particular, es la biología 
molecular, empleando diferentes técnica que estudian el ADN (genómico, nuclear o mitocondrial) para establecer diferencias no sólo genéricas sino también específicas que afectan a los dermatofitos (Pereiro y col. 1999; Makimu-

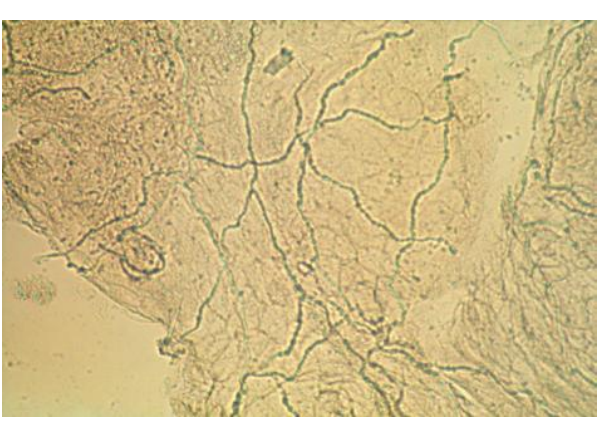

Figura I-15. - Escamas de un herpes circinado (Tinea Corporis), donde se observan micelios ramificados y tabicados, aspecto que no permite la identificación del hongo (observación postratamiento con $\mathrm{KOH}$ al $30 \%)$.

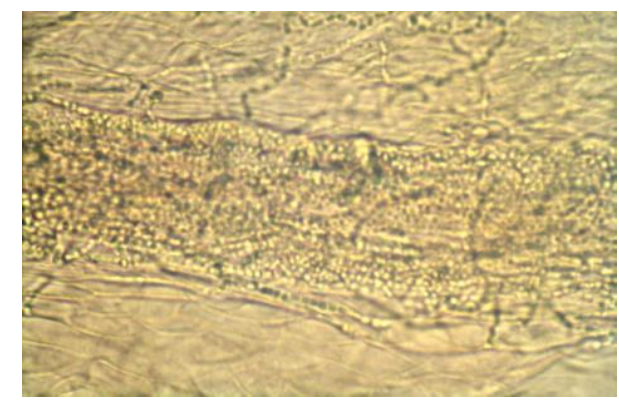

Figura I-16.- Parasitación endotrix de un pelo en una tiña tricofítica. Las hifas se fragmentan en artrosporas que se hallan en el interior del pelo (tratado $\mathrm{KOH} 30 \%$ ).

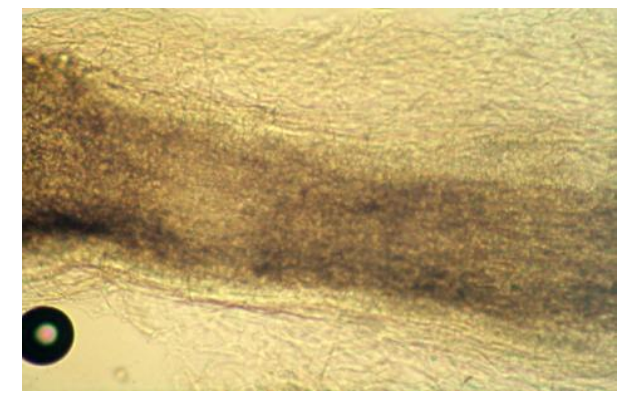

Figura 1-17.- Parasitación ectotrix de un pelo en una tiña microspórica. Numerosos artrosporos, redondos, de pequeño tamaño (microsporos), se encuentran en la superficie del pelo (tratado con $\mathrm{KOH} 30 \%)$. ra, 2001; Jackson, 2001; Bergmans y col., 2008; Erhard y col., 2008; Kong y col., 2008; Wu y col., 2009).

Tradicionalmente a los dermatofitos se los considera agentes patógenos "queratinófilos", es decir, con capacidad para parasitar, solamente, estructuras queratinizadas (capa córnea, pelos, uñas, cuernos), zonas donde los encontramos habitualmente y no en otros niveles de la piel (dermis) o en otros órganos (músculo, hígado, pulmón, etc.). Sin embargo, es conocido que los dermatofitos pueden desarrollarse en estructuras profundas, cuando los cultivamos sobre trozos de piel escindida o sobre otros órganos. Hoy sabemos que en el suero existe un factor antifúngico (ligado a las transferrinas insaturadas) que inhibe el desarrollo del hongo (King y col., 1975). Esta es la razón por la que los dermatofitos no pueden penetrar más allá de la capa córnea ni de la zona queratógena del pelo (Kligman, 1956, Lorincz y col., 1958, Blank y col., 1959, Roth y col., 1959, HildickSmith, 1964; Ogawa y col., 1998; Muhsin y Hadi, 2001). Cuando en circunstancias muy especiales estos hongos parasitan estructuras cutáneas profundas (dermis e hipodermis) originan reacciones granulomatosas similares a las observadas en micosis profundas, con

células epitelioides y gigantes multinucleadas, de evolución muy crónica, des- 
critas originalmente por Blannk y col. (1959) en un paciente que carecía del factor antifúngico y posteriormente por otros en pacientes con o sin otros desórdenes inmunológicos (Chen y col., 1993; Tsang y col., 1996; Ogawa y col., 1998; Sentamilsevi y col., 1998; Voisard y col., 1999; Chastain y col., 2001; Smith y col., 2001).

\section{Inmunología}

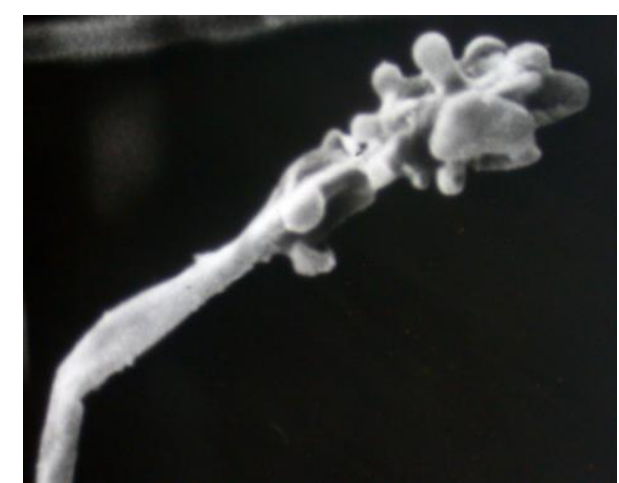

Figura I-18. - Hifa "pectinada" o en peine, característica del M. audouinii. Tomada de Martín Pascual y Vázquez, 1979.



Figura 1-19.- Típicos "candelabros fávicos" característicos del $T$. schonleinii, responsable del favus o tiña fávica. Tomada de Martín Pascual v Vázquez, 1979.
Pese a parasitar estructuras en eliminación de la superficie de la piel (capa córnea, pelos) los dermatofitos producen sustancias con capacidad antigénica (glicopéctidos y queratinasas) que se difunden a través de los tejidos, induciendo una respuesta inmunológica que afecta tanto a la inmunidad celular, linfocitaria, como a la humoral, responsables de las lesiones clínicas y de la reacción a la tricofitina (Ito, 1965; Grappel y Blank, 1972; Jones y col., 1974; Calderon, 1989; Jones, 1993; Weitzman y Summerbell, 1995). Los hongos adaptados a una determinada especie animal inducen escasa respuesta inmunológica, que se traduce en lesiones de evolución crónica con mínima reacción inflamatoria. En cambio, cuando estos mismos hongos parasitan otras especies, dan lugar a cuadros clínicos con intenso componente inflamatorio (kerion).

Esta respuesta inmunológica es la responsable de la curación espontánea de las tiñas en plazos más o menos largos, dependiendo de la intensidad de esta respuesta y dejando una inmunidad permanente en condiciones normales; es 
también la razón, por la que las epizootias afecten a animales jóvenes, siendo raras en adultos (Lorincz y col., 1958; Rot-



Figura I-20.- M. canis. Macroconidios grandes, fusiformes, tabicados. En superficie son visibles las espinas. (Azul de lactofenol). 400x. man, 1947).

Histológicamente, esta respuesta inmunológica se traduce en fenómenos inflamatorios epidérmicos con exocitosis linfocitaria (espongiosis) e infiltrados perivasculares dérmicos de células mononucleadas. Fenómenos similares observamos a nivel del epitelio folicular.

\section{Rasgos generales de las tres especies estudiadas}

\section{$T$. mentagrophytes ( $v$. mentagrophytes)}

Del T. mentagrophytes existen dos variedades: una forma antropofílica ( $v a-$ riedad interdigitale) y otra zoofílica (variedad mentagrophytes) (Georg 1954). La primera parasita únicamente al hombre produciendo cuadros de evolución crónica, con escasa reacción inflamatoria. La variedad zoofílica parasita a diferentes especies animales, generalmente roedores (conejos, ratas, etc.), pe-

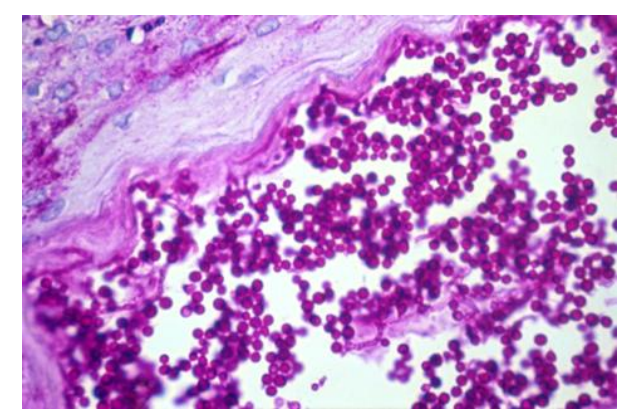

Figura 1-21: Parasitación intrafolicular de un pelo. Se observan abundantes esporos con desestructuración del tallo piloso. Esta es la razón por la que el pelo se rompe, originando placas pseudoalopécicas, tonsurantes. PAS (ácido periódico de Schiff). 400 x ro también otras especies (vacas, cerdos, etc.). Es, sin duda, el hongo patógeno de mayor difusión en el reino animal (Kaufman y col., 2007).

En estos animales produce lesiones con mínimo componente inflamatorio, reconocibles únicamente por la tonsura o ruptura del pelo; en cambio, cuando infecta al hombre origina cuadros clínicos con intensa reacción inflamatoria (kerion) (Velasco y col., 1979; Pereiro y col., 1991). 
La variedad interdigitale, por lo general no parasita el pelo, mientras que la zoofílica ( $v$. mentagrophytes) lo hace disponiéndose los esporos sobre su superficie (parasitación de tipo ectótrix). Fig. I-21 e I-22.

Todas las variedades de $T$. mentagrophytes perforan el pelo "in vitro", mediante unas formaciones miceliales especiales ("órganos perforantes"), rasgo que permite su diferenciación con otras especies como el $T$. rubrum (Mercer y col., 1963).



Figura 1-22: Parasitación de un folículo piloso, donde se observa el epitelio folicular y abundantes micelios, de negro intenso, sobre la queratina del pelo. Nitrato metanamina de plata (GOMORIGROCOTT). 400x.
En medios de cultivo, el $T$. mentagrophytes ( $v$. mentagrophytes) puede presentar gran riqueza de estructuras microscópicas. Se observan típicos microconidios dispuestos como "racimos de uvas" y abundante micelio. Los microconidios pueden encontrarse también dispuestos lateralmente sobre las hifas, mostrando formas y tamaños variables. Es frecuente y característica la presencia de hifas en espiral ("spiral coil") y otras con distinta forma y disposición ("en astas de ciervo" y

otras). Pueden observarse también clamidosporos, tanto terminales (en el extremo de la hifa) como intermedios (Rebel-Taplin, 1974).

La variedad mentagrophytes puede presentar macroconidios fusiformes, tabicados y de superficie lisa o con alguna verrugosidad. Todas las especies de $T$. mentagrophytes desarrollan su estado perfecto (sexuado), como Artroderma benhamiae, cuando se cultivan sobre pelos en la superficie de tierra (Ajello y Cheng, 1967, Padhye y col., 1973).

\section{T. erinacei}

El T. erinacei descrito por Marples y Smith (1960), Smith y Marples (1963), Morris e English (1969), se considera una variedad del T. mentagrophytes. Es una especie zoofilica que parasita habitualmente al erizo, que constituye su principal reservorio. Ocasionalmente puede parasitar al hombre originando cuadros de tinea corporis (herpes circinado) y tinea capitis (English y col., 1962, 
Quaife, 1966, Rush-Munrd y Smith, 1971). Se desarrolla bien en los medios de cultivo estándar, dando lugar a colonias pulverulentas, blanco-cremosas y superficie inferior amarilla brillante.

Microscópicamente, presenta abundantes microconidios dispuestos en racimos o lateralmente sobre las hifas (similares al $T$. mentagrophytes, $v$. mentagrophytes). Es frecuente la presencia de clamidosporos en disposición terminal e intermedios. Los macroconidios son de aspecto fusiforme, septados y de superficie lisa.

Como otras variedades de T. mentagrophytes, el T. erinacei puede desarrollar su estado perfecto como Arthroderma benhamine, variedad erinacei (Takahashi y col., 2003).

\section{M. canis}

El M. canis es el agente causal más frecuente de Tiñas Tonsurantes (tinae capitis) en nuestro medio (Velasco y col., 1979). Su reservorio principal lo constituyen los gatos, en los que produce lesiones características de tiñas, frecuentemente localizadas en la cabeza, similar a las producidas por el $T$. mentagrophytes ( $v$. mentagrophytes) en los roedores. Puede producir también infecciones en perros aunque con menor frecuencia (pese a denominarse canis). A partir de estos animales infecta al hombre (sobre todo a niños), ocasionando, algunas veces, brotes de epidemias familiares. En niños originan tiñas tonsurantes en grandes placas, generalmente muy inflamatorias y menos crónicas que las producidas por especies antropofílicas (M. audouinii) (Velasco y col., 1979) (Fig I-5).

Sus colonias crecen con rapidez y, microscópicamente, se caracterizan por la presencia de abundantes macroconidios grandes, fusiformes, con presencia de “espinas" en su superficie y septos prominentes, generalmente más de seis. Estos elementos permiten reconocerlo y diferenciarlo de otras especies, de acuerdo con Rebel y Taplin (1974) (Fig. I-20). 


\section{Repercusiones; epidemiológicas y económicas}

Las dermatofitosis son extraordinariamente molestas y en ellas se emplean millones de dólares para su tratamiento.

Como se ha dicho, en la actualidad se admite la existencia de unas 40 especies de dermatofitos, si bien, que sean capaces de producir dermatofitosis son unas 30. Existe una gran variabilidad climática, geográfica y socioeconómica, que dan lugar a cambios en la distribución de los agentes etiológicos. Algunos tienen una distribución geográfica limitada, como el $T$. concrentricum que se corresponde con Oceanía o el T. soudanense con África, si bien los flujos migratorios pueden dar lugar a que algunas especies se encuentre en otros países donde no es habitual su existencia (Kwon-Chung y Bennett, 1992).

Se han detectado dermatofitosis en más de 100 países de varios continentes y en algunos con gran incidencia (Sarkisov y Koromyslov, 1983). Aunque en España no existen estudios sobre el particular, si los hay en otros países; las pérdidas son considerables debido a que producen alteraciones en el crecimiento de los animales que detiene el flujo zootécnico y a la devaluación de las pieles (Mitchell, 1983; Proenca, 1990; López y col., 1994; Bofill y col, 1996) lo que da lugar a que tengan una gran repercusión económica difícil de cuantificar de forma objetiva (Ajello, 1974; Pereiro, 1982).

Grosshans y col. (1986), analizan dermatofitosis en trabajadores de minas de carbón, de postasa o en cocineros y trabajadores de factorias de motocicletas y encuentran que un $40,7 \%$ presentan dermatofitosis, siendo el T. mentagrophytes, seguido de T. rubrum, los más frecuentes.

Khosravi y col., 1994, hacen un amplio estudio de dermatofitois en Iran, entre los años 1986-1991. Afectan sobre todo, por edad, a dos grupos de población, uno entre los 1-9 años y otro entre los años 20 -29. De los casos estudiados, 9345 fueron confirmados como dermatomicosis, de los cuales, 1633 lo fueron por microscopía, 429 por cultivo y el resto, por ambas técnicas. De más a menos frecuentes las dermatofitosis encontradas fueron: Tinea corporis, pedis, cruris, manum, unguium y barbae y los dermatofitos y también por orden de frecuencia: M.canis, T.rubrum, E. flocosum, T. mentagrophytes ( $v$ interdigi- 
talis), $T$. verrucosum, $T$. violaceum, $T$. schoenleinii, $T$.tonsurans, $T$. erinacei y M. gallinae.

Entre el personal militar de EEUU y del Reino Unido estudios de Mitchell (1983) se apreció una incidencia de del $17-24 \%$ de dermatofitisis; Rosell y De la Fuente (2009) encuentran, en granjas de conejos estudiadas durante dos años, que la morbilidad de gazapos afectados era variable, en algunos casos del $10 \%$ y en otros se elevaba hasta el $80-90 \%$ de los individuos. 
Hipótesis del trabajo 
Teniendo en cuenta todos estos aspectos señalados en el capítulo precedente, es evidente que los dermatofitos sufren cambios genéticos que se traducen en modificaciones morfológicas y reproductoras importantes, cuando pasan de saprofitos, en estructuras queratinizadas del suelo, a parasitar distintas especies animales o al hombre. En este último, hay especies que han desarrollado mayor capacidad patógena ( $T$. mentagrophytes, $v$. mentagrophytes), mientras que otras quedan restringidas a, prácticamente, una sola especie ( $T$. mentagrophytes, v. erinacei) que sólo parasita al erizo. Es posible, por tanto, que estas diferencias patógenas se correspondan con diferencias morfológicas estructurales finas, que podemos identificar con microscopía electrónica.

Además debemos añadir que, debido a la pandemia de Sida que apareció en los años 80 ha favorecido la aparición de micosis sistémicas poco habituales hasta entonces e incluso, los transplantes de órganos y las terapias anticancerosas ha ampliado el numero de enfermos con factores de riesgo para contraer una infección fúngica invasora (ver Pemán y col., 2001); ello da lugar a que es necesario un seguimiento más concreto y que se debe hacer un diagnóstico rápido y preciso, sabiendo incluso que existen muchas cepas resistentes a tratamientos antifúngicos.

Como ejemplos podemos citar los trabajos de Mitchell y col. (1983), que afirman la existencia de infecciones micóticas raras como la cromoblastomicosis que puede afectar al hombre, provocándole úlceras tórpidas donde se encuentran hifas, tanto en dermis como en epidermis. Igualmente López y col. (1994) en enfermedades tipo blastomicosis, que afectan a la piel y también a los pulmones, pueden llegar a provocar queratitis oftalmológicas. De Hoog y col. (2000a) en pacientes con cromoblastomicosis, llama la atención que se debe analizar el problema de la fagocitosis para determinar si los Ascomicetos son o no patógenos. 
En nuestro trabajo, estudiaremos dos especies del género Trichophytum ( $T$. mentagrophytes, $v$. mentagrophytes) muy patógenas y $T$. erinacei, patógena restringida. Es posible que la distinta agresividad de estas dos variedades del mismo hongo puedan corresponderse (como hemos dicho) con alguna diferencia ultraestructural, demostrable en el micelio reproductor obtenido en medios de cultivo artificial, donde la riqueza y abundancia de estructuras nos permite material suficiente para su estudio.

Del género Microsporum estudiaremos el M. canis, especie zoofílica patógena para distintos animales (gatos, perros, roedores) a partir de los cuales infecta al hombre. Es un hongo agresivo, que puede producir epidemias a nivel familiar o en grupos (escuelas) y que puede permitirnos comparar con las otras especies de Trichophytum antes mencionadas.

Nuestra hipótesis está encaminada a determinar si existen o no diferencias morfológicas ultraestructurales en relación con el grado de patogenicidad.

\section{Objetivos:}

El estudio que hemos propuesto está englobado en una línea de investigación cuyo objetivo principal es analizar diferencias morfológicas ultraestructurales en relación con la patogenicidad de diferentes especies de dermatofítos.

\section{Como objetivos concretos, consideraremos:}

Estudiar dos especies zoofílicas, de dos géneros diferentes, muy frecuentes en nuestro medio ( $T$. mentagrophytes y M.canis) y una tercera ( $T$. erinacei) menos patógena y de escasa incidencia.

1. Analizar comparativamente los órganos reproductores (macro y microconidios) con el microscopio electrónico de barrido.

2. Estudiar a nivel ultraestructural el micelio y los órganos reproductores de los dermatofitos reseñados, centrándonos en los espacios interséptales y el propio septo.

Para poder conseguir los objetivos propuestos se ha tenido en cuenta el siguiente diseño experimental: 
1. Puesta al día de la bibliografía existente en relación con los hongos, en general, y con los dermatofitos en particular.

2. Obtención y procesado de las muestras para el estudio microscópico a nivel ultraestructural. Para lo cual se han obtenido los hongos a partir de lesiones clínicas en diferentes especies animales. Las muestras se han cultivado en medios estándar de dextrosa-agar de Saboureaud y mycobotic agar (DIFCO).

3. Las especies se han identificado por microscopía óptica a partir de muestras de las colonias desarrolladas.

4. Finalmente, con un punch de $8 \mathrm{~mm}$ se tomaron muestras de los cultivos para su fijación y posterior procesamiento estándar para estudio con el microscopio electrónico de barrido y de transmisión.

5. Estudio morfológico comparativo, a nivel ultraestructural, del micelio reproductor de los dermatofitos seleccionado para el estudio.

6. Presentación ordenada de los resultados, a través de la iconografía obtenida con los microscopios electrónicos de barrido y de transmisión.

7. Discusión de los hallazgos en las especies analizadas y elaboración de comentarios tras contrastar los resultados con los datos existentes en la bibliografía internacional.

8. Resumen final de resultados y elaboración de las conclusiones.

9. Exposición de las referencias bibilográficas manejadas. 


\section{Material y Métodos}




\section{Muestras analizadas}

Para el estudio del $T$. mentagrophytes ( $v$. mentagrophytes) se recogieron muestras de escamas de lesiones clínicas de tiñas en conejos (fundamentalmente) y cerdos. Para el M. canis, las tomas se hicieron de tiñas de gatos. El T. erinacei, difícil de obtener por parasitar exclusivamente en erizos y ser raras las infecciones en el hombre, nos fueron facilitadas las colonias, en medios de cultivo, por el Dr. Pereiro de la cátedra de Dermatología de la Facultad de Medicina de Santiago de Compostela, obtenidas de una lesión de herpes circinado sobre el dorso de la mano de un varón agricultor, de 38 años.

Las tres especies fueron identificadas con microscopía óptica por observación de los órganos reproductores, aspecto del micelio reproductor, macro y microconidios. La técnica para la recogida de muestras es sencilla y el material necesario está al alcance de todos. Se requieren:

- Pinzas de depilar, para extraer el pelo roto (“tonsurado") en las lesiones de tiña, y tijeras finas y fuertes para tomar muestras de estructuras queratinizadas como uñas.

- Cucharilla de raspado de Brocq o bien bisturí, para recoger escamas.

- Dos portaobjetos estériles para conservar las muestras. Para el transporte de las mismas es preferible usar fragmentos de papel plegados.

- Asa de platino utilizada para sembrar las muestras.

- Medios de cultivo en agar glucosado de Sabouraud con o sin antibióticos.

\section{Siembra de las muestras.}

En nuestro estudio, hemos usado los cultivos estándar dextrosa-agar de Saboureaud con cicloheximida y cloranfenicol (el cloranfenicol controla la contaminación bacteriana y la cicloheximida, los mohos saprofitos) y el Mycobiotic agar (DIFCO), en tubos de ensayo.

Es necesario contar con estufa y nevera para conservar los medios de cultivo. 
En las lesiones cutáneas secas y descamativas (tiñas) las escamas se obtienen del borde de la lesión, raspando con una cucharilla u hoja de bisturí y se colocan entre dos portaobjetos estériles o flameados.

Para la recogida de pelos, que sobre las lesiones aparecen rotos (tonsurados) y entre abundantes escamas, se utilizan pinzas de depilar con las cuales se arrancan fácilmente. La muestra debe tomarse en el borde de la lesión entre la región sana y la enferma.

Antes de iniciar el cultivo de las muestras obtenidas es necesario efectuar un examen directo de las mismas, que permite observar el hongo sin modificaciones y cuantificar la cantidad de elementos.

Las muestras con queratina, como pelos y escamas, son difíciles de observar, por lo que deben utilizarse sustancias aclarantes que destruyan la queratina y permitan visualizar los hongos. Hemos utilizado como reactivo una solución de potasa $(\mathrm{KOH})$ al $30 \%$. El análisis se realiza en pocos minutos calentando previamente la laminilla. Es un método sencillo, barato y rápido.

Las muestras se recogen con el asa de platino previamente calentada al rojo y enfriada en el medio de cultivo estéril, lo cual facilita la adherencia de pelos y escamas. Los especímenes se conservan a temperatura ambiente o en estufa entre $27-30^{\circ} \mathrm{C}$, hasta el desarrollo de las colonias en una o dos semanas.

El estudio anatomopatológico de los dermatofitos y micosis superficiales en general, no tienen utilidad práctica pues los hongos se encuentran en la capa córnea o el pelo, por lo cual se reconocen fácilmente con un examen directo. Para visualizarlos sobre cortes histológicos se usa la técnica de PAS (Ácido periódico de Schiff) colorante con gran afinidad por los mucopolisacáridos que contienen las paredes fúngicas y que colorean de rojo. También se emplea la impregnación argéntica con nitrato metanamina de plata (GOMORI-GROCOTT) que colorea de negro intenso las paredes del hongo (Figs. I-21 e i-22). 


\section{Procesado de las colonias para su estudio ul- traestructural (MET y MEB)}

A partir de los cultivos se extrajeron muestras para su observación al microscopio electrónico de transmisión (MET) y de barrido (MEB), siguiéndose las pautas que se exponen a continuación.

\section{Microscopía electrónica de transmisión.}

Para el estudio de los dermatofitos al MET, se siguieron los siguientes pasos:



Figura- MM-1.- Microscopio Electrónico de Transmisión Zeiss-900 del Servicio de Microscopía electrónica de la USAL.
1.- Fijación. Se utilizó el método de Kellenberger (Kellenberger $\mathrm{y}$ col., 1958) con tetraóxido de osmio al $1 \%$ en tampón Michaelis $(0,1 \mathrm{M}, \mathrm{pH} 6,1)$ al que se agregó cloruro cálcico. El material fue fijado durante 2 horas, a $4^{\circ} \mathrm{C}$.

2.- Lavado y tallado de las muestras. El material se lavó con solución de Kellemberger (tampón Michaellis más cloruro cálcico) a $\mathrm{pH} 6,1$ y se tallaron las muestras en bloques de aproximadamente 1 $\mathrm{mm}^{3}$.

3.- Deshidratación. Las muestras siguieron un proceso gradual de deshidratación con acetonas: 30\%, 50\%, 70\%, 80\%, 90\% y acetona absoluta (100\%). En cada paso por acetona permanecieron durante 30 minutos. Además, a la acetona de $70 \%$ se le agregó $2 \%$ de acetato de uranilo para el contraste en bloque y las muestras permanecieron incluidas durante toda la noche. La acetona absoluta se renovó tres veces. Para finalizar la etapa de deshidratación las muestras se pasaron dos veces por óxido de propileno, a razón de 5 minutos cada pase. 
4.- Inclusión. Las piezas fueron pasando gradualmente por mezclas de óxido de propileno-araldita hasta araldita pura, siguiendo las técnicas habituales de inclusión.

5.- Obtención de cortes semifinos, ultrafinos y contrastado de los cortes. Se obtuvieron cortes semifinos (entre 1 y $2 \mu \mathrm{m}$ de espesor) con un ultramicrotomo LKB (ultratome III) que se tiñeron con azul de toluidina para la elección de la zona a estudiar. Localizada la zona de estudio se practicaron cortes ultrafinos de $40 \mathrm{~nm}$, que fueron contrastados con el método de Reynolds (1963).

6.- Observación y fotografiado de las muestras. Parte del material fue estudiado en un MET, Philips EM-201, perteneciente al Servicio de Microscopia Electrónica del Hospital Clínico Universitario de Salamanca y el resto se analizó con el MET Zesis-900, del Servicio de Microsopia Electrónica de la Universidad de Salamanca. En el primer caso, las fotografías del material estudiado se tomaron en película negativa, blanco y negro, de $25 \mathrm{~mm}$., utilizándose tiempos de exposición de 2 segundos, con un diafragma de contraste de 30 micras. En el segundo caso, las imágenes, de tipo digital, se tomaron con una cámara digital acoplada al MET Zeiss-900 ("Wide-angle dual Speed SlowScan CCD camera TRS" para MET) y archivadas en formato TIFF, empleando para su tratamiento ulterior el programa informático ImageSP Viewer ${ }^{\circledast}$

Los aumentos de las imágenes se expresa, bien mediante barras calibradas en las propias micrografías electrónicas o bien, en la leyenda de las figuras, en cuyo caso la cifra consignada corresponde al aumento del negativo multiplicado por 3 (aumento final de la imagen positiva impresa en las hojas A4).

\section{Microscopía electrónica de barrido.}

Para el estudio de los dermatofitos al MEB, los pasos metodológicos fueron:

1.- Fijación del material. Las muestras se fijaron en glutaraldehido al $6 \%$ en tampón fosfato $(0,1 \mathrm{M}, \mathrm{pH} 7,4)$ a temperatura de $4^{\circ} \mathrm{C}$. Se utilizaron tiempos variables de fijación, entre 3 y 6 horas, dependiendo del grosor y cualidades de la muestra. 
2.- Lavado y tallado. El material se lavó durante 2 horas con tampón fosfato $(0,1 \mathrm{M}, \mathrm{pH} 7,4)$, al que se agregó $6,84 \%$ de sacarosa para mantener la osmolaridad. A continuación se talló el material en piezas de $4 \times 8 \times 2 \mathrm{~mm}$.

3.-Post-fijación. Las piezas se post-fijaron en tetraóxido de osmio al $1 \%$ en tampón fosfato $(0,1 \mathrm{M}, \mathrm{pH} 7,4)$, durante 2 horas y a $4^{\circ} \mathrm{C}$, para después ser lavadas nuevamente en tampón fosfato con sacarosa.

4.-Deshidratación. Las muestras se deshidrataron en acetonas de porcentaje progresivo: 30\%, 50\%, 70\%, 80\%, 90\% y acetona absoluta. En cada acetona se dejaron aproximadamente 30 minutos, excepto en las de 70\% que fue de 12 a 20 horas. La acetona absoluta se renovó tres veces.

5.- Secado por el procedimiento del "punto crítico". Las muestras se introdujeron en la cámara de presión de aparatos de secados, marcas Polaron E3000 y Bio-Rad, sumergidas en acetona absoluta. En la cámara se verifica el cambio de acetona por dióxido de carbono líquido. Eliminada la acetona se calienta lentamente la cámara por medio de agua hasta que el dióxido de carbono pasa, en su punto crítico $\left(31,5^{\circ} \mathrm{C}\right)$, de líquido a gas, secando a la muestra y preservando su superficie de las tensiones que sufrirían si se utilizase otro método de secado, como por ejemplo, el secado al aire.

6.- Metalización. Después de fijar las muestras a los porta-muestras con plata

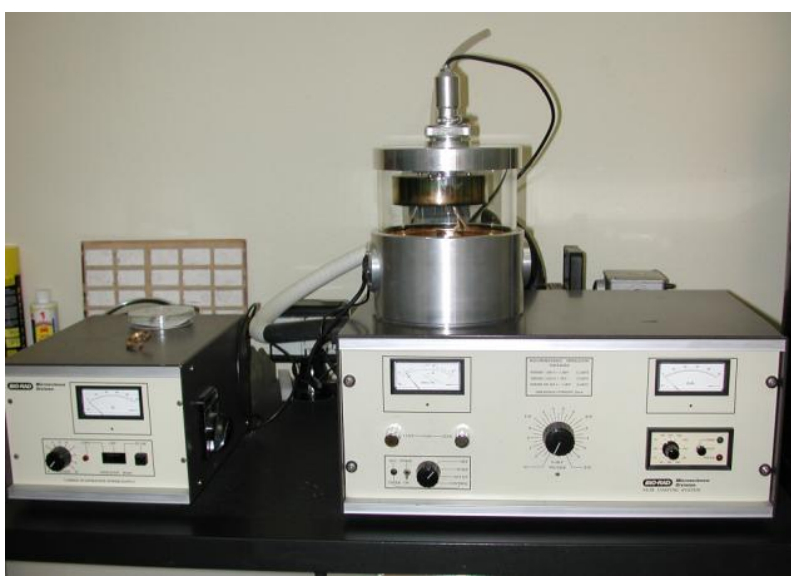
coloidal, se colocaron en la campana de un metalizador (ISI E-5000 - Bio-Rad), para revestirlas con una capa de oro, de unos $20 \mathrm{~nm}$ de espesor. Los tiempos de descarga fueron de 2 a 3 minutos manteniendo el amperaje a 20 miliamperios.

Figura MM-2.- Aparatos de secado ("punto crítico") y de metalización de la casa Bio-Rad. 
7.- Observación y fotografiado de las muestras. Como en el caso de la microscopía electrónica de transmisión, parte del material fue estudiado en un

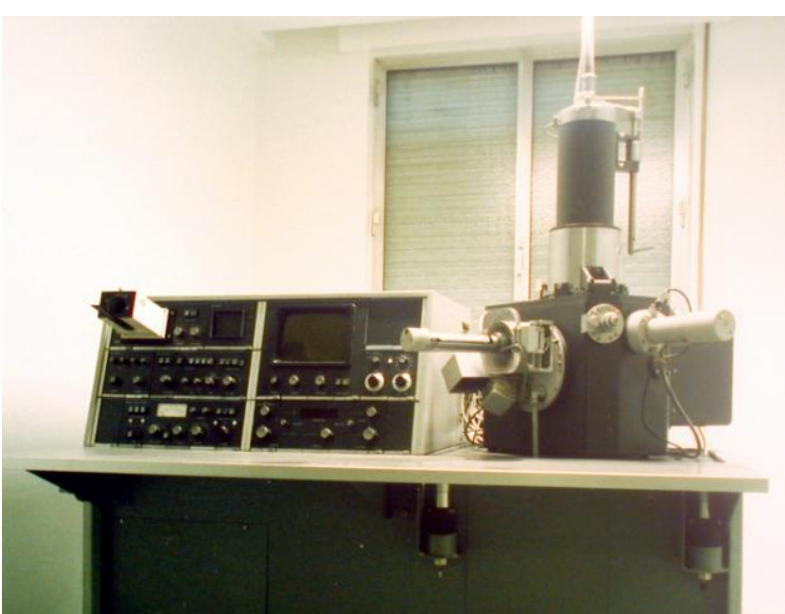

Figura MM-3.- Microscopio electrónico de barrido Philips SEM-500 del Servicio de ME del Hospital Clínico Universitario de Salamanca.

MEB (Philips PSEM-500), perteneciente al Servicio de Microscopia Electrónica del Hospital Clínico Universitario de Salamanca; el resto se analizó con el MEB del Servicio de Microscopía ca de la Universidad de ca, Zeiss DSM 940.

El voltaje de aceleración varió entre 12 y 50 kilovoltios, así como el tamaño del haz incidente sobre las muestras, con rangos de 250 a 32, dependiendo de los aumentos utilizados para el visionado de las muestras. Los diafragmas y el tiempo de barrido varió con las características técnicas de cada equipo, en el caso del MEB Philips PSEM-500, los diafragmas utilizados se aplicaban manualmente y fueron de 400, 200 y 100 micras y el tiempo de barrido por cuadro, de 32 milisegundos. Con el MEB Zeiss DSM 940, la mayoría de las operaciones, se realizan de forma automática, ajustando diafragmas y tiempo de barrido a la magnificación de la imagen.

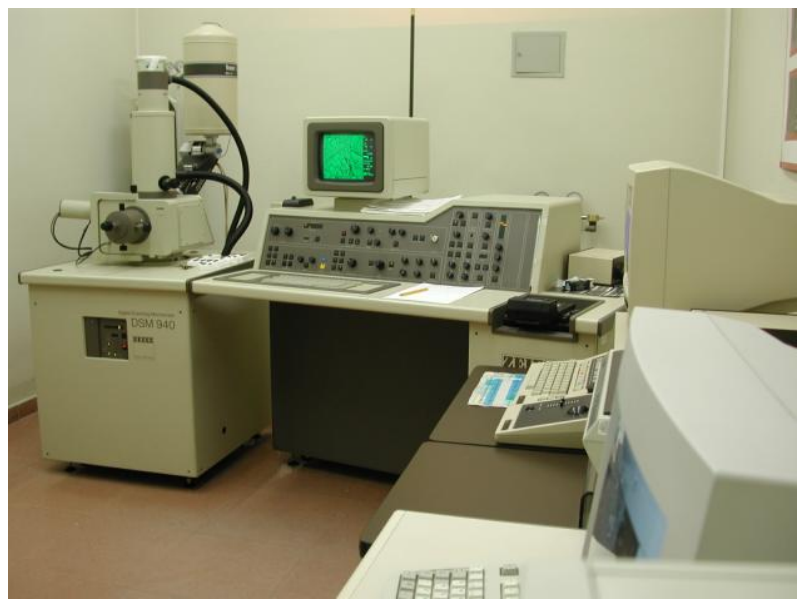

Figura MM-4.- Microscopio electrónico de barrido Zeiss DSM-940 del Servicio de ME de la USAL.
En cuanto a las microfotografías obtenidas, también hubo variación dependiendo del equipo microscópico empleado. Con el Philips PSEM 500, se utilizó película negativa, en blanco y negro de $35 \mathrm{~mm}$ y 400 ASA de sensibilidad, mientras que en el Zeiss DSM 940 las imágenes elegidas fueron directamente digitalizadas en un ordenador Hp Workstation “XW 8000" de 
Hewlett-Packard y tratadas con su software de aplicación y archivadas en formato TIFF.

Los aumentos de las imágenes en el presente trabajo de Tesis se expresan mediante barras calibradas en las propias micrografías electrónicas que aportaban los equipos microscópicos empleados.

Tratamiento de texto e imágenes. Edición final.

El procesado de los textos y la edición final se realizó con el programa de Microsoft Word (Office 2007 Profesional para Windows XP Profesional), utilizando ordenadores PC, con procesadores superiores a $2500 \mathrm{MHz}$ montados en placas Pentium IV.

La impresión final se realizó en las impresoras laser de blanco y negro (Canon E-6000) y color (Oki C-5600). 


\section{T. mentagrophytes (v. mentagrophytes)}

\section{Microscopía Electrónica de Barrido}

El micelio reproductor está constituido por abundantes hifas finas, sobre las que se disponen los microconidios con formas y disposición diferentes. En algunos sectores, los microconidios aparecen dispuestos lateralmente sobre las hifas con un corto pedículo de inserción (Figs. 1, 2 y 5). En otros sectores se observan numerosos microconidios dispuestos en formaciones que semejan "racimos de uvas" y abundante micelio con hifas finas y entrelazadas. Los microconidios son de forma redondeada u oval, de superficie lisa y con un fino pedículo de inserción que indudablemente recuerda, en conjunto, "un racimo de uvas", tanto por la forma como por la disposición (Figs. 3 y 4).

Los microconidios pueden observarse también en disposición lateral sobre las hifas, de aspecto redondeado o piriforme y con un corto pedículo de fijación (formas en “clavija”) (Fig.5). Se observan también numerosas hifas terminales filamentosas, enrolladas en forma de muelle (spiral coil) (Figs. 6 y 7). Es frecuente la presencia de clamidosporos, tanto en disposición terminal como intermedia (Fig. 8). 
Figura 1.- T. mentagrophytes (v. mentagrophytes): MEB. Panorámica del micelio reproductor del borde libre de la colonia, con microconidios redondeados o piriformes en disposición lateral sobre las hifas .1250 x 





Figura 2.- T. mentagrophytes (v. mentagrophytes): MEB. A mayores aumentos de la figura anterior, se observan con detalle la forma y disposición de los microconidios (formas en "clavija") con un corto pedículo de inserción. $5000 \mathrm{x}$ 


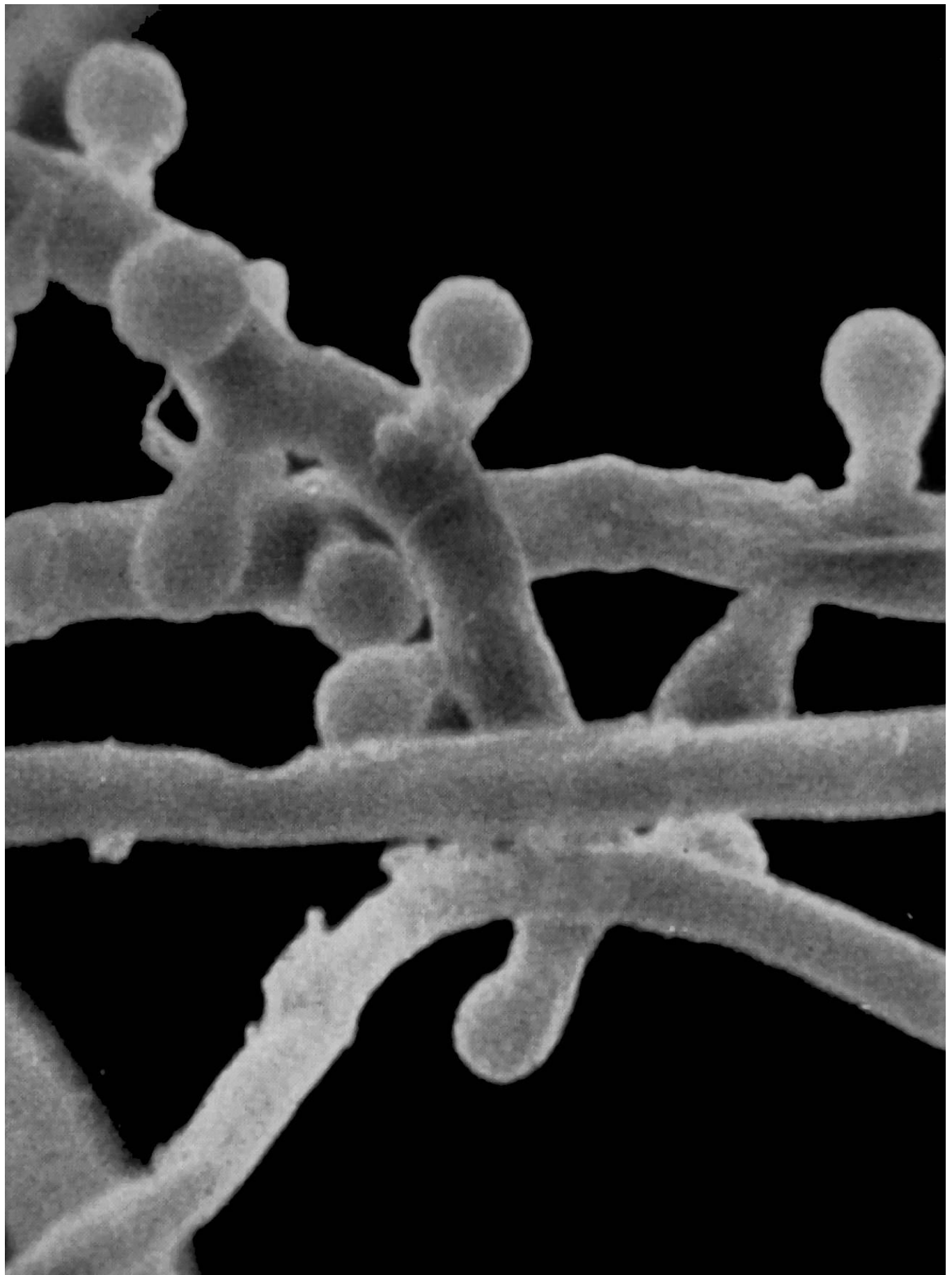


Figura 3.- T. mentagrophytes ( $\mathrm{v}$. mentagrophytes): MEB. Panorámica del micelio reproductor con presencia de hifas finas, de superficie lisa, sobre las que se desarrollan abundantes microconidios dispuestos en racimos. $1250 \mathrm{x}$ 





Figura 4.- T. mentagrophytes (v. mentagrophytes). MEB. Detalle de los microconidios de forma ovalada, semejando un “racimo de uvas".5000 x 


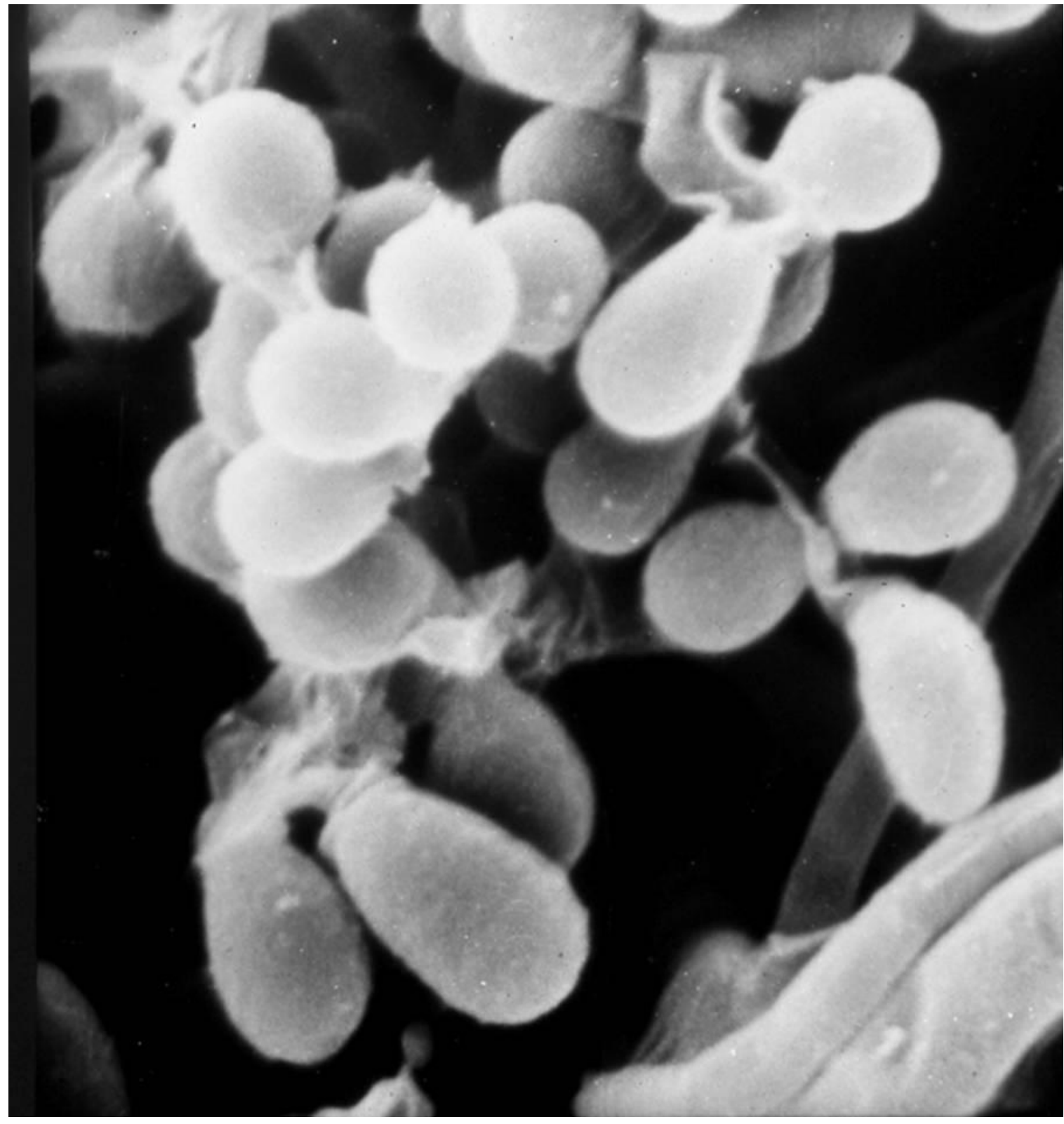


Figura 5.- T. mentagrophytes ( $\mathrm{v}$. mentagrophytes). MEB. Otro aspecto del micelio reproductor con microconidios en disposición lateral (formas "en clavija").2500x 


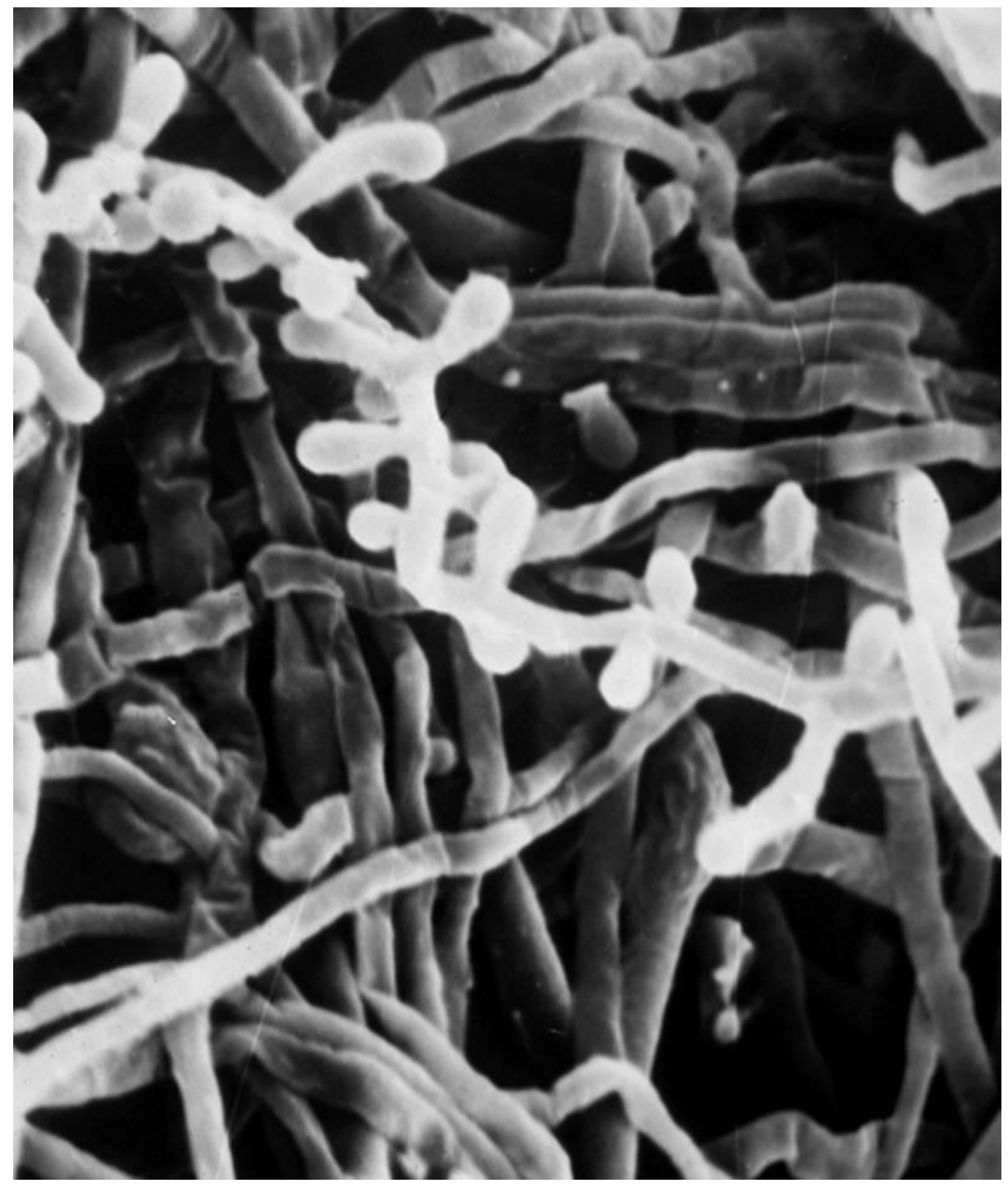


Figura 6.- T. mentagrophytes ( $v$. mentagrophytes). MEB. Micelio reproductor con abundantes hifas enrolladas en forma de muelle (spiral coil). $640 \mathrm{x}$ 





Figura 7.- T. mentagrophytes ( $v$. mentagrophytes). MEB. Detalle de las hifas de la figura anterior con su aspecto característico. Estas formaciones son exclusivas de esta especie y alguna de sus variantes. 1250x. 


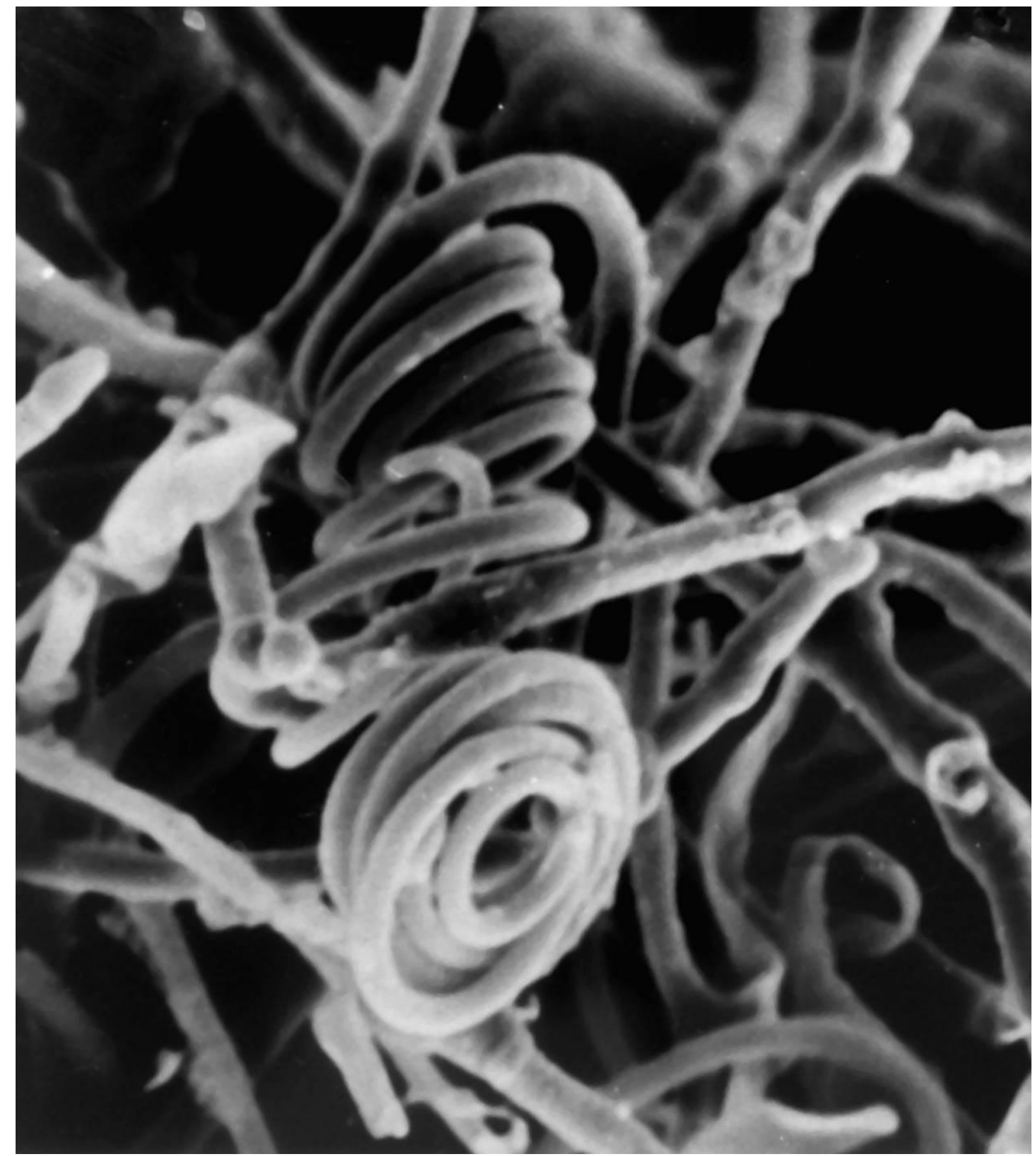


Figura 8.- T. mentagrophytes ( $v$. mentagrophytes). MEB. Micelio reproductor con clamidosporos en disposición terminal en el extremo distal de la hifa (T) e intermedios (I). 2500x. 





Estas formaciones junto con los micro y macroconidios, constituyen un rasgo más para su identificación, pues, aunque no exclusivas de él (también las presenta el T. erinacei, entre otros) no suelen ser tan abundantes en otras especies.

Los macroconidios aparecen como elementos fusiformes con el extremo distal afilado y el proximal unido a la hifa por un estrecho pedículo. Su superficie es lisa, siendo visibles las elevaciones anulares de los septos, más resaltadas en el extremo distal (Fgs. 9 y 10). 
Figura 9.- T. mentagrophytes (v. mentagrophytes). MEB. Micelio reproductor con presencia de macroconidios fusiformes, de superficie lisa. 1250x. 





Figura 10.- T. mentagrophytes (v. mentagrophytes). MEB. Otro aspecto de macroconidio entre el micelio reproductor. 2500x 


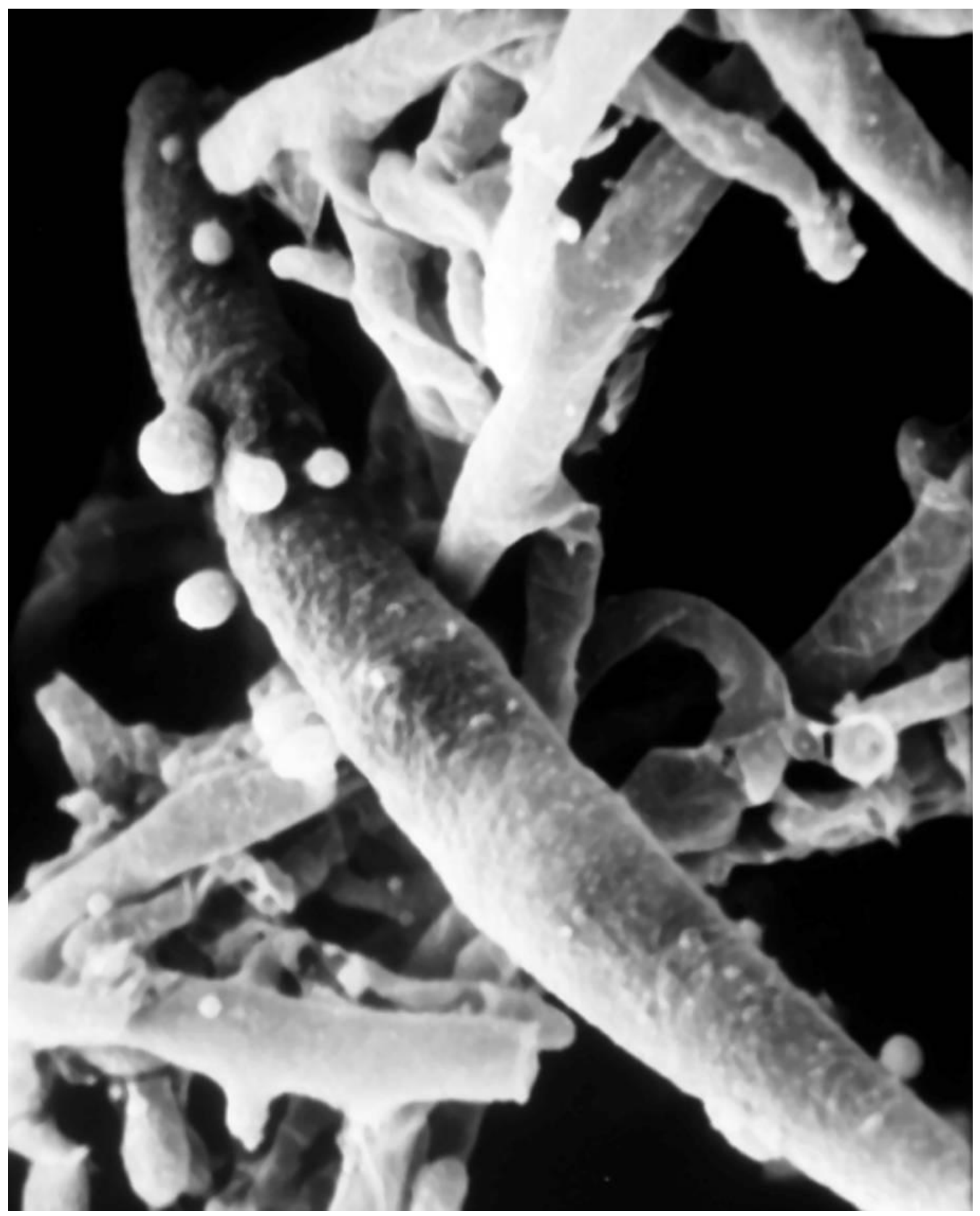




\section{Microscopía Electrónica de Transmisión-}

Las hifas muestran una fina pared en la cual pueden distinguirse una capa externa (e) densa y una interna (i) más gruesa y de menor densidad. El citoplásma presenta amplias zonas vacuolizadas, entre las cuales se observan algunas mitocondrias y cuerpos lipídicos (Figs. 11 y 12). En la pared de algunas hifas se observa una prominencia a modo de yema, bien delimitada por una pared similar a la de la hifa y con contenido citoplasmático (Fig. 12); estas formaciones corresponden a microconidios en su fase inicial.

En algunas hifas se observan sobre la capa externa excrecencias verrucosas de mayor densidad electrónica, que se originan en la capa externa y que podían corresponder al inicio más precoz de un microconidio (Fig. 11). 
Figura 11.- T. mentagrophytes ( $v$. mentagrophytes). MET. Hifa del micelio reproductor: capa externa (e), capa interna (i), verrucosidad (v). Es posible que esta verrucosidad sea el inicio temprano de la formación de un microconidio. $27.300 x$ 


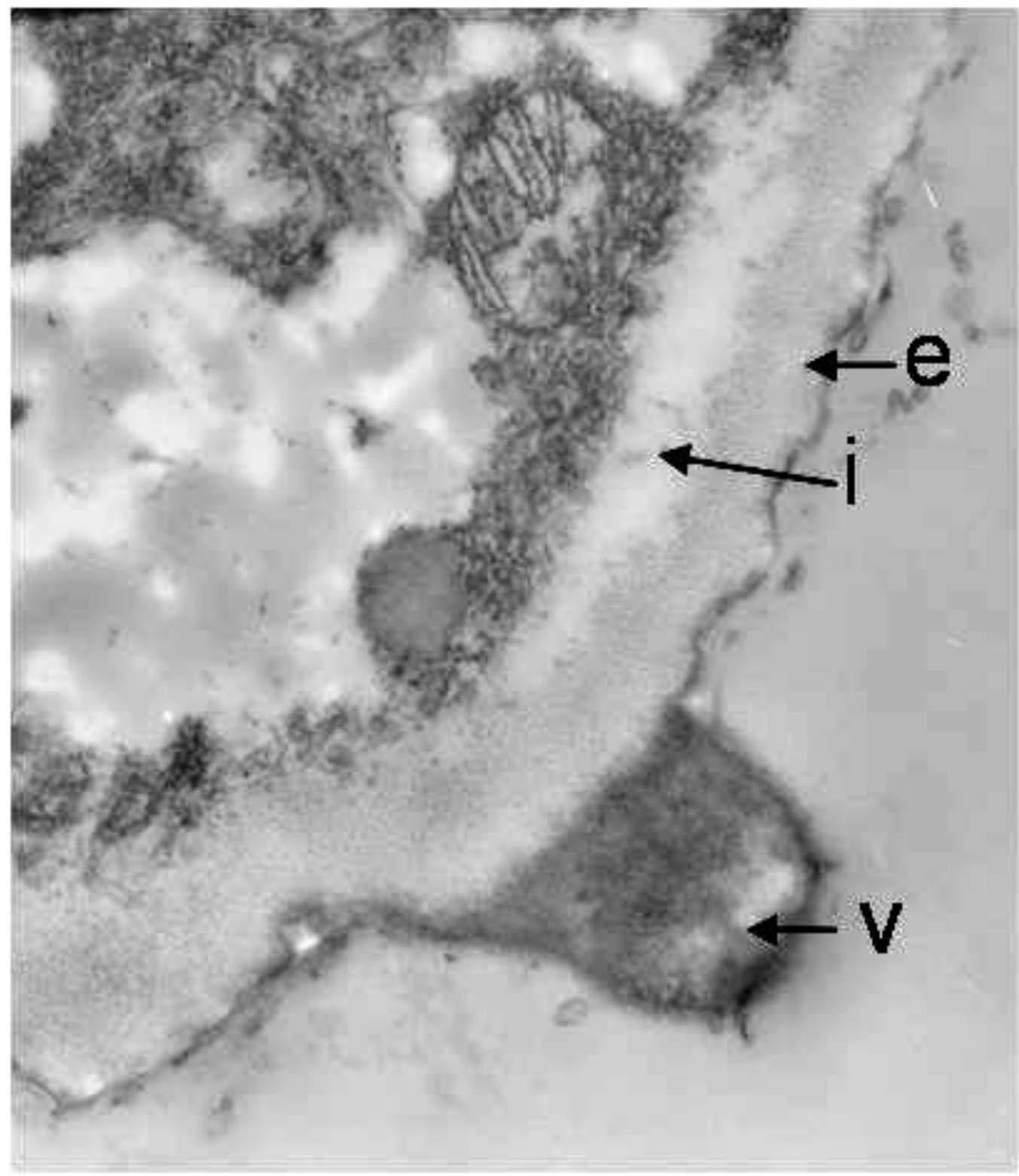


Los diferentes segmentos de la hifa están aparentemente separados por una pared o septo, el cual está formado por la membrana interna, que separa dos segmentos de la hifa. En la parte central del septo puede verse el poro septal, que comunica ambos segmentos o compartimientos de la hifa y el cual puede tener un orificio mayor o menor dependiendo de la actividad del hongo, permitiendo el intercambio de material citoplasmático, incluyendo el núcleo (Figs. 13, 14, 15 y 16).

El contenido de las hifas está formado por zonas densas próximas a los septos $y$, en el resto, por material vacuolado sin que puedan diferenciarse orgánulos citoplasmáticos. En otras, sin embargo, se observan mitocondrias irregulares con crestas transversales $(\mathrm{m})$ y membranas distribuidas irregularmente por el citoplásma (Figs. 16-17).

Las hifas en espiral presentan una pared no tan bien definida, con una capa externa fina y una interna menos densa que en las hifas normales. El citoplasma presenta un aspecto vacuolado, con pequeñas vesículas y algunas mitocondrias (Fig 17).

Los macroconidios, observados en un corte sagital, muestran su pared con una capa externa y otra interna de mayor grosor, que forma los septos. En el citoplasma se observa la membrana plasmática, vacuolas, núcleo, mitocondrias y cuerpos lipídicos (Figs. 18, 19 y 20). 
Figura 12.- T. mentagrophytes ( $v$. mentagrophytes). MET. Hifas del micelio reproductor. En una de ellas cortada en sentido longitudinal se puede observar el inicio de la formación de un microconidio $(\mathrm{m})$. En la pared se distingue una capa externa densa (e) y una interna (i), más gruesa y de menor densidad. $4.500 x$ 


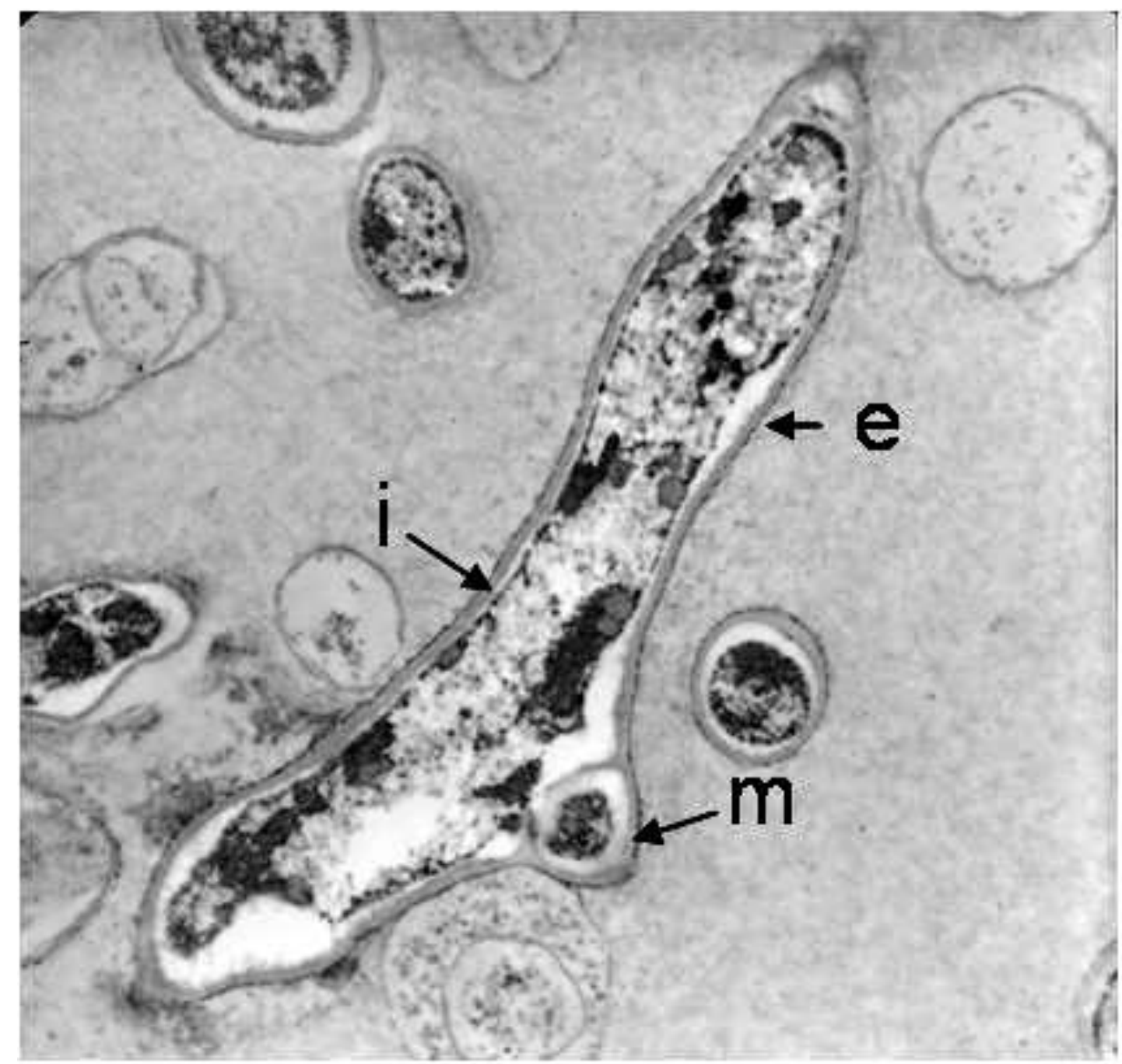


Figura 13.- T. mentagrophytes (v. mentagrophytes). MET. Hifa del micelio reproductor donde se aprecia la pared que constituye el septo (s) y el poro septal (p). En el citoplasma son visibles cuerpos lipídicos (L) y vacuolas (v). $27.300 x$ 


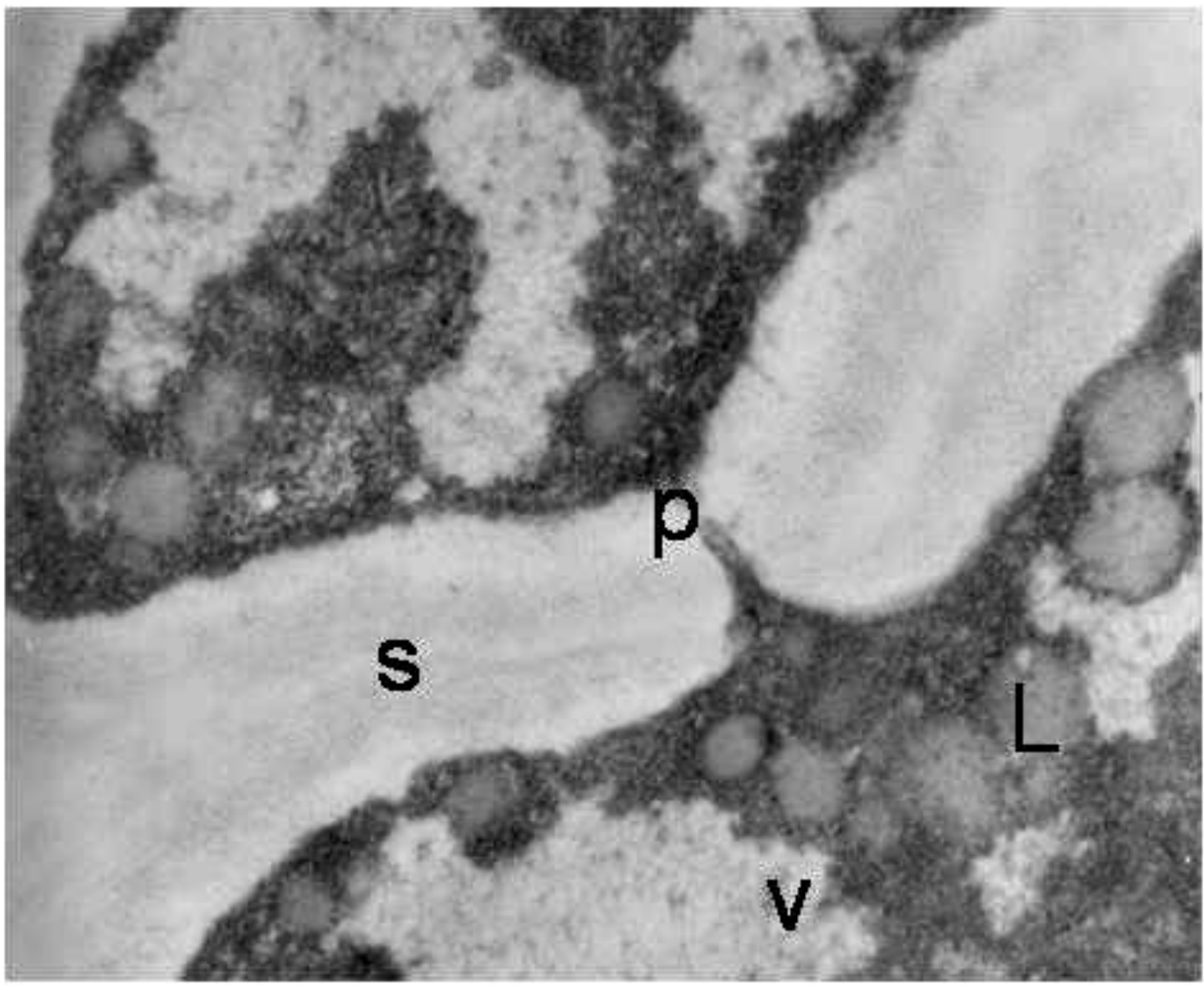


Figura 14.- T. mentagrophytes (v. mentagrophytes). MET. Hifa del micelio reproductor. Se aprecia como la pared septal (s) está formada por la capa interna de la pared de la hifa (i). El poro septal que comunica los dos segmentos de la hifa $(p)$ está limitado por la membrana plasmática $(\mathrm{m})$; en el citoplasma hay abundantes cuerpos lipídicos(L). 41.700x 


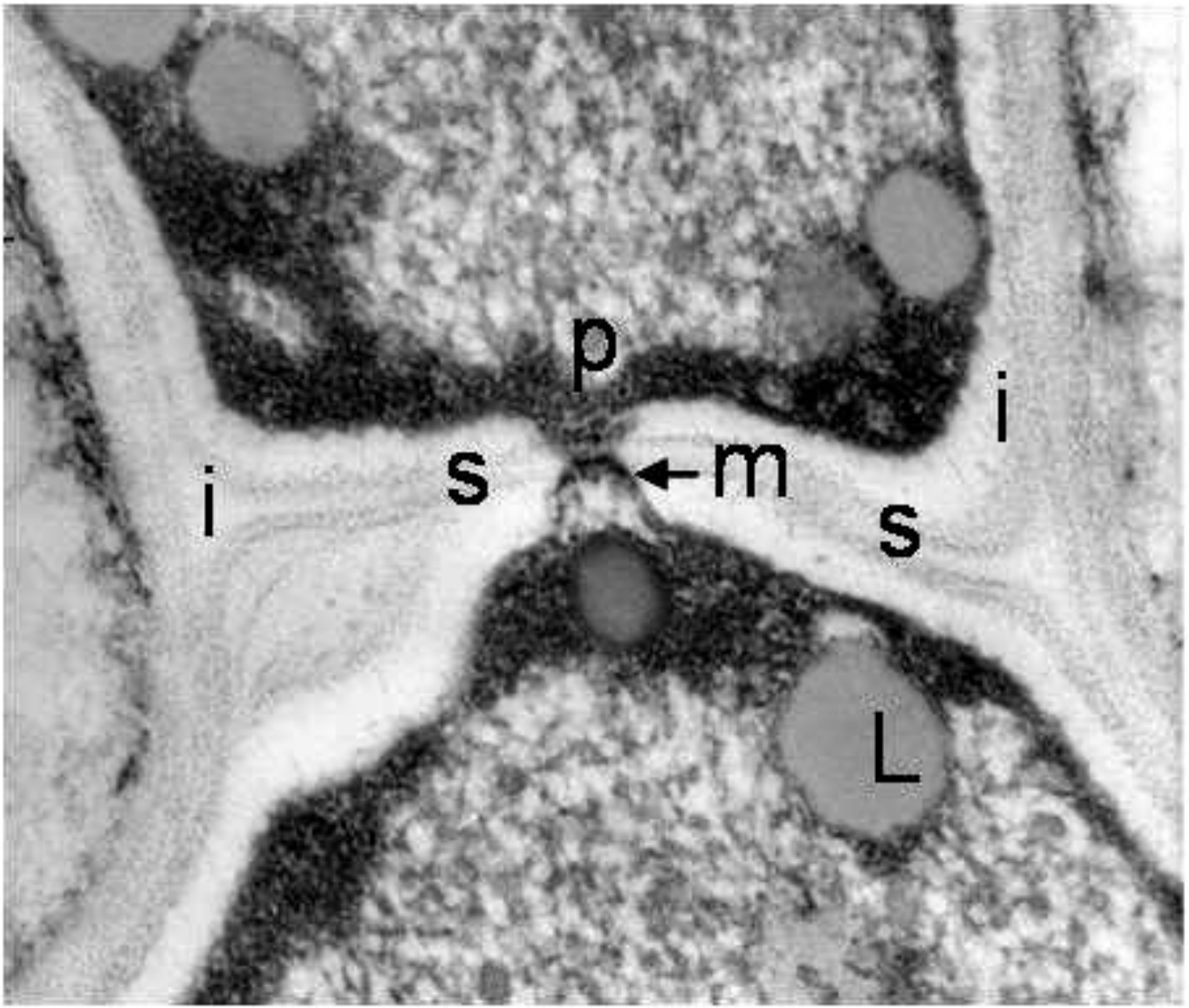


Figura 15. - T. mentagrophytes ( $v$. mentagrophytes). MET. Hifa del micelio reproductor donde es visible el paso de contenido citoplasmático de ambos segmentos a través del poro septal (p). Cuerpos lipídicos (L). 41.700x 


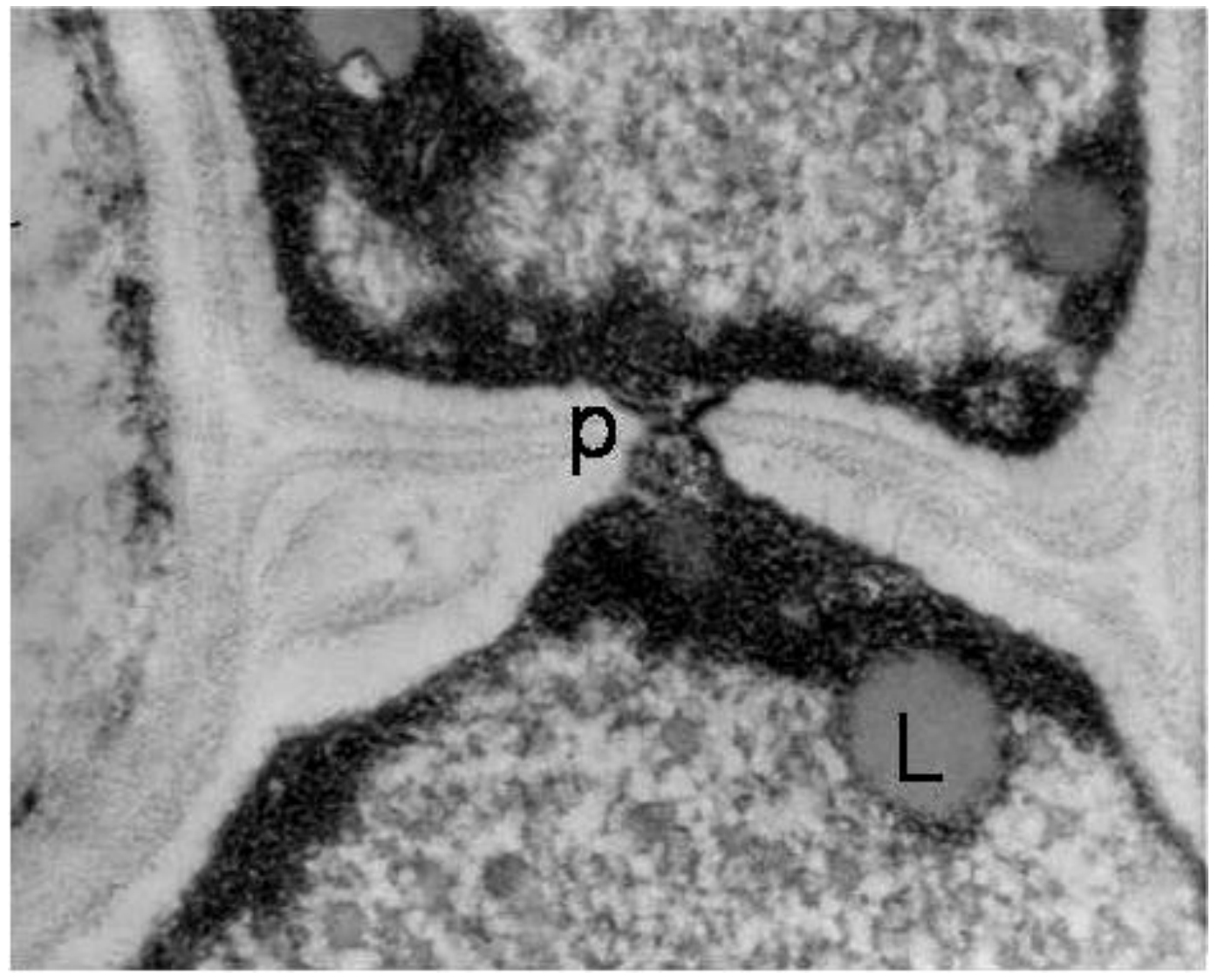


Figura 16.- T. mentagrophytes ( $v$. mentagrophytes). MET. Hifas del micelio reproductor cortadas en diferentes secciones. Es visible la pared septal (s) y diferentes elementos del contenido citoplasmático. En el centro, se observa un poro septal muy abierto, solo reconocible por la pared septal a uno y otro lado (flechas), con evidente intercambio entre ambos compartimientos de material citoplasmático (recuadro superior). 6.700x (recuadro: 15.750x) 





Figura 17.- T. mentagrophytes (v. mentagrophytes). MET. Sección de una hifa en espiral con su capa externa (e), interna (i) y en el citoplasma alguna mitocondria $(\mathrm{m}) \cdot 4 \cdot 500 \mathrm{x}$ 


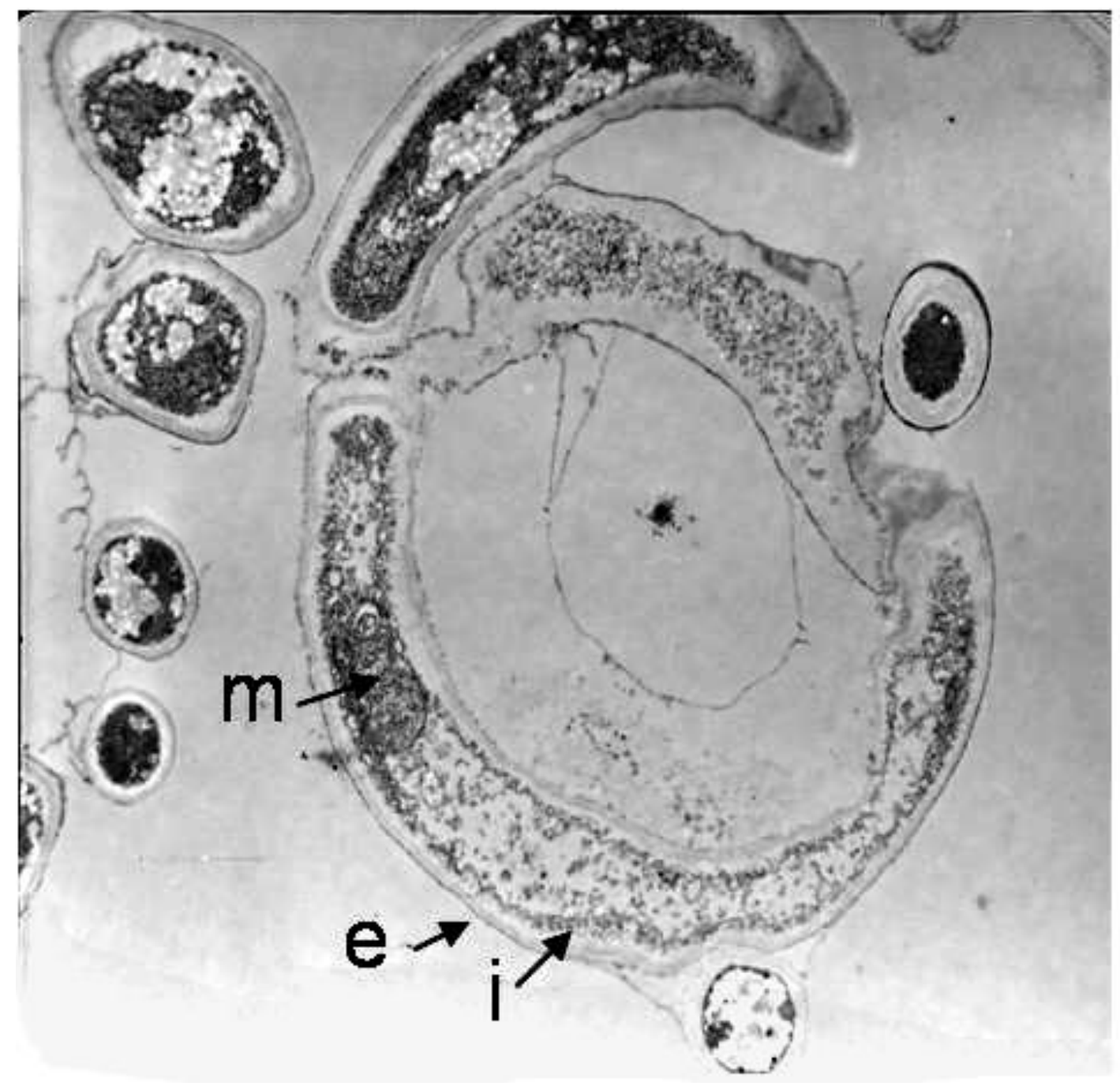


Figura 18.- T. mentagrophytes (v. mentagrophytes). MET. Macroconidio en un corte sagital donde se observa su pared con la capa externa (e), capa interna (i) que forma los septos (s). En el citoplasma se ve la membrana plasmática $(\mathrm{mp})$, mitocondrias $(\mathrm{m})$ y cuerpos lipídicos (L). 6.000x 


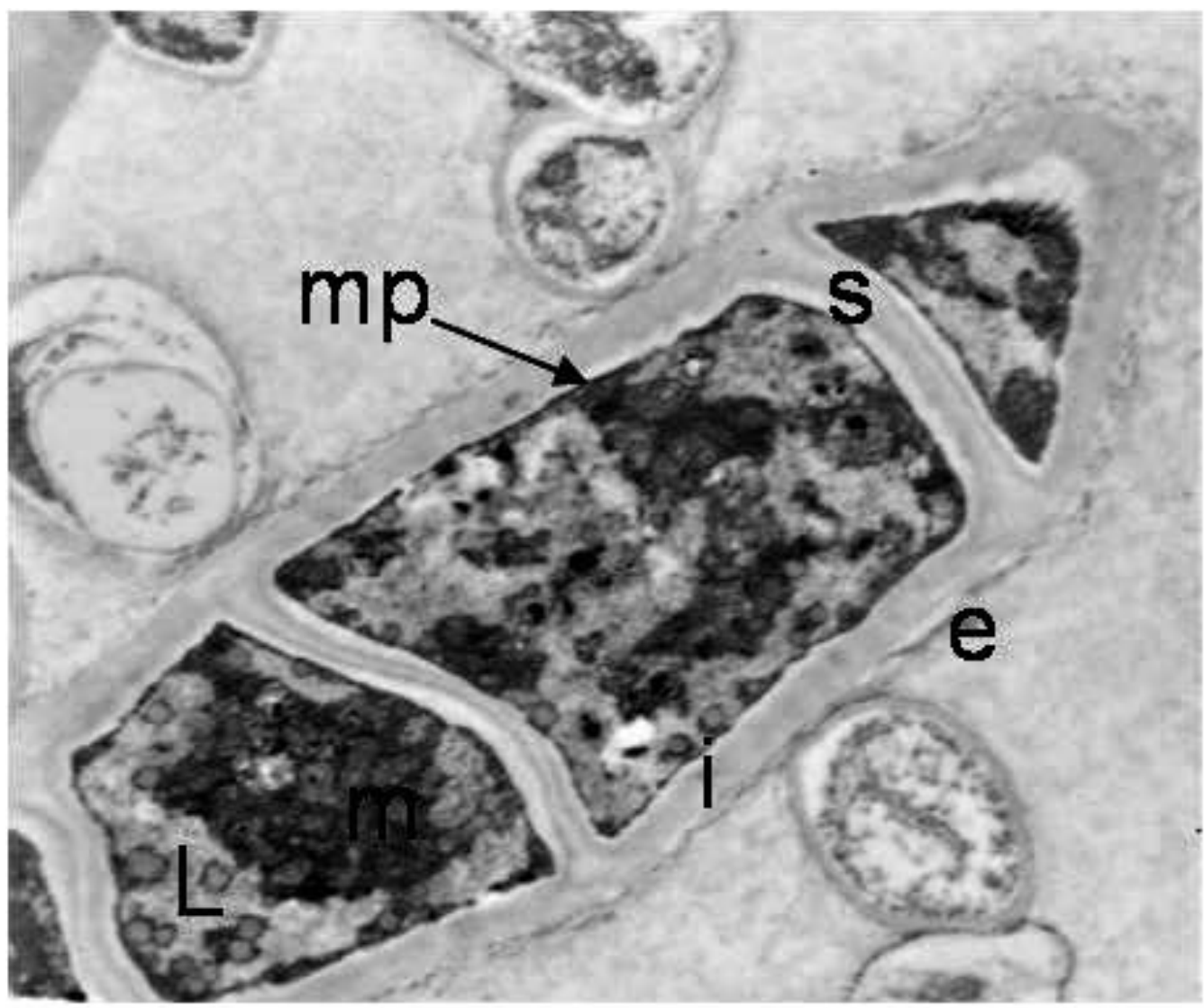


Figura 19.- T. mentagrophytes (v. mentagrophytes). MET. Macroconidio. A mayores aumentos se observa el contenido citoplasmático. Cuerpos lipídicos (L) y mitocondrias (m). $27.300 \mathrm{x}$ 


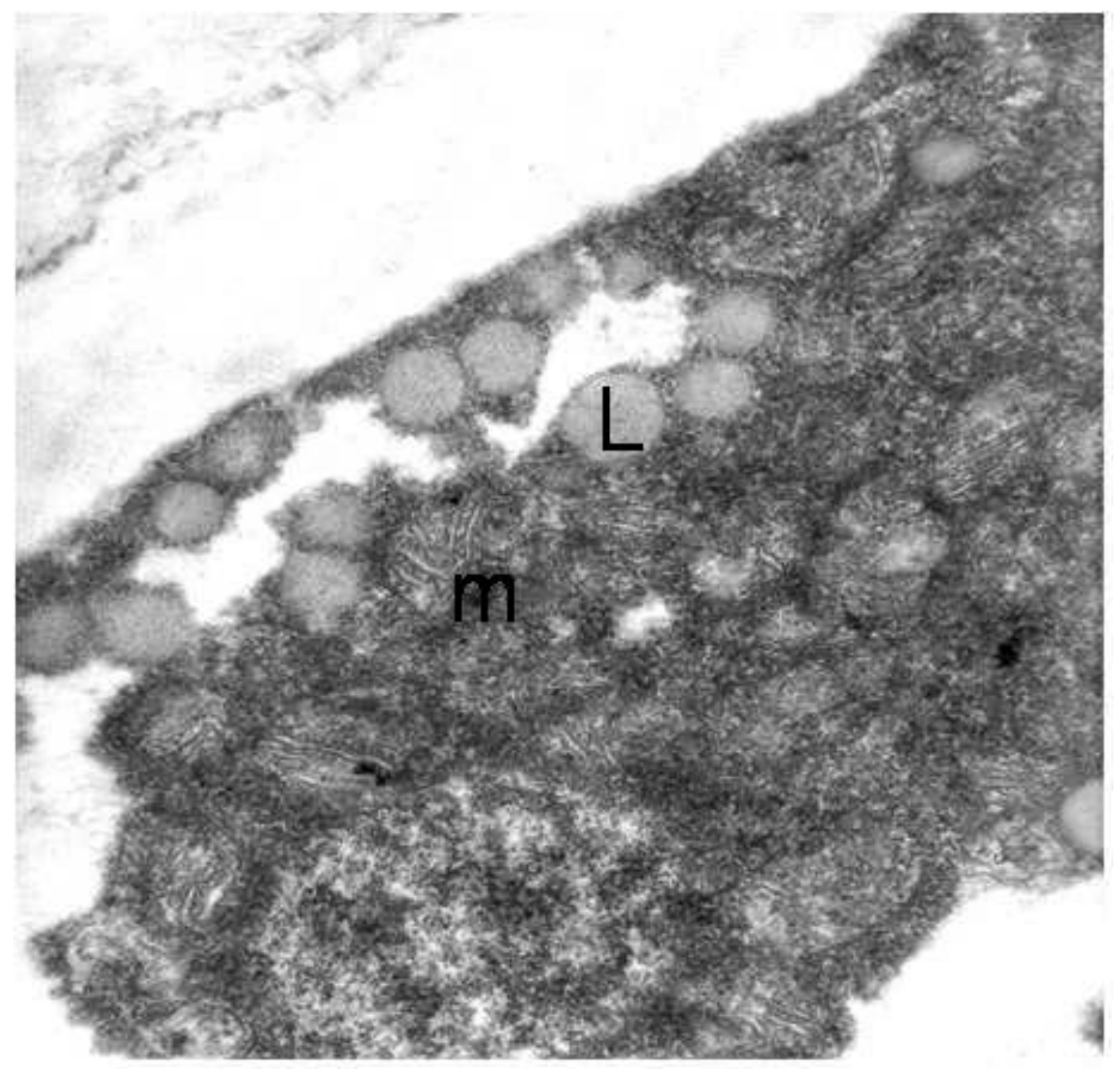


Figura 20.- T. mentagrophytes (v. mentagrophytes). MET. Macroconidio. Es visible la membrana plasmática (mp), lípidos (L) y mitocondrias $(\mathrm{m}) .18 .225 \mathrm{x}$ 


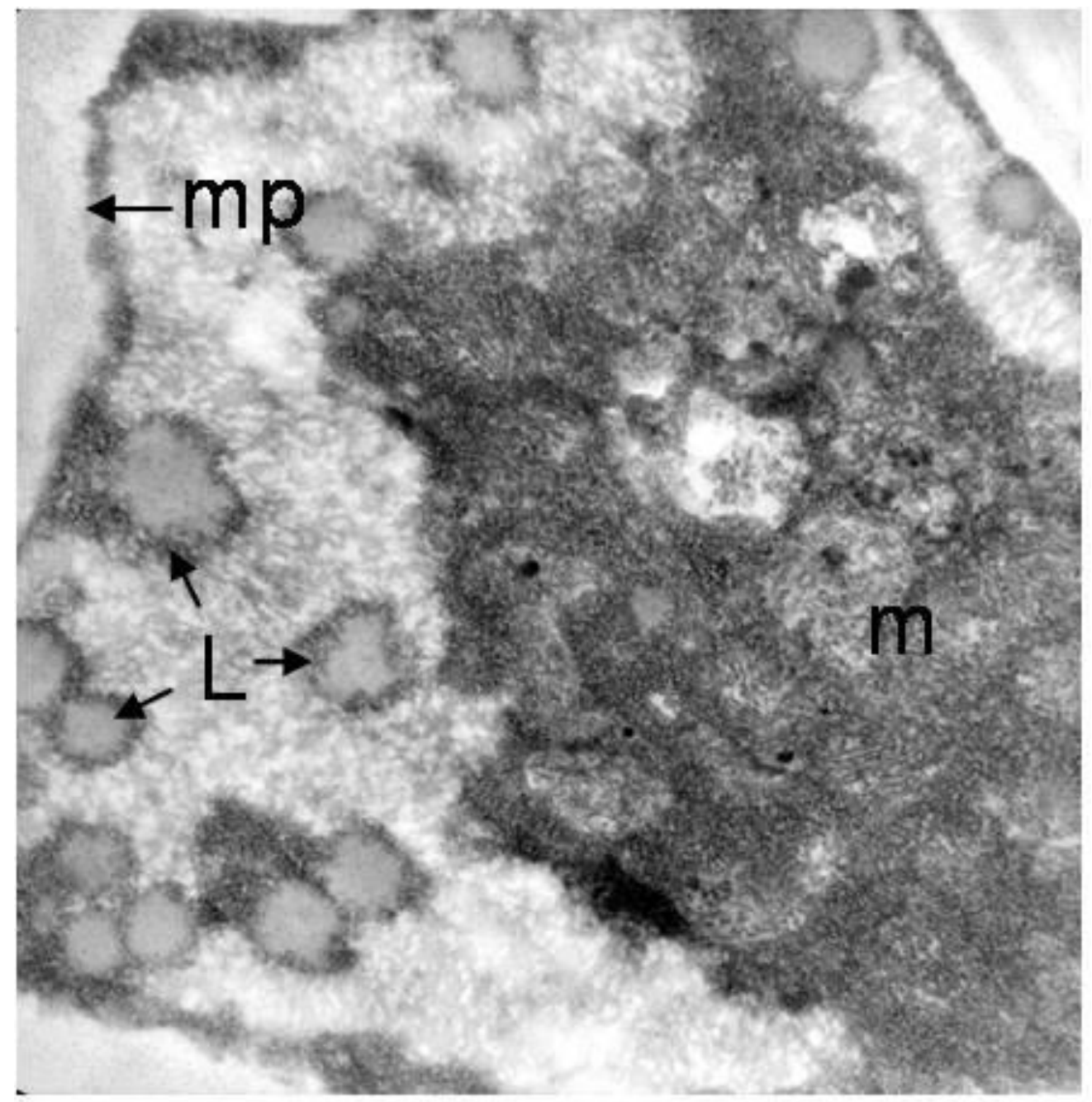




\section{M. canis}

\section{Microscopía Electrónica de Barrido}

M. canis con el MEB las hifas que constituyen el micelio reproductor son abundantes pero poco significativas, apareciendo como elementos finos, alargados y ramificados. Algunas presentan irregularmente engrosamientos a modo de yemas, mal definidas y de difícil interpretación. El rasgo distintivo y diferencial del micelio reproductor lo constituyen los macroconidios; estos, de diferentes tamaños, aparecen como elementos fusiformes, de superficie rugosa, con abundantes verrucosidades que recuerdan a “copos de algodón”. Es evidente también el pedículo de inserción con la hifa (Fig. 21 y 22). 
Figura 21 A. M canis. MEB. Macroconidio joven, fusiforme, de superficie lisa, en el que se evidencia el resalte de los septos. $1250 \mathrm{x}$.

Figura 21 B. M canis. MEB. Macroconidio en cuyo extremo distal se inician las formaciones algodonosas que caracterizan a las formas maduras. $2500 \mathrm{x}$.

Figura 21 C. M canis. MEB. Macroconidio de aspecto fusiforme con numerosas verrucosidades en su superficie. Hifas del micelio reproductor $(H)$. 1250x 

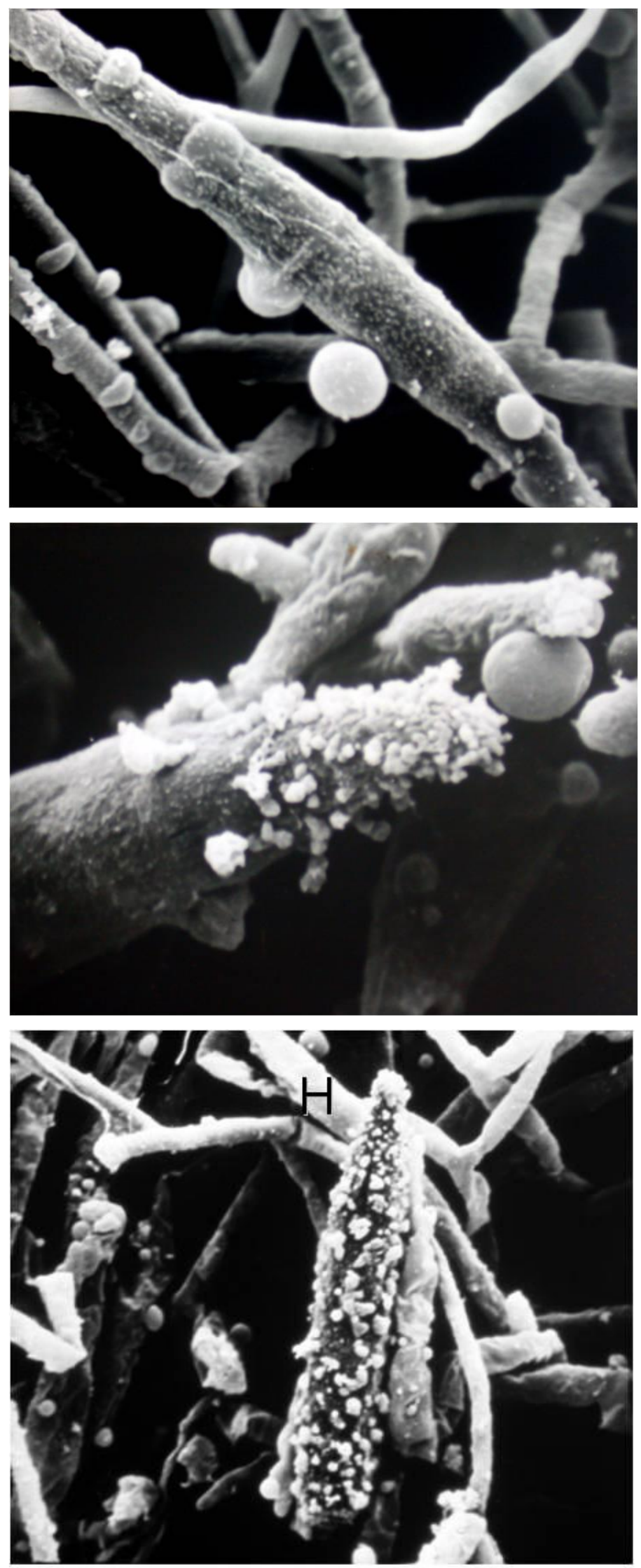
Figura 22.- M canis. MEB. Macroconidio. Detalle, a mayor aumento, de las verrucosidades, con aspecto algodonoso (hemos comparado a "copos de algodón”). Estos elementos se corresponden también con las “espinas” observadas en microscopía óptica, que son características de esta especie. 5000x 


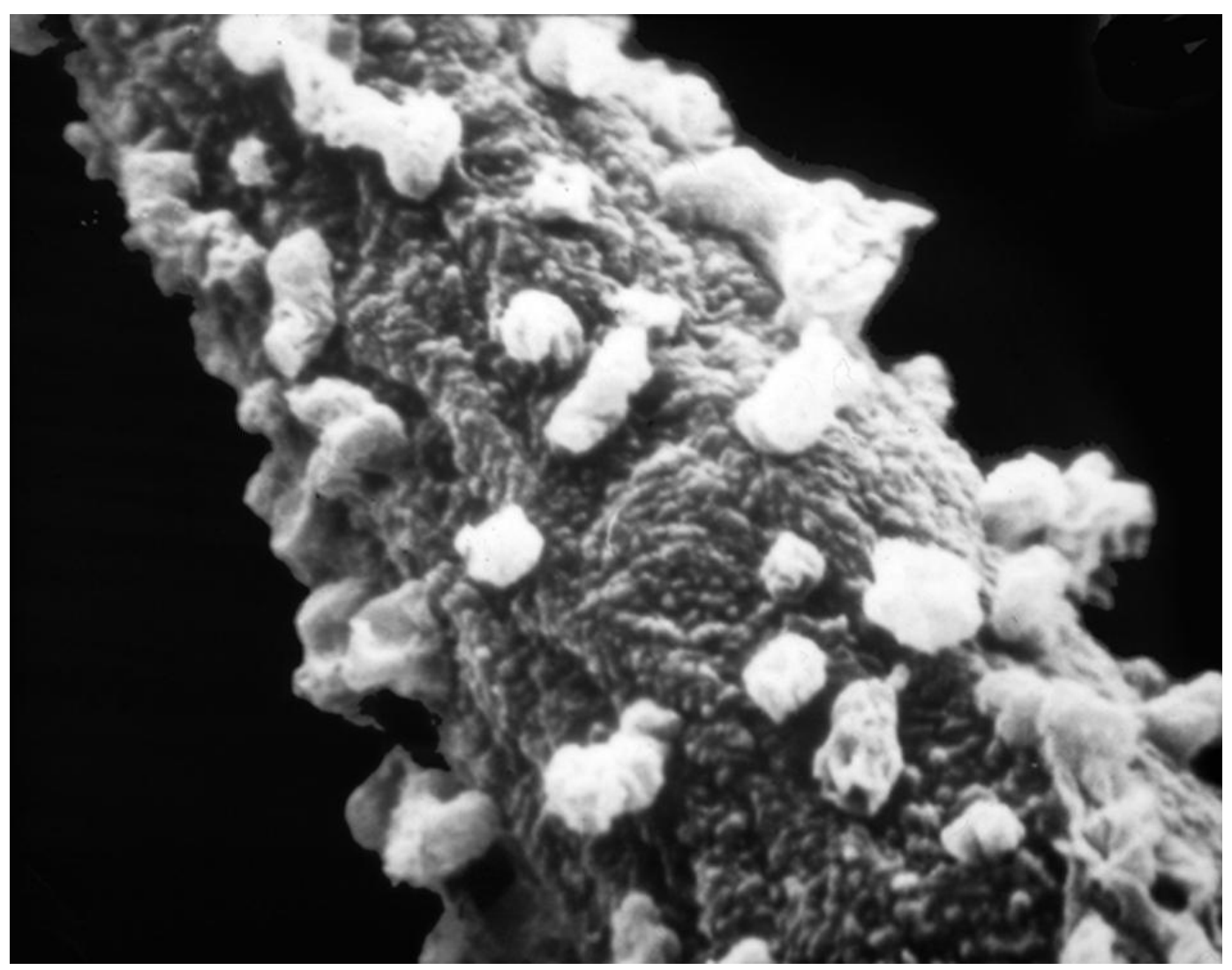




\section{Microscopía Electrónica de Transmisión}

En las colonias jóvenes los macroconidios aparecen sin verrucosidades y, a medida que maduran, éstas aparecen por el extremos apical extendiéndose después por toda su superficie (Figs. 21 A, B y C)

Con el MET, las hifas del micelio reproductor aparecen finas, alargadas y tabicadas (Fig.23-A). En ellas se diferencia claramente la pared, con una capa externa (e) desflecada e otra interna (i) de mayor grosor dispuesta en estratos fibrilares. El contenido de las hifas está formado por zonas densas de material amorfo mal diferenciado, cuerpos lipídicos y restos mitocondriales (Fig. 23-B, 24, 25 y 26). En otras sin embargo, se observan mitocondrias bien desarrolladas con crestas transversales (Fig. 27 y 28 ) y en algunos sectores material vacuolizado (Fig. 29).

Son evidentes los septos constituidos por la capa interna, apreciándose en la zona media de algunos de ellos el inicio del poro septal y la presencia, a uno y otro lado, de corpúsculos de material denso (cuerpos de Woronin) (Fig. 30 y 31). Es posible observar también el paso de contenido citoplasmático a uno y otro lado del septo (Fig. 32). En la figura 33 son evidentes unas formaciones densas, redondeadas, situadas a nivel del poro septal, que corresponden a cuerpos de Woronin bien desarrollados. 
Figura 23 A.- M canis. MET. A pocos aumentos, hifa del micelio reproductor donde son visibles los septos que separan los diferentes segmentos. 2.100x

Figura 23 B. - M canis. MET. Hifa del micelio reproductor con su pared contituida por una capa externa (e), otra interna más gruesa (i) y contenido citoplasmático. $13.100 \mathrm{x}$ 

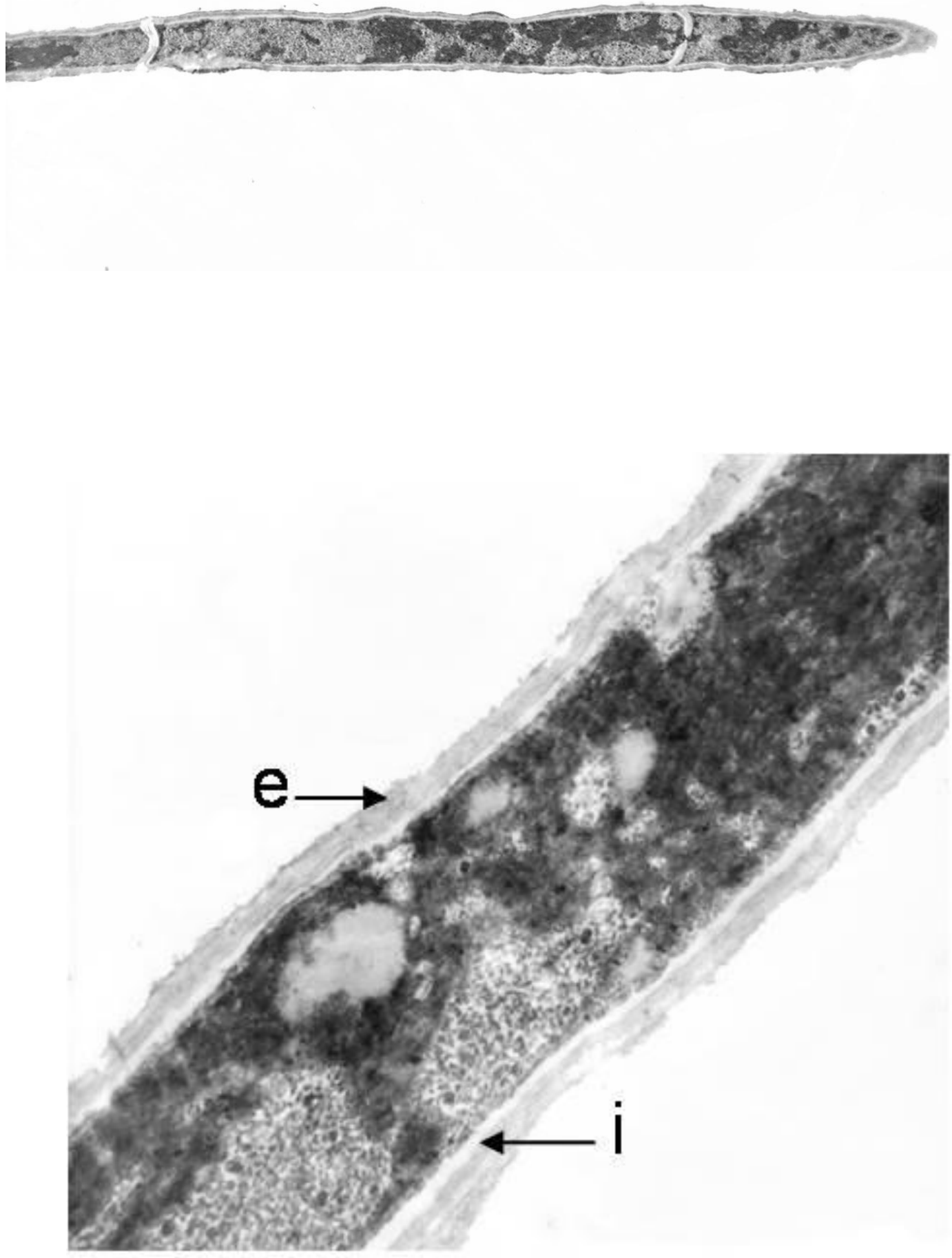
Figura 24. - M canis. MET. Hifa del micelio reproductor donde son visibles los septos (s) que separan diferentes segmentos de la hifa. $6.700 \mathrm{x}$ 


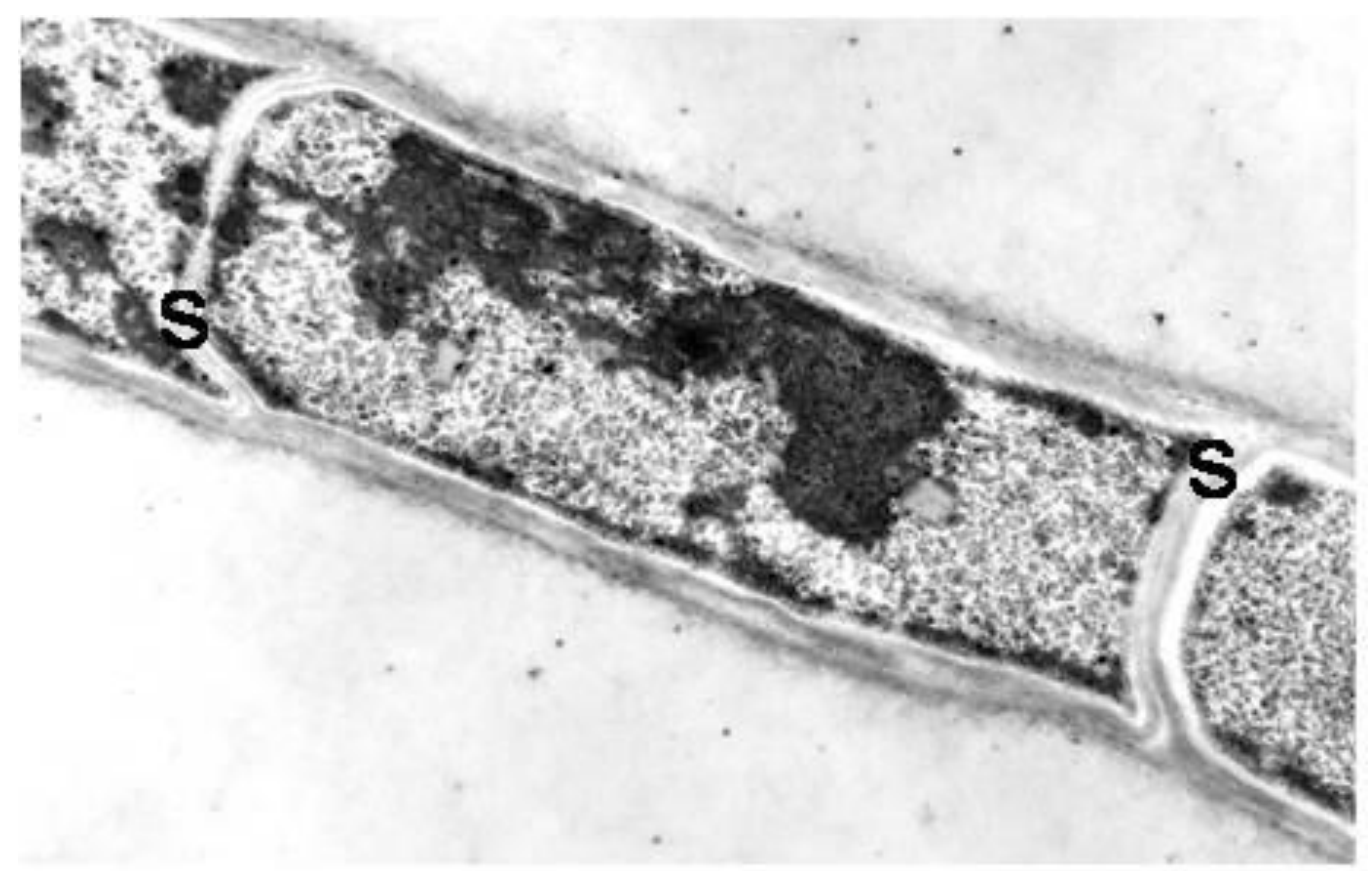


Figura 25.- $M$ canis. MET. Hifa del micelio reproductor donde se observa con mayor nitidez la capa externa desflecada (e), la interna (i) y el contenido citoplasmático con cuerpos lipídicos (L) y mitocondrias (m). $13.100 \mathrm{x}$ 


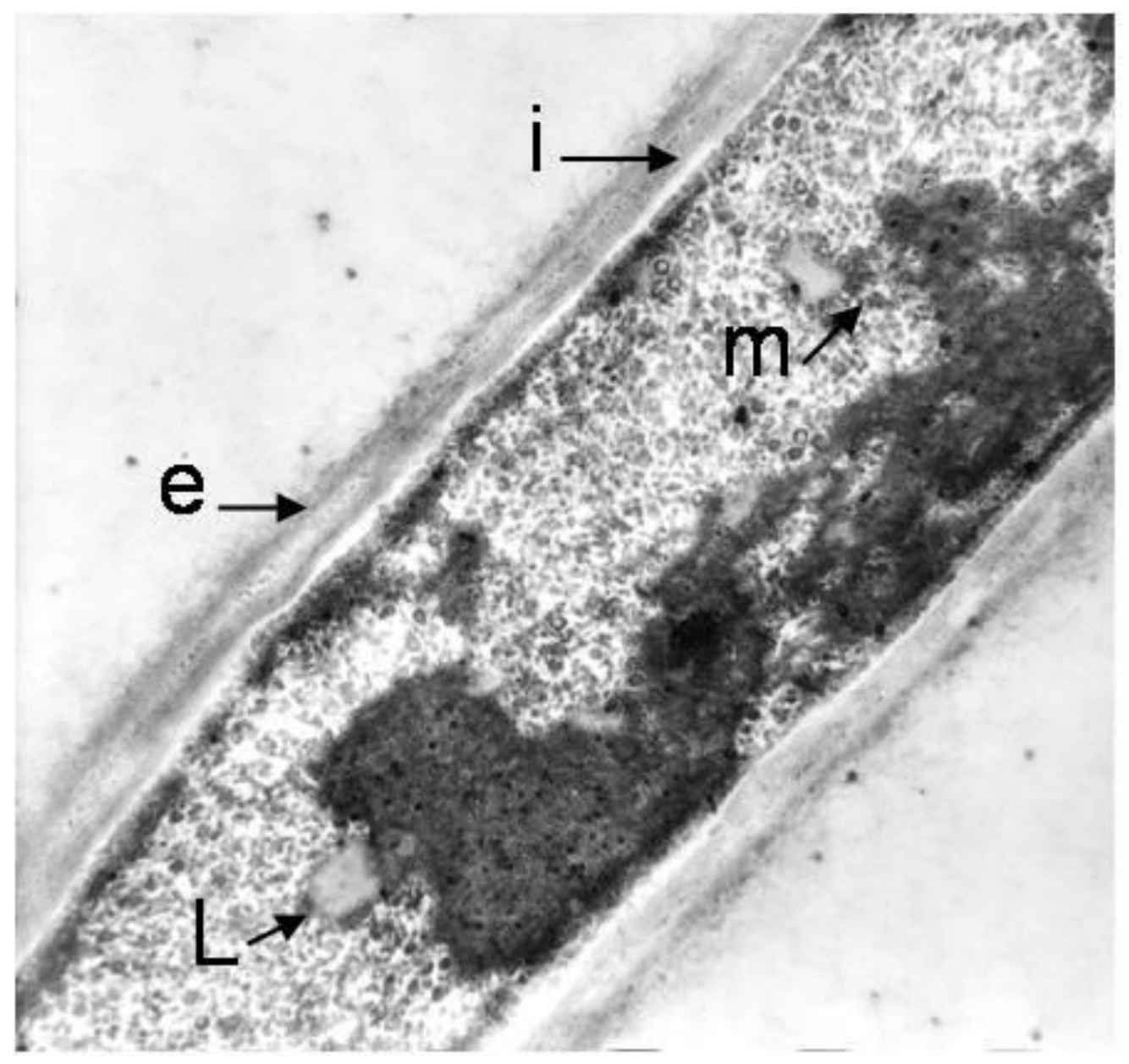


Figura 26. - M canis. MET. A mayores aumentos, se ve claramente la pared de la hifa con su capa externa (e), su capa interna (i), la membrana plasmática (mp), cuerpos lipídicos (L) y mitocondrias (m). $27.300 \mathrm{x}$ 


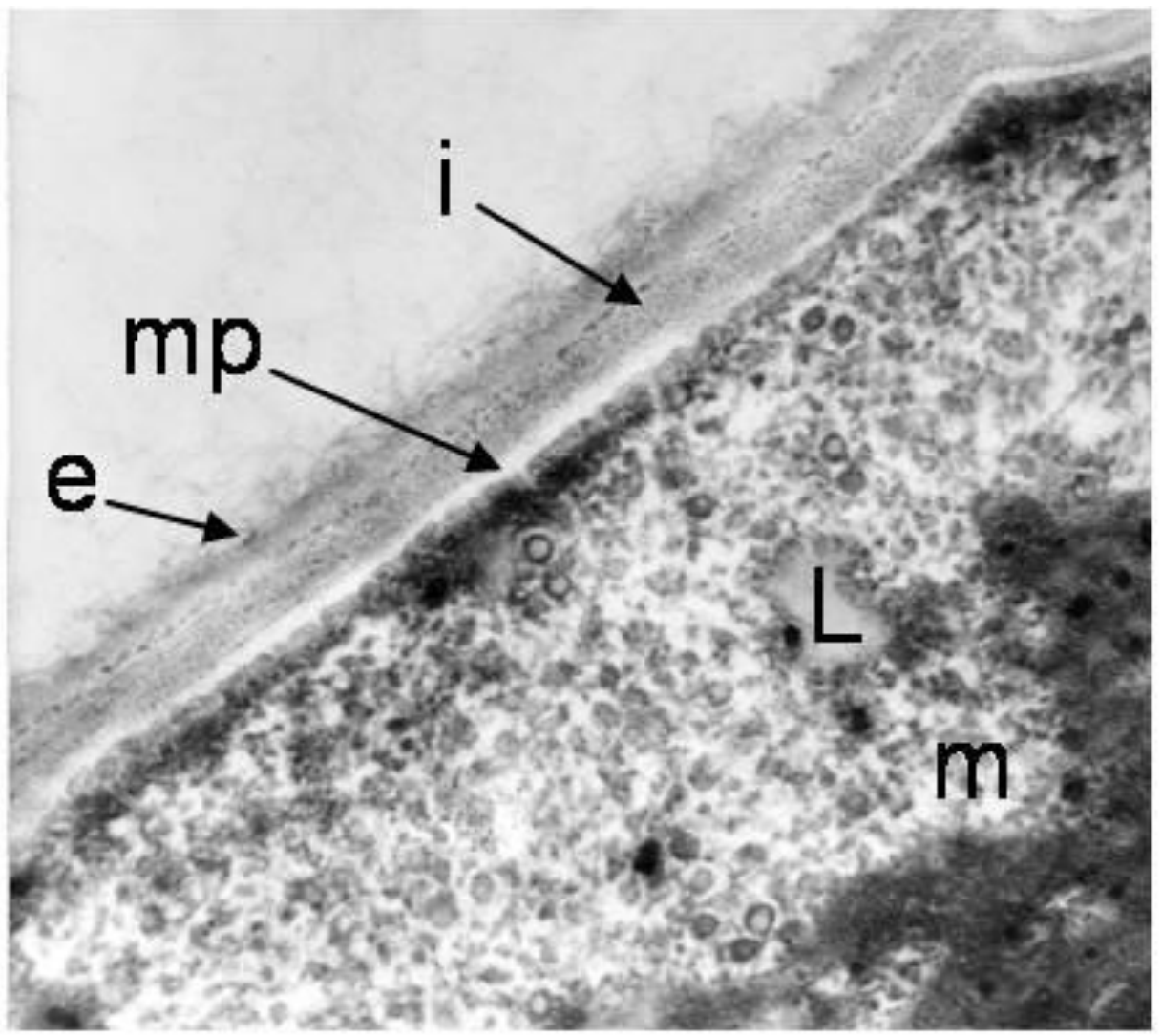


Figura 27. M canis. MET. En algunos segmentos de las hifas del micelio reproductor se observan abundantes mitocondrias (flecha). $6.700 \mathrm{x}$

Figura 28.- $M$ canis. MET. Detalle, a mayor aumento de la figura anterior, en el que se observan claramente las mitocondrias (flecha) con sus crestas y el contenido citoplasmático amorfo 13.100 x 

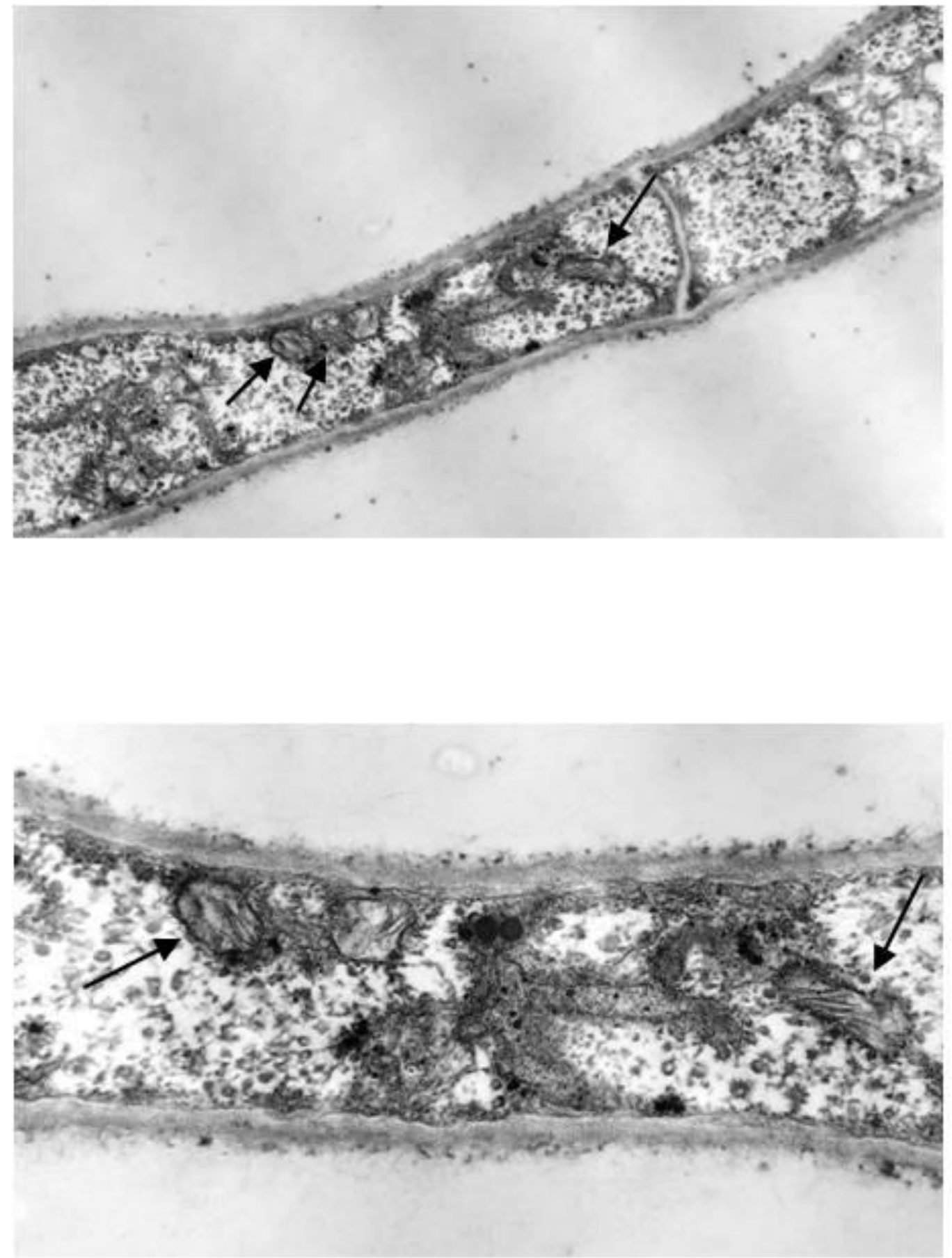
Figura 29.- M canis. MET. En otros segmentos de las hifas se observan abundantes vacuolas (v). $13.100 \mathrm{x}$ 


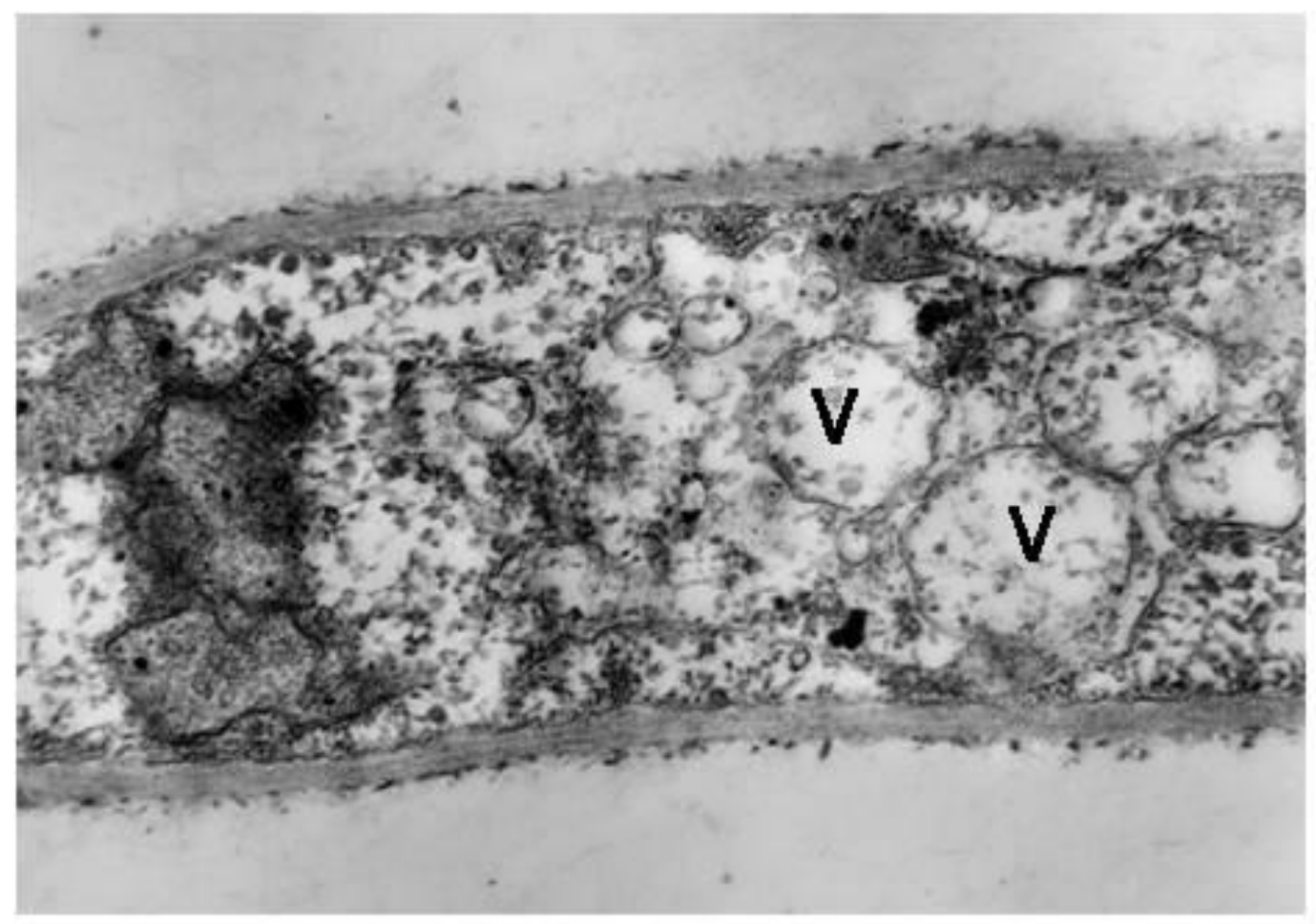


Figura 30.- A pocos aumentos, en esta hifa del micelio reproductor son visibles los septos que separan distintos segmentos, así como su pared y contenido citoplasmático. $6.700 \mathrm{x}$ 


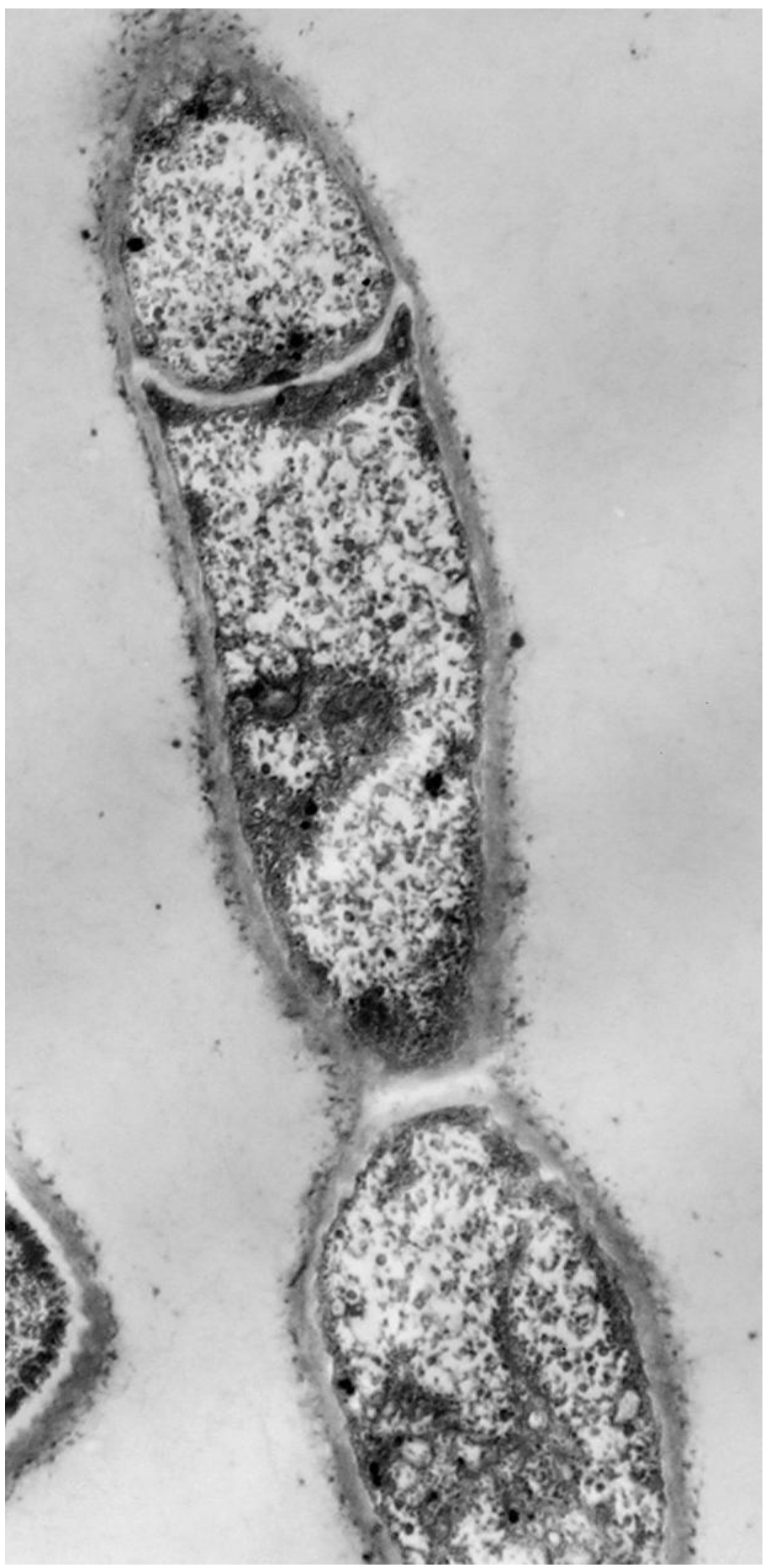


Figura 31.- $M$ canis. MET. Detalle, a mayor aumento de la figura anterior, donde se observa el inicio del poro septal (p) y un corpúsculo de material denso (cuerpo de Woronin, flecha). $13.100 \mathrm{x}$ 


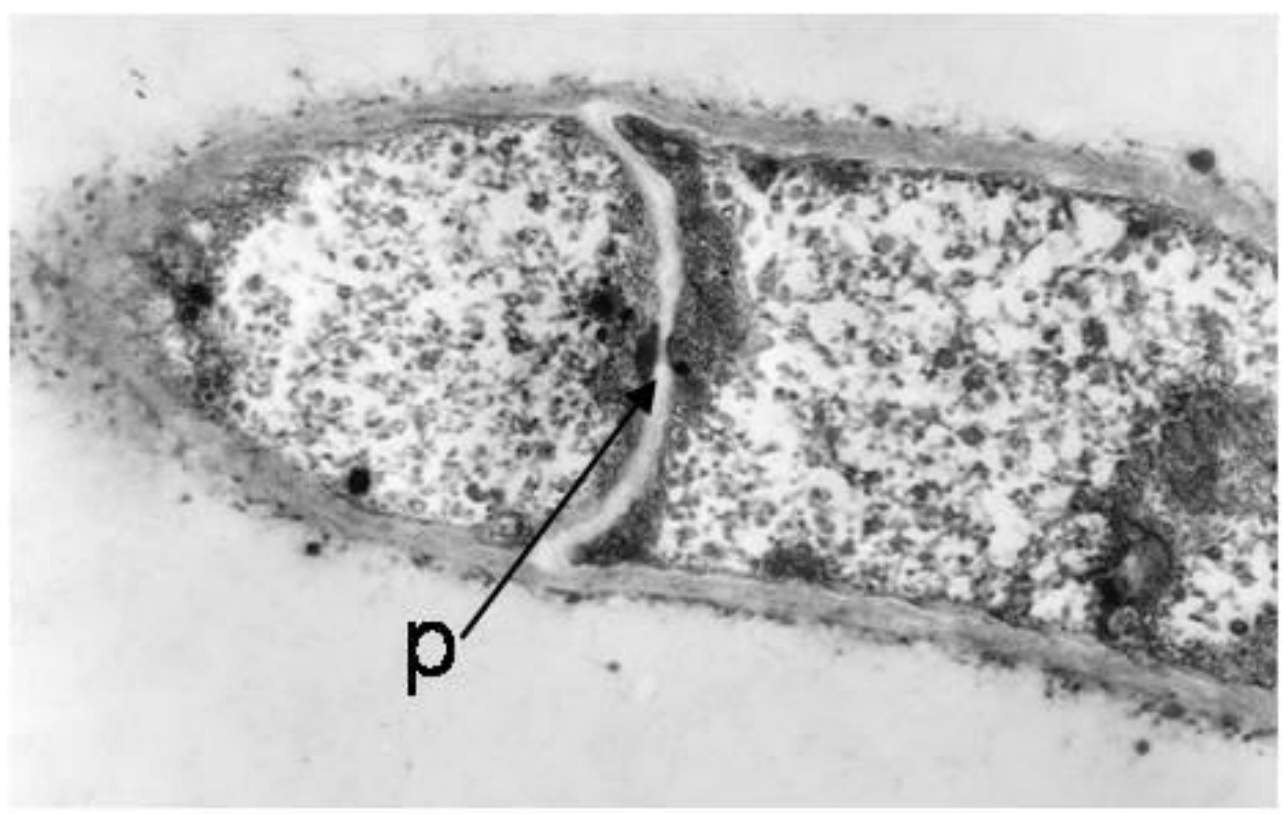


Figura 32.- $M$ canis. MET. En esta hifa del micelio reproductor es visible el poro septal (p) con paso de contenido citoplasmático entre ambos segmentos. $13.100 x$ 


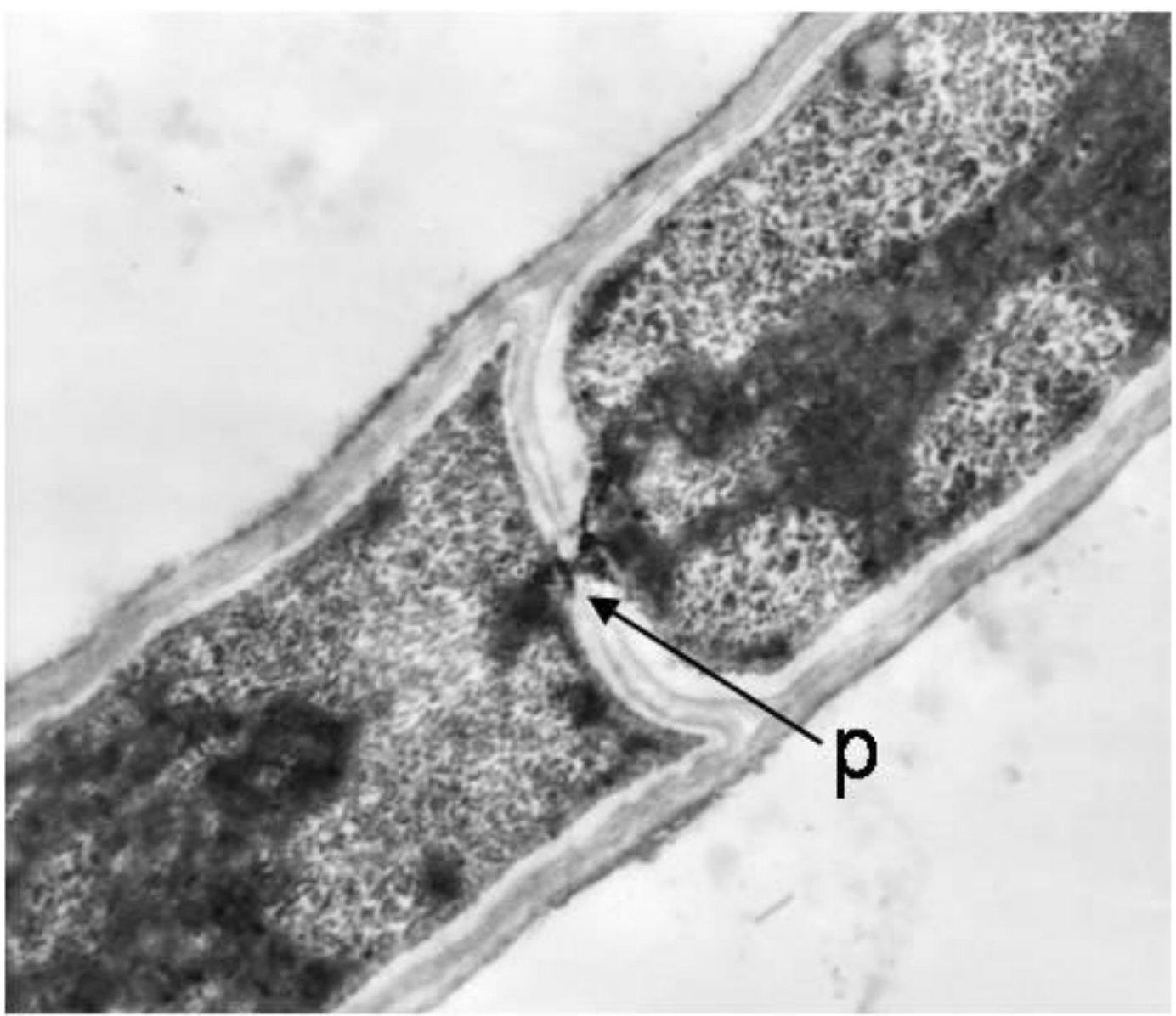


Figura 33.- $M$ canis. MET. Hifa del micelio reproductor. En el septo y en su parte central se observan unas formaciones densas, redondeadas, situadas a nivel del poro septal, que corresponden a los cuerpos de Woronin (W). 27.300 X 


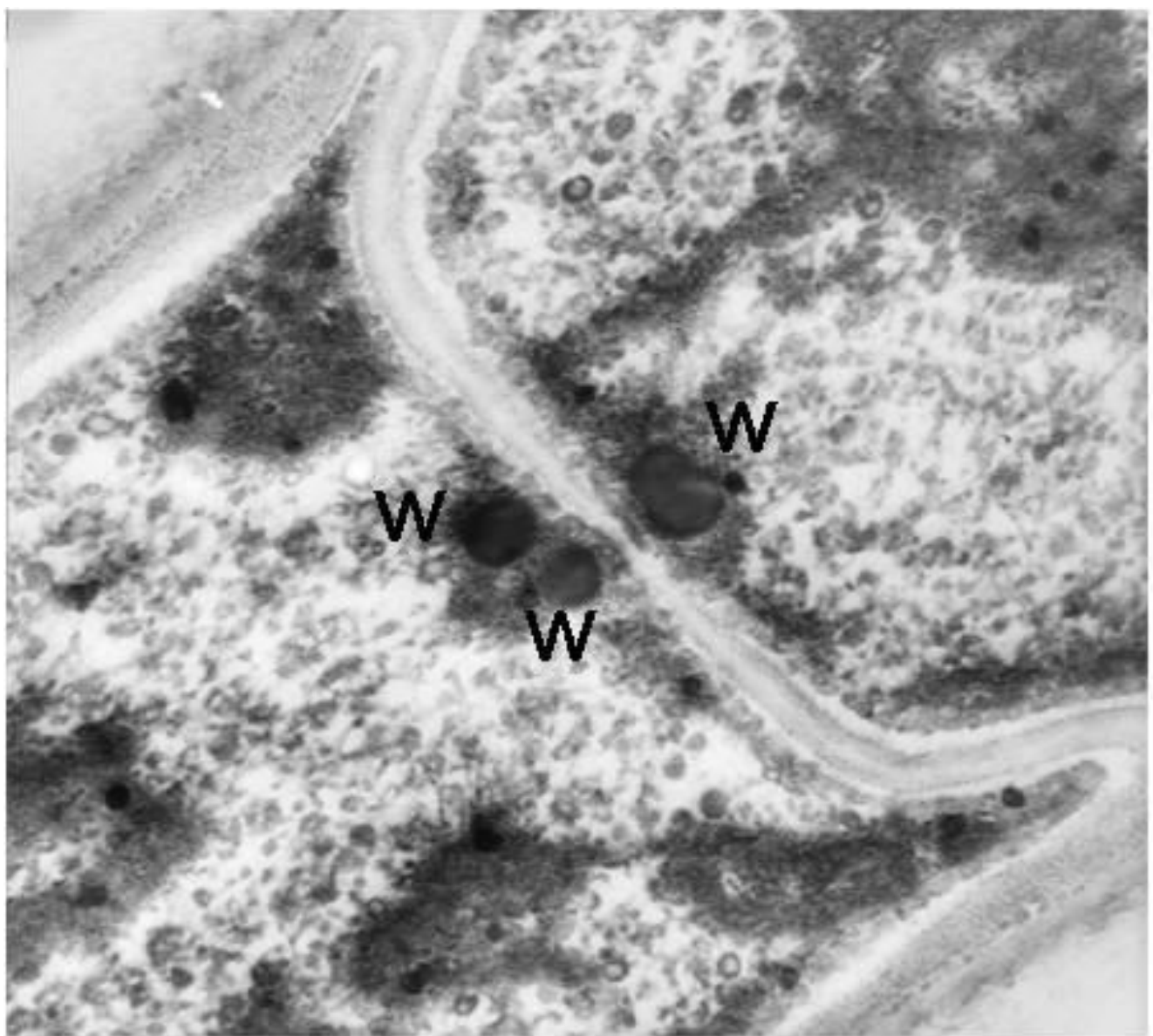


Los macroconidios observados con el MET, poseen una gruesa pared en la que se distinguen una capa externa (e) de gran densidad, y otra interna (i) mucho más amplia y de menor densidad electrónica. Los septos son anchos y están formados por el mismo material de la capa interna (Fig. 34), la cual limita el contenido citoplasmático de aspecto denso, con zonas vacuolizadas (Fig. 35) y donde, a mayores aumentos se pueden observar mitocondrias $(\mathrm{m})$ y formaciones densas pequeñas y numerosas, así como vesículas que semejan mitocondrias modificadas y restos de membranas (Figs. 36, 37 y 38 ).

La capa externa del macrocanidio presenta una superficie irregular, rugosa, con varias elevaciones; de ella surge una formación a modo de penacho, deshilachada, que corresponde a las verrucosidades que se observan con el MEB y a las "espinas" que se observan con microscopía óptica (Figs. 39 A, B y C). La capa interna presenta un aspecto fibrilar, mostrando una zona de menor densidad electrónica, correspondiente a un septo (Fig. 39 B). 
Figura 34.- M canis. MET. Macroconidio con una gruesa pared, en la que se observa una capa externa (e), fina, de gran densidad electrónica y otra interna (i), más amplia y de menor densidad. Los septos (s) también amplios están constituidos por el mismo material de la capa interna. $13.100 \mathrm{x}$ 


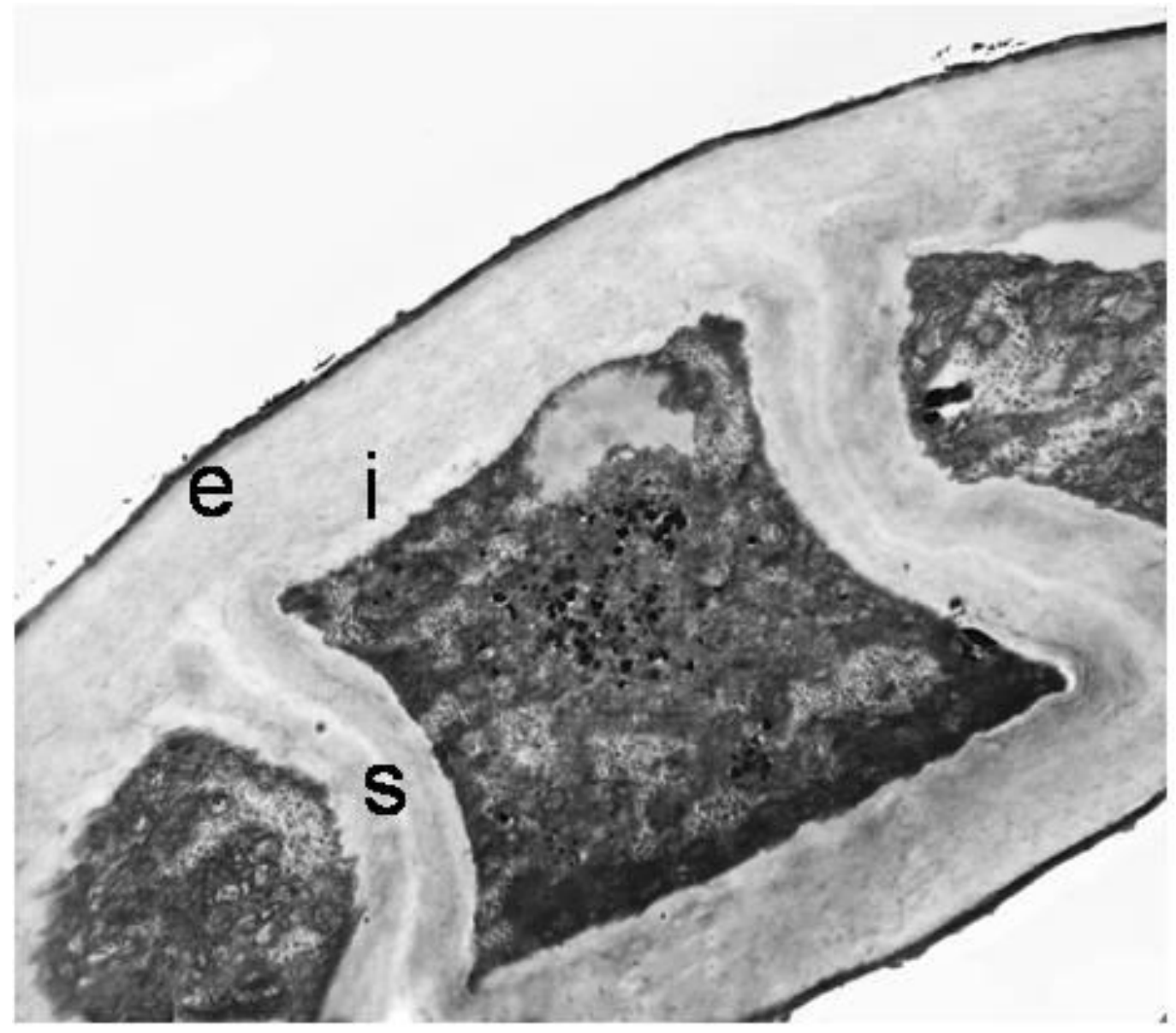


Figura 35.- M canis. MET. Macroconidio. En esta figura se observa la capa interna (i), el septo (s) la membrana plasmática (mp) y vacuola (v). $6.700 \mathrm{x}$ 


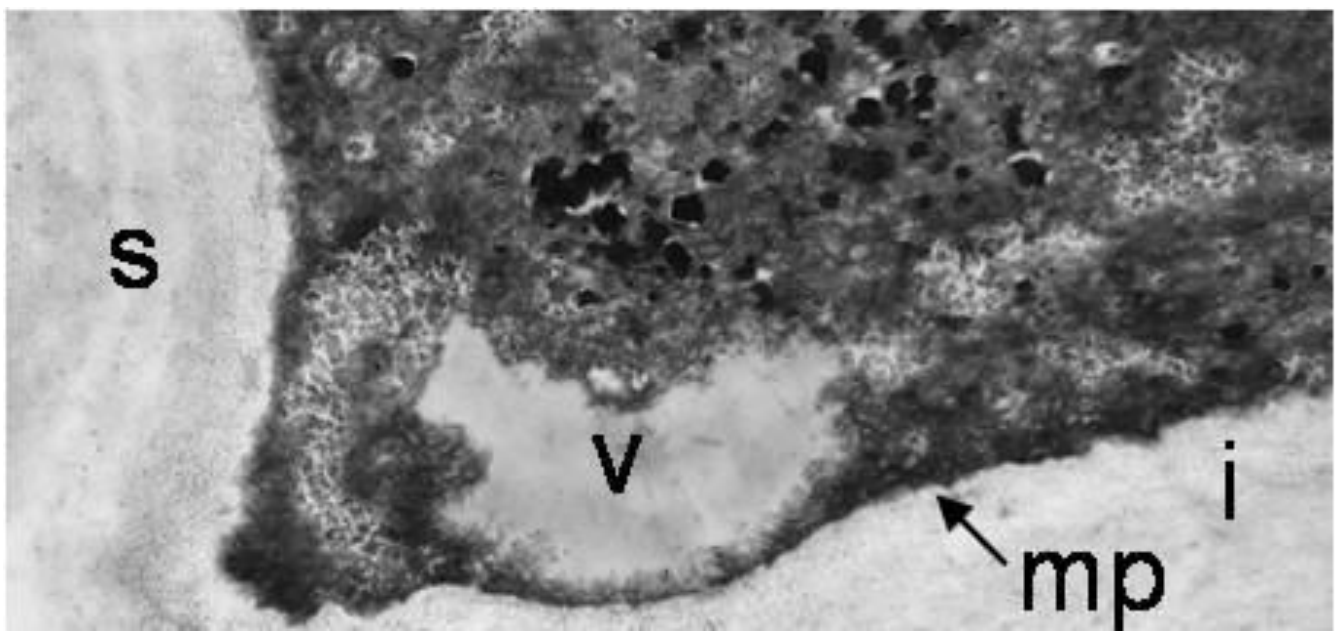


Figura 36.- $M$ canis. MET. Macroconidio. Contenido citoplasmático con material mal diferenciado, grumoso, con restos de mitocondrias $(m)$ y pequeñas formaciones densas (flecha). $13.100 \mathrm{x}$ 


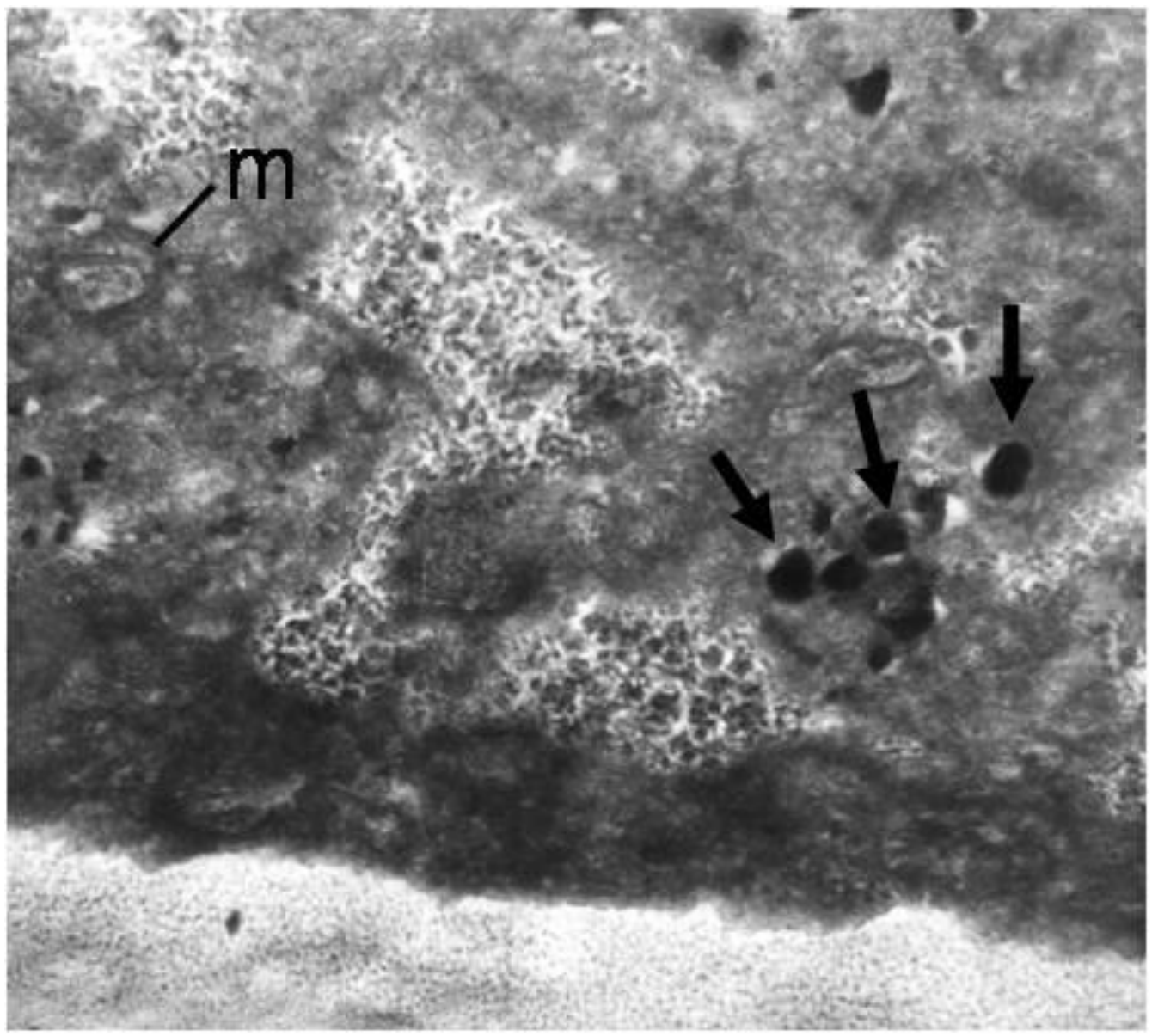


Figura 37.- M canis. MET. Macroconidio. Se observa la gruesa capa interna (i) y en el citoplasma restos de membranas mitocondriales y material denso. $27.300 x$ 


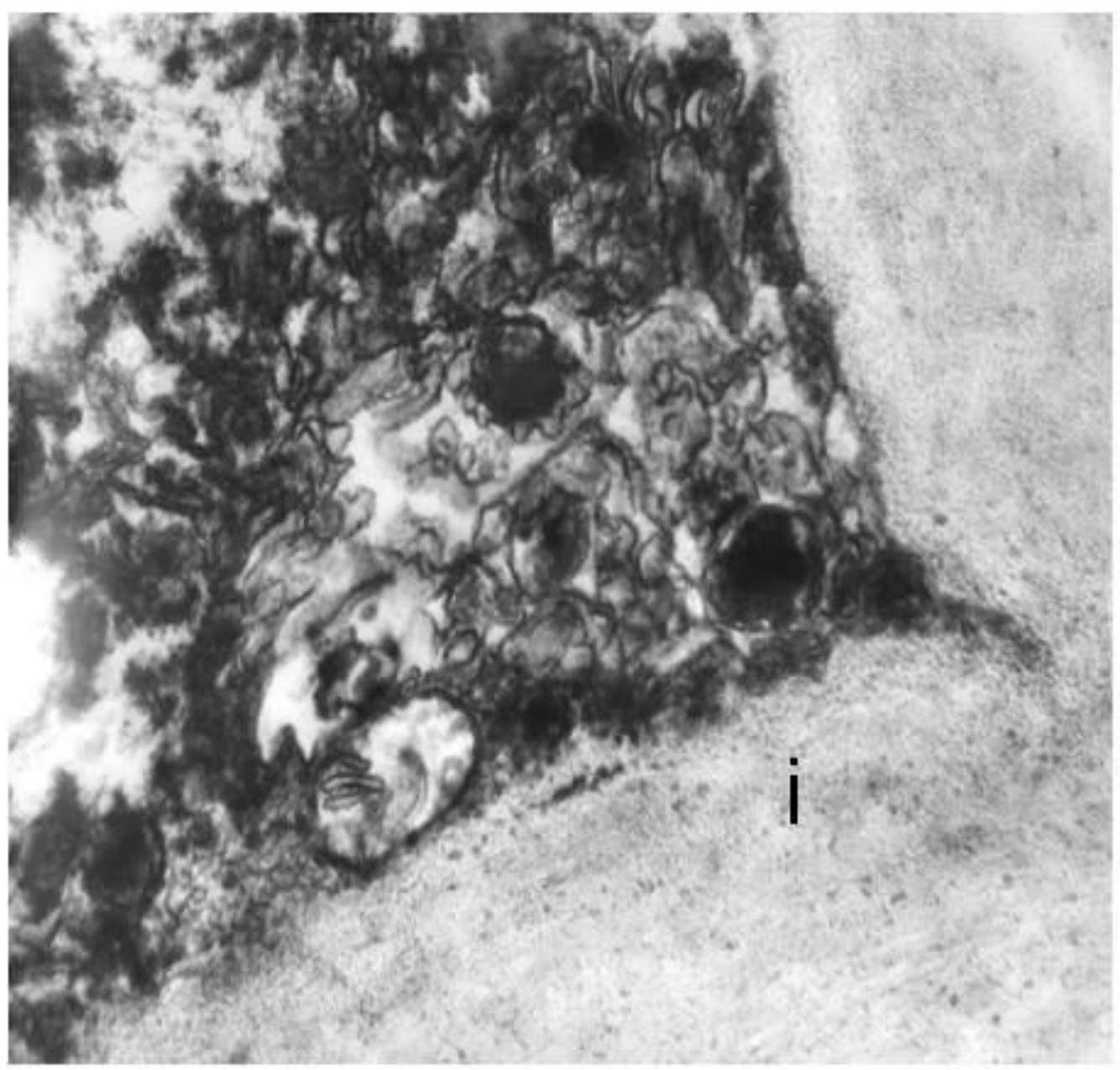


Figura 38.- $M$ canis. MET. Macroconidio. Se aprecia la doble pared del septo separadas por una zona clara (A) bien diferenciada. En el citoplasma material denso irregular y mitocondrias (m). $27.300 \mathrm{x}$ 


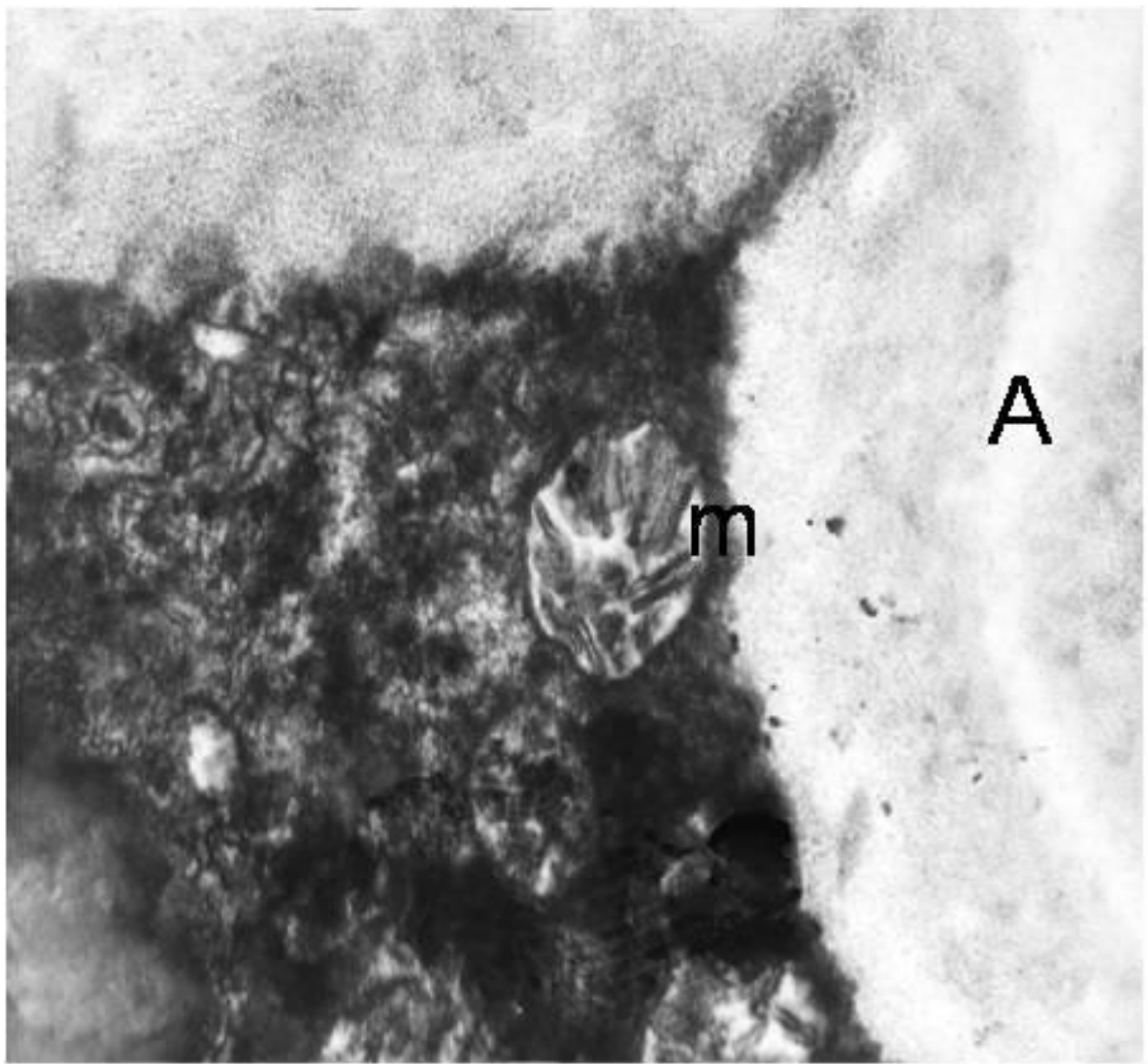


Figuras 39 A, B y C.- M canis. MET. Macroconido. En su capa externa (e) aparecen unas formaciones filamentosas, como penachos, que corresponden a las imágenes de aspecto algodonoso (“copos de algodón") que observamos con el MEB (figs. 21 y 22). También son visibles la capa interna (i) y el septo (s). A: $27.300 x ; B: 13.100 x$ y C: $27.300 x$ 

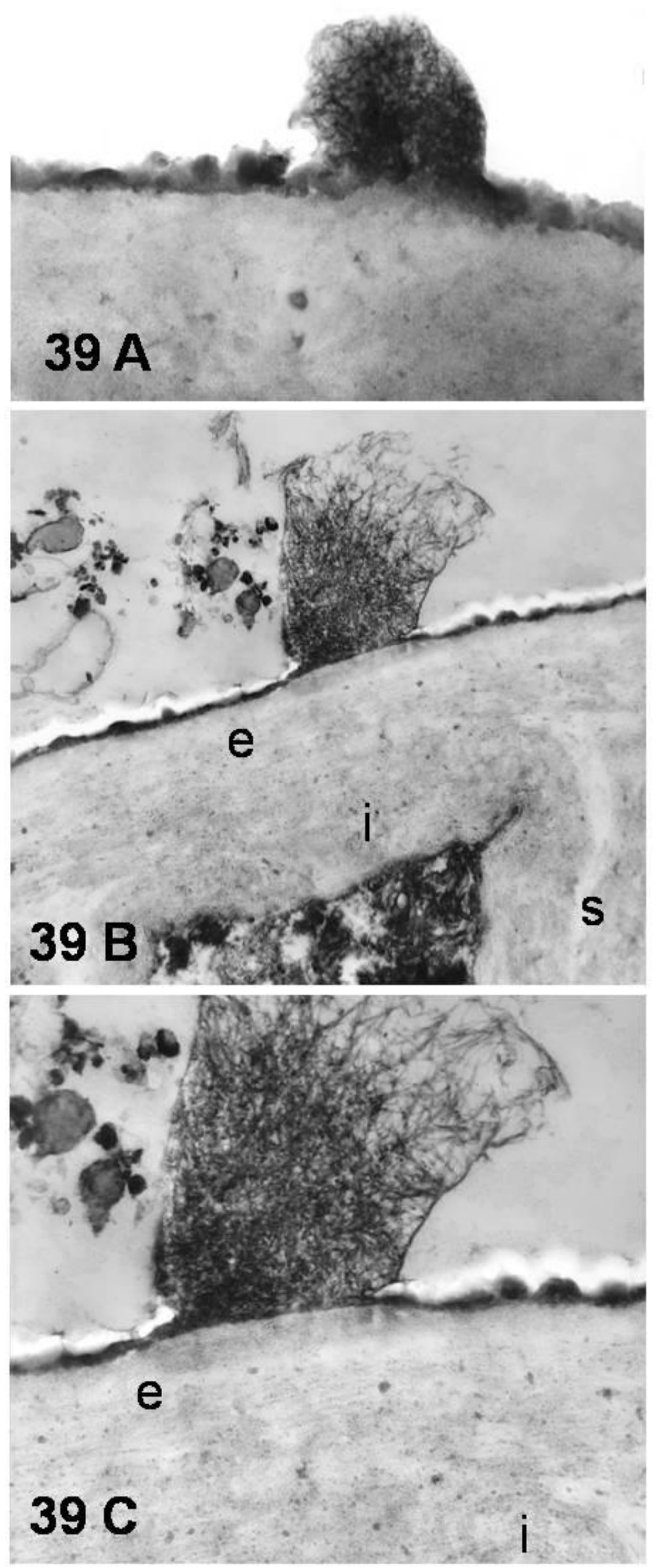


\section{T. erinacei}

\section{Microscopía Electrónica de Barrido}

Con el MEB se observan abundantes microcondios dispuestos en racimos o lateralmente sobre las hifas, semejantes a las que presenta el T. mentagrophytes (v. mentagrophytes) (Figs. 40 a 43). 
Figuras 40 y 41.- M erinacei. MEB. Micelio reproductor con hifas finas, lisas y abundantes microconidios formando racimos irregulares. 

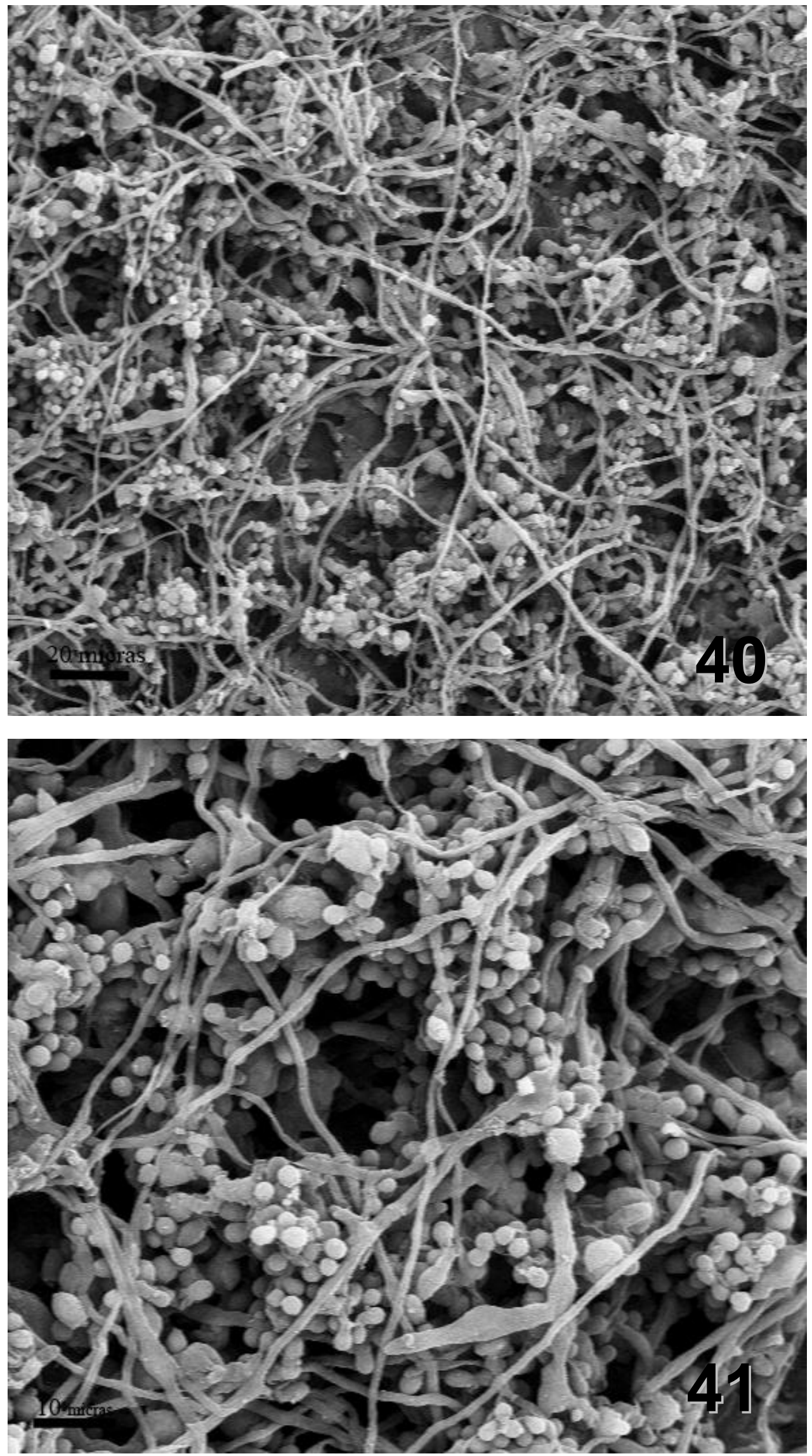
Figuras 42 y $43 .-$ M erinacei. MEB. A mayores aumentos, se observan los microconidios con sus pequeños pedículos de inserción y algunos desprendidos. Estas imágenes son similares a las observadas en el T. mentagrophytes ( $\mathrm{v}$. mentagrophytes) que recuerdan a los "racimos de uvas" (ver figuras 3 y 4 ). 

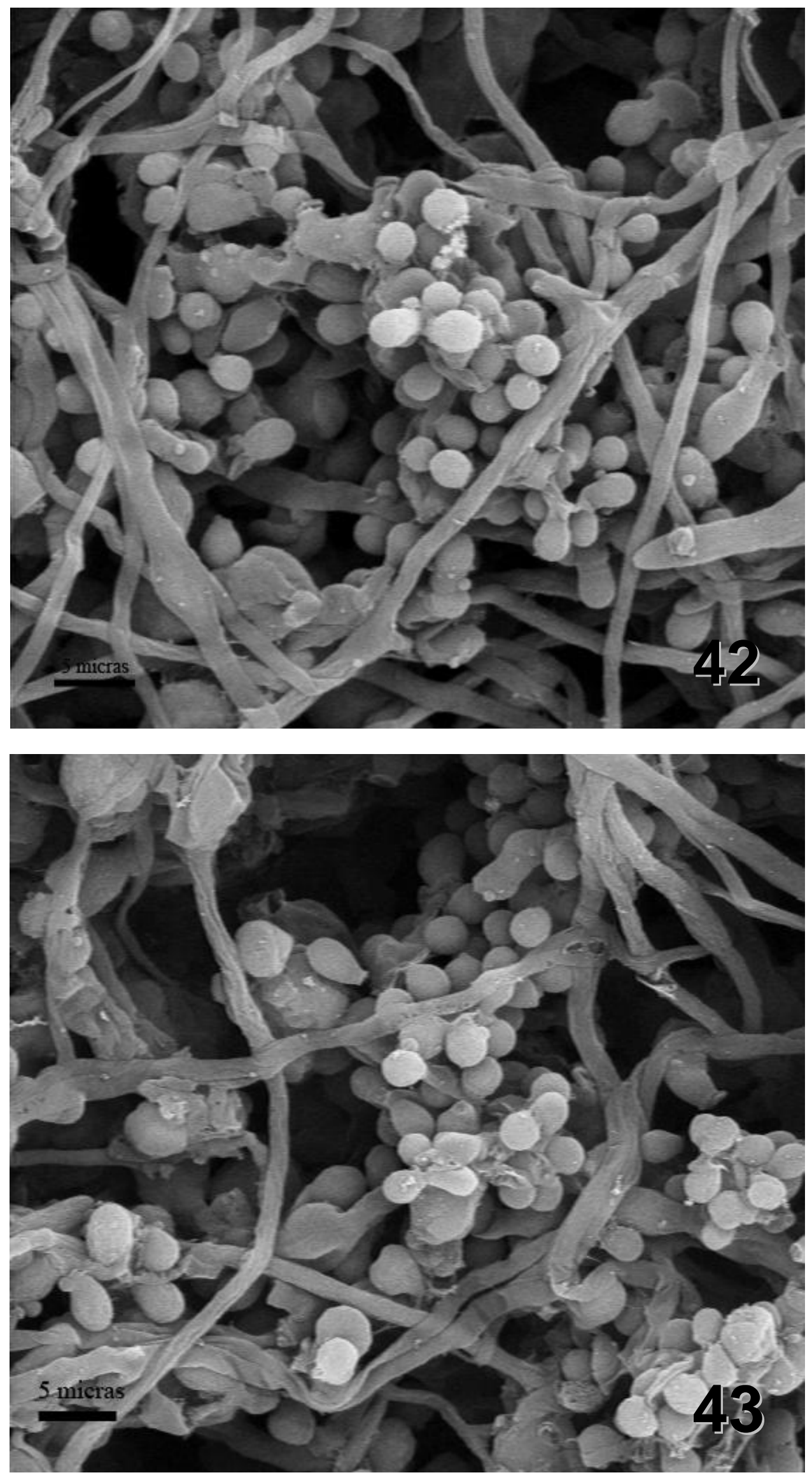
A veces los microconidios los vemos adheridos a la hifa a lo largo de la superficie y, en ocasiones, simulando racimos (Figs. 44 a 47), siendo visible el pedículo de inserción del microconidio con la hifa (Fig. 48). También se observan abundantes clamidosporos en disposición terminal (en el extremo de la hifa) o intermedios (Figs. 49 y 50), algunos de gran tamaño (Fig. 51).

Los macroconidios son fusiformes, de superficie lisa, siendo visible el resalte de los septos (Figs. 52 y 53) y dispuestos sobre las hifas con mínimo pedículo de inserción (Fig. 52). 
Figuras 44 y 45.- M erinacei. MEB.. En estas imágenes se puede observar como los microconidios aparecen sobre la superficie de la hifa unidos por un pequeño pedículo (flecha en fig. 45). 

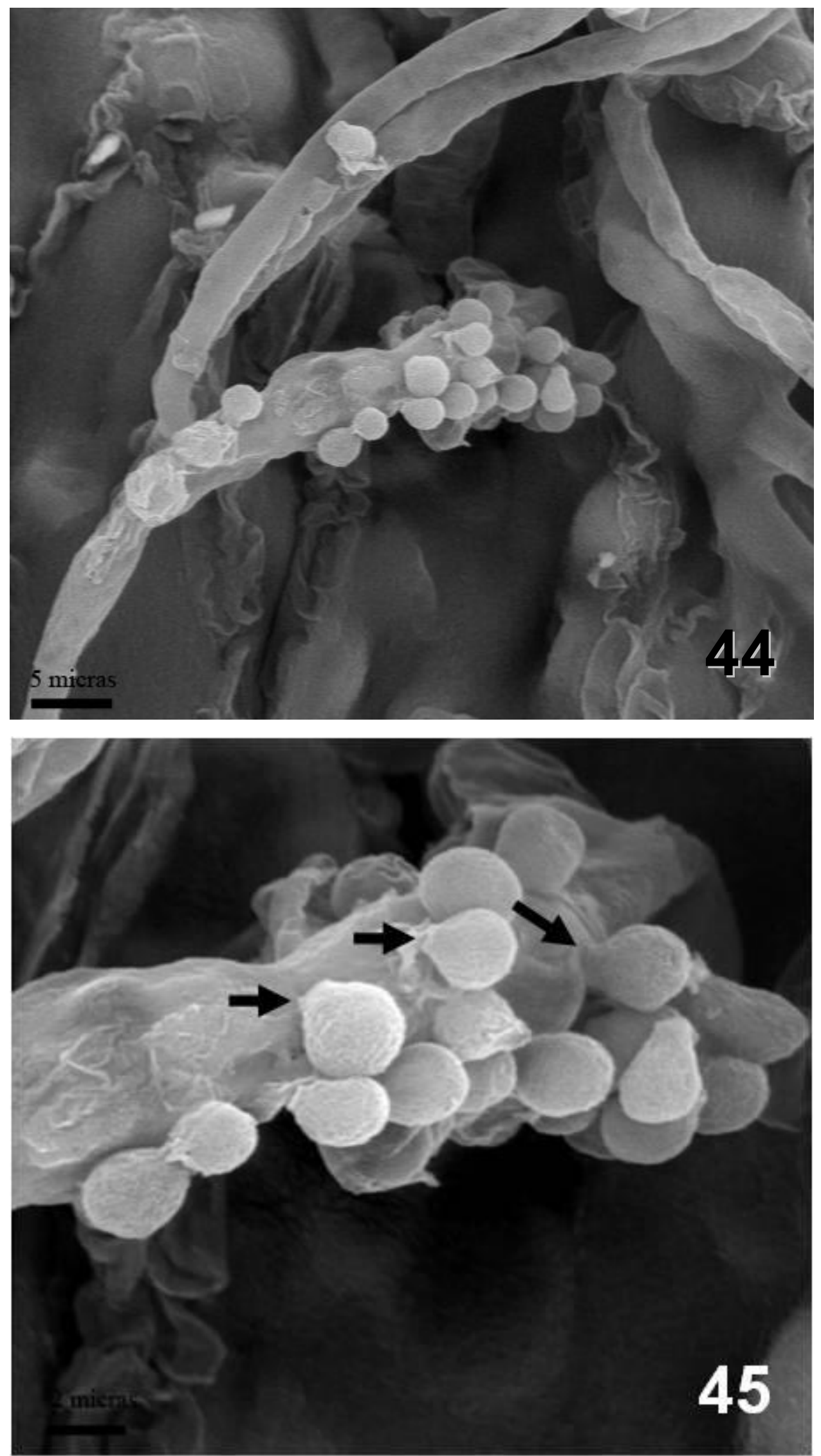
Figura 46. M erinacei. MEB. En esta figura aparecen los microconidios apiñados en forma de "racimos de uvas". 


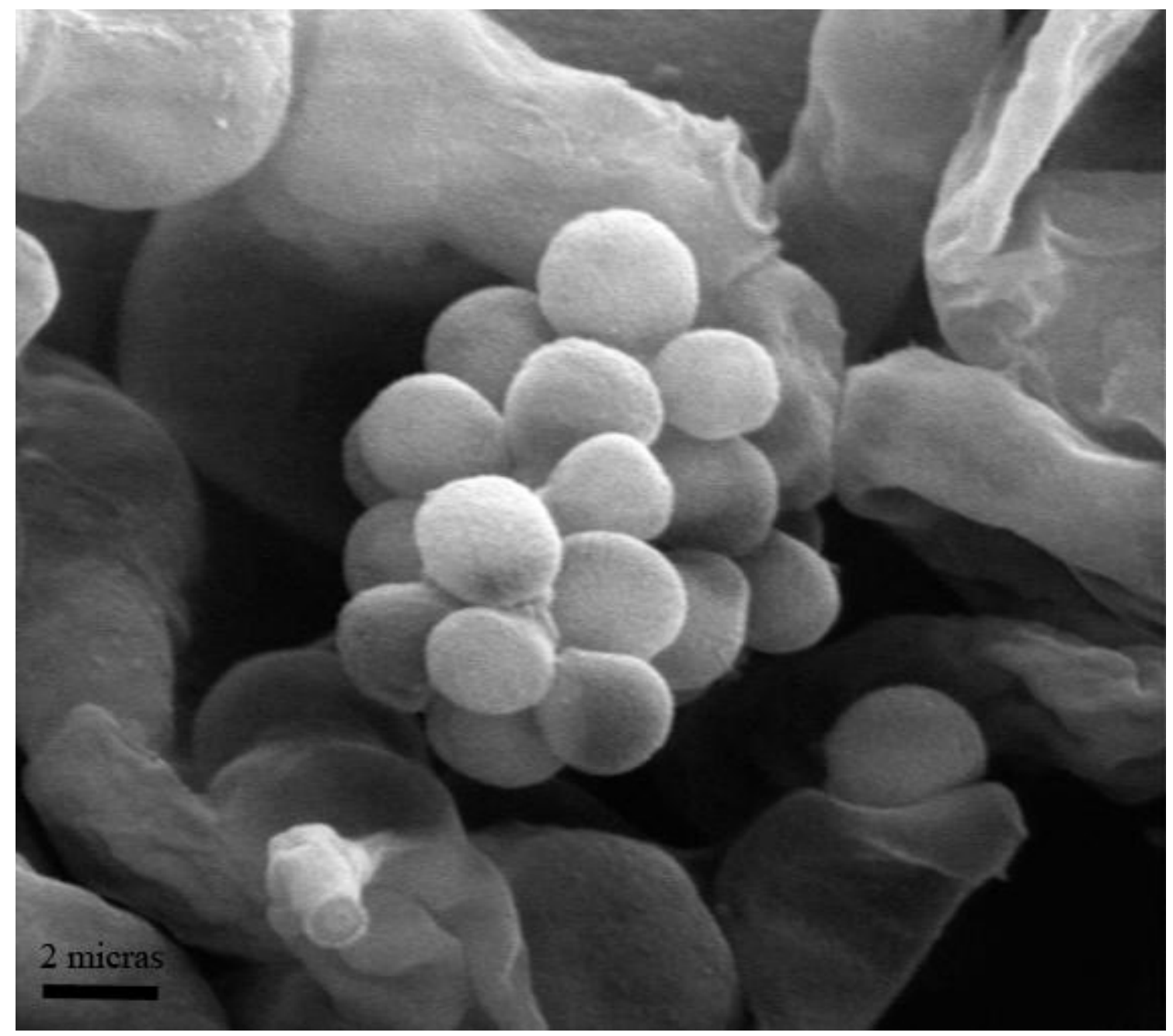


Figura 47.- M erinacei. MEB. Micelio reproductor en el que se observa, además de los microconidios ya descritos en la figura anterior, otros "en clavija" dispuestos lateralmente sobre las hifas (flecha). 


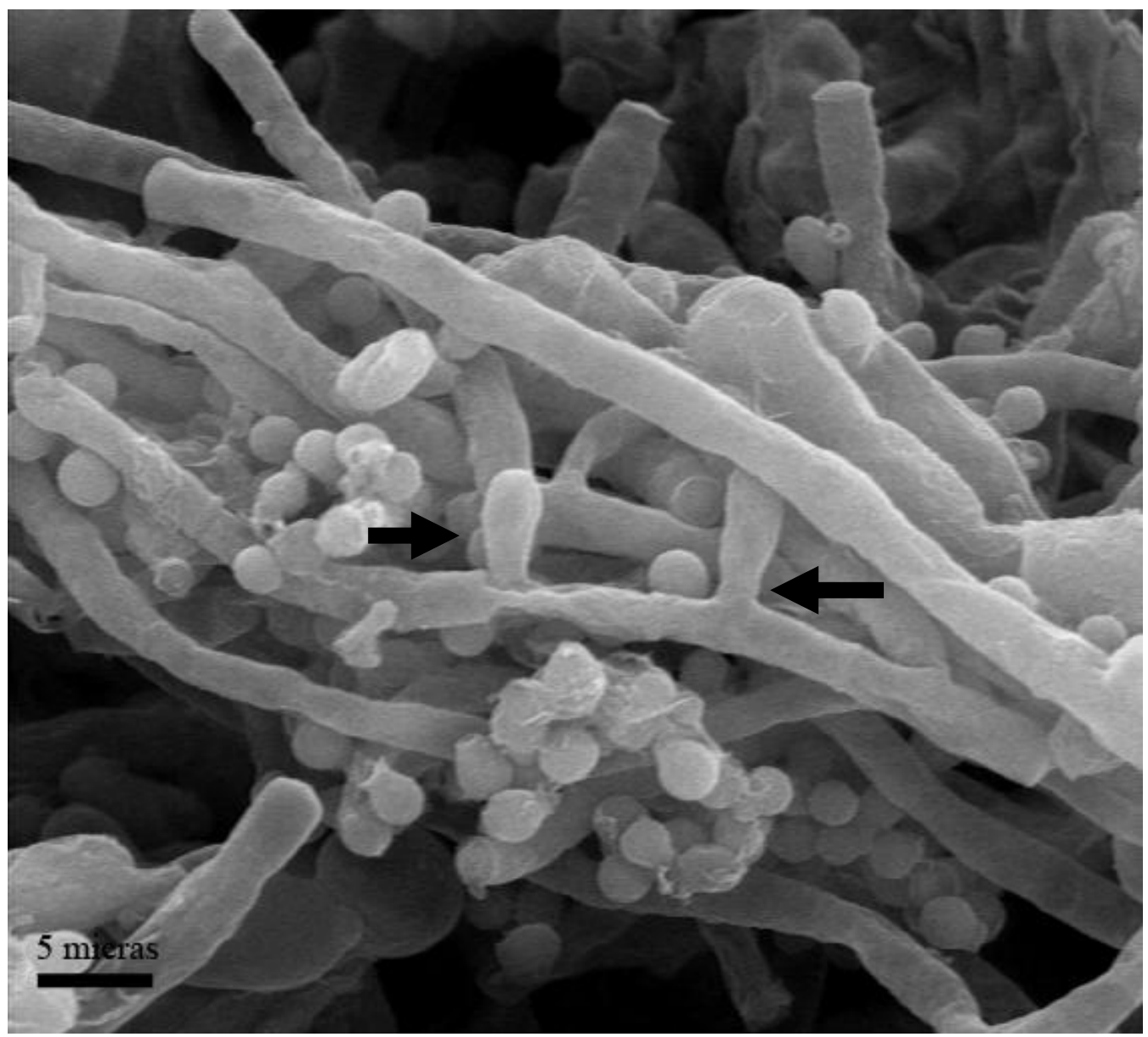


Figura 48.- M erinacei. MEB. A mayores aumentos se puede observar, con detalle, el pedículo de inserción de los microconidios con la hifa (flecha) 


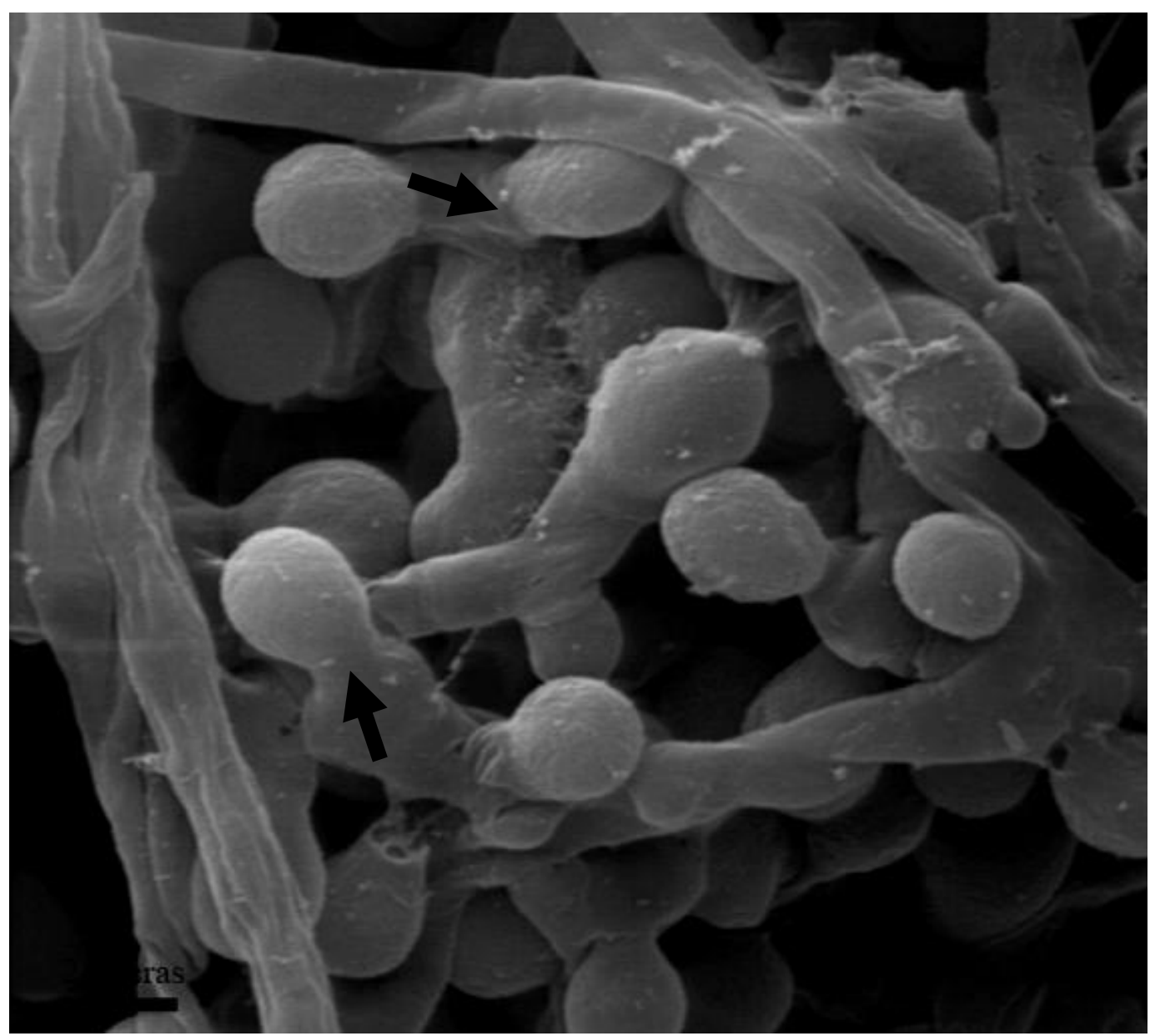


Figura 49. - M erinacei. MEB.En el centro de la figura se observa clamidosporos intermedios en una hifa del micelio reproductor $(C)$. 


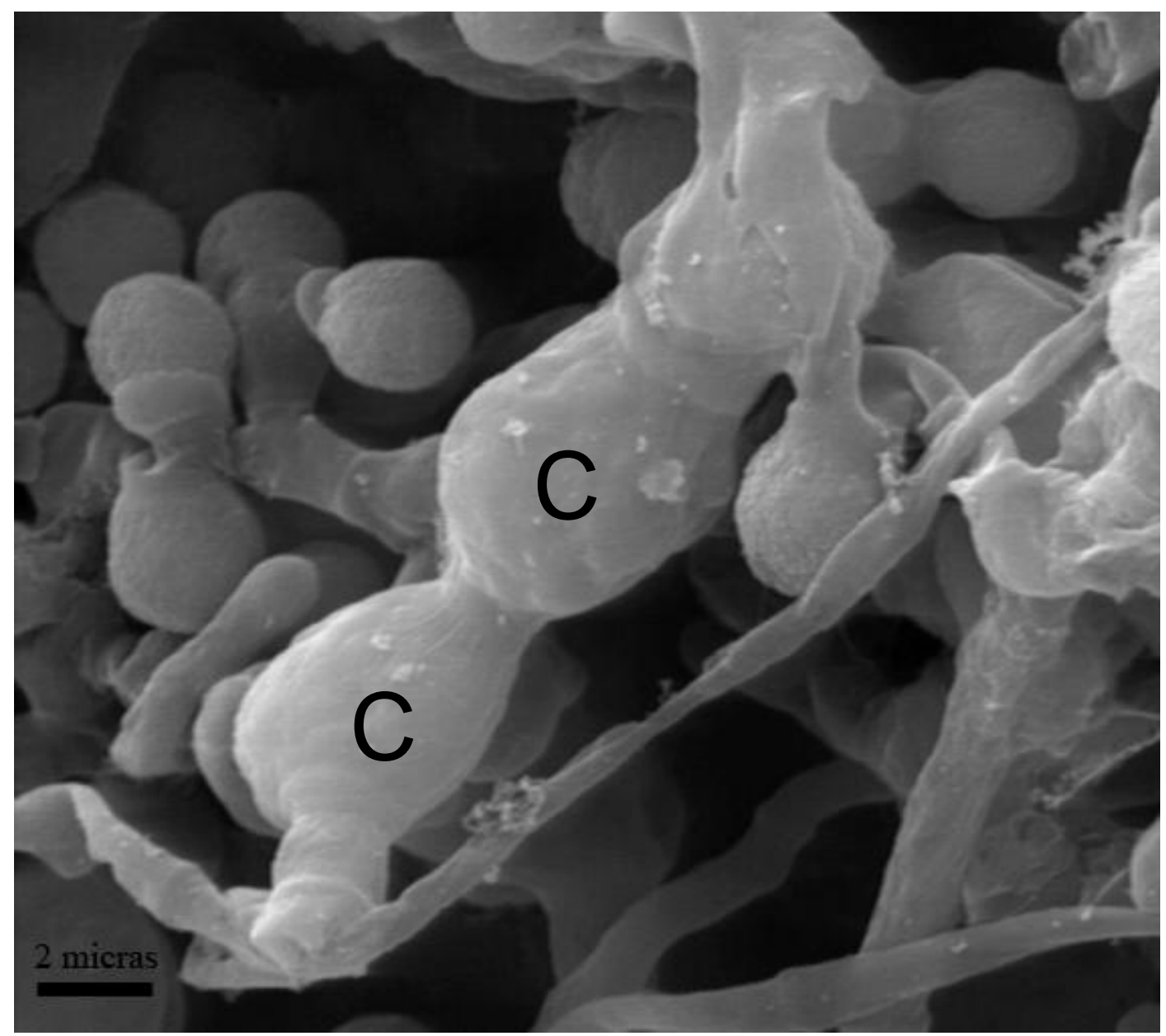


Figura 50. - M erinacei. MEB.También se observan clamidosporos terminales en el extremo distal de la hifa (C). 


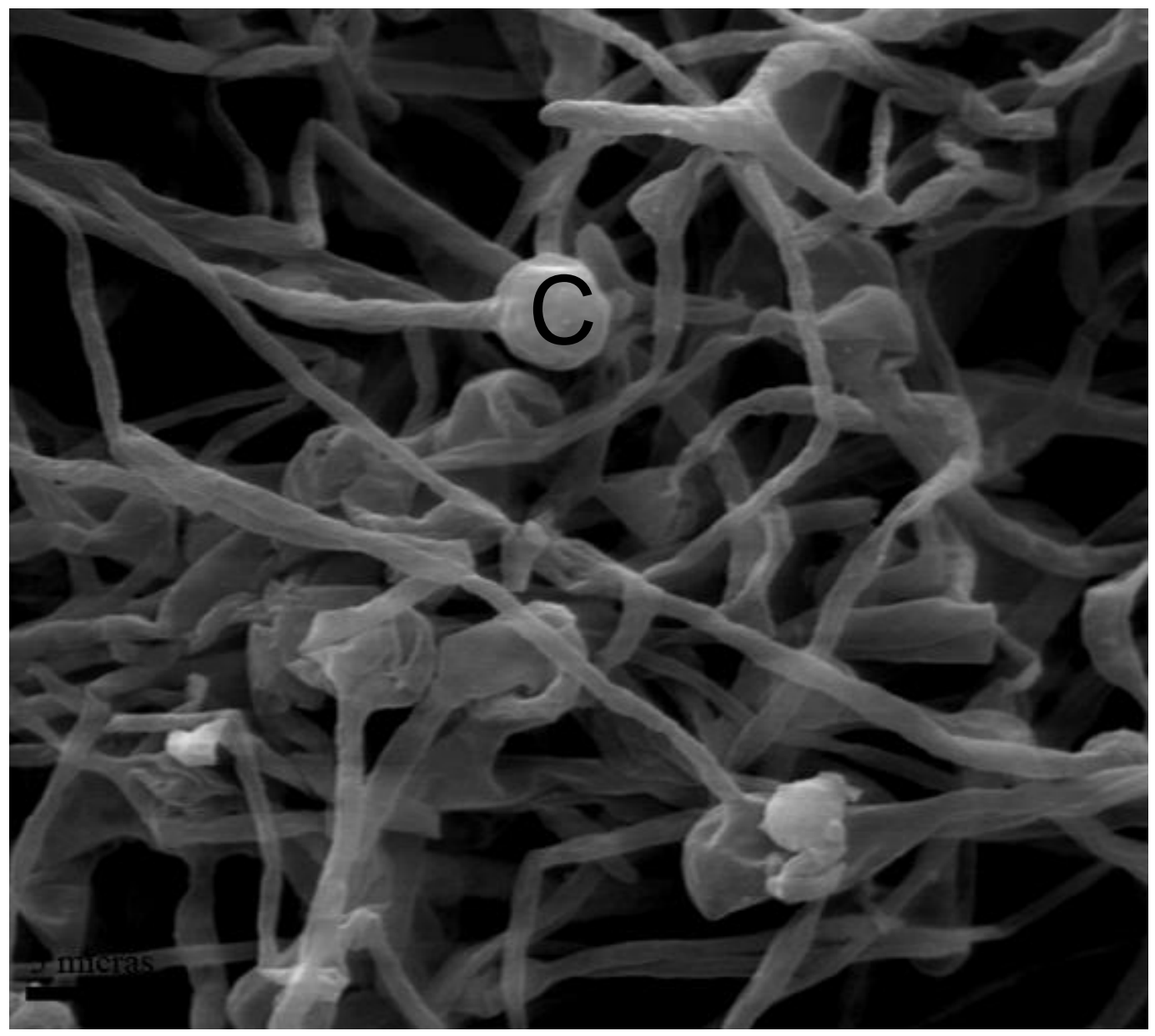


Figura 51.- M erinacei. MEB. Más raramente se pueden observar clamidosporos terminales de gran tamaño $(C)$. 


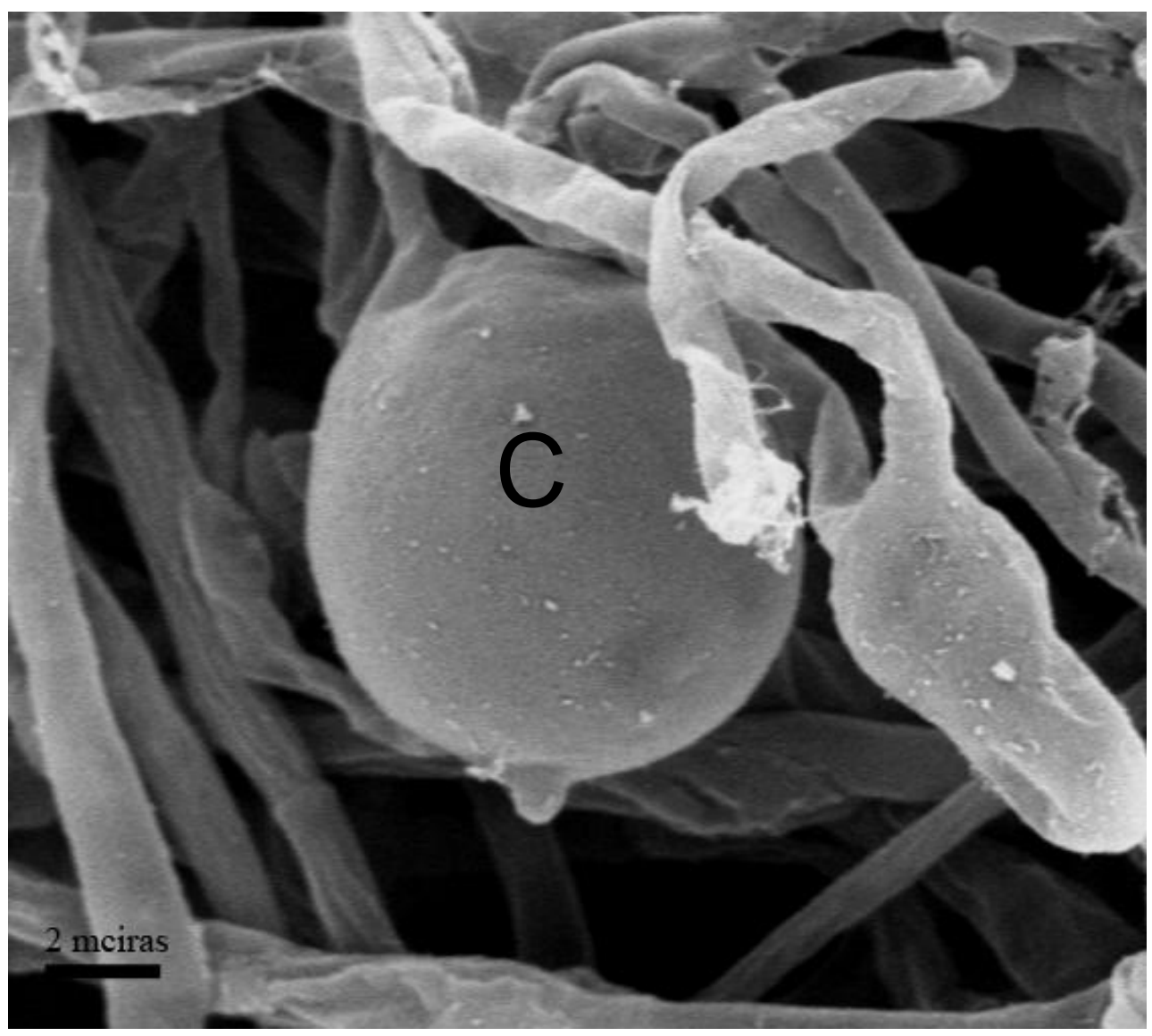


Figura 52.- M erinacei. MEB. En el micelio reproductor se pueden ver macroconidios fusiformes de superficie lisa y con mínimo pedículo de inserción (flecha). 


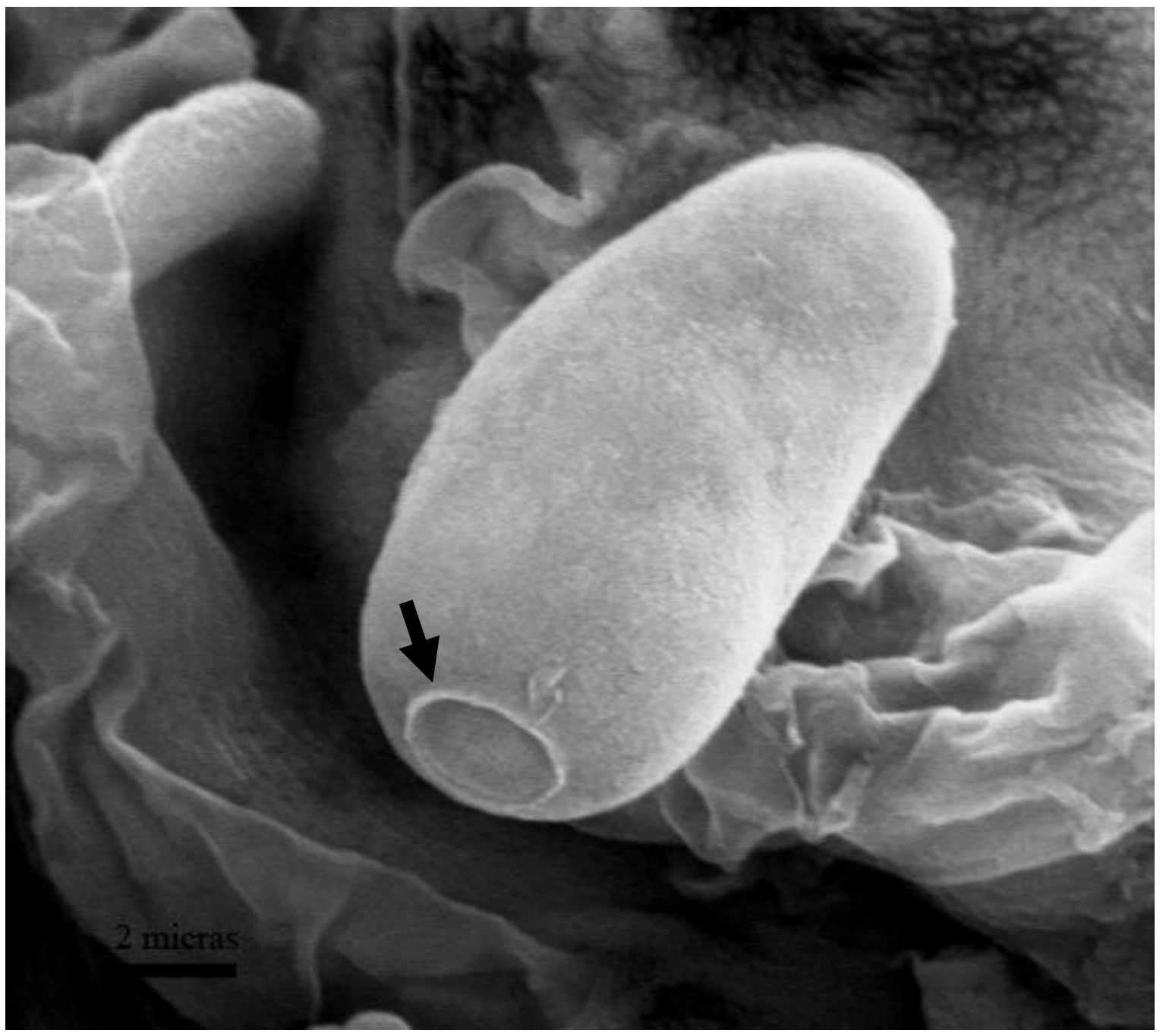


Figura 53.- M erinacei. MEB. Otra visión de un macroconidio, fusiforme, donde son visibles en su superficie el resalte de los septos (flecha). 


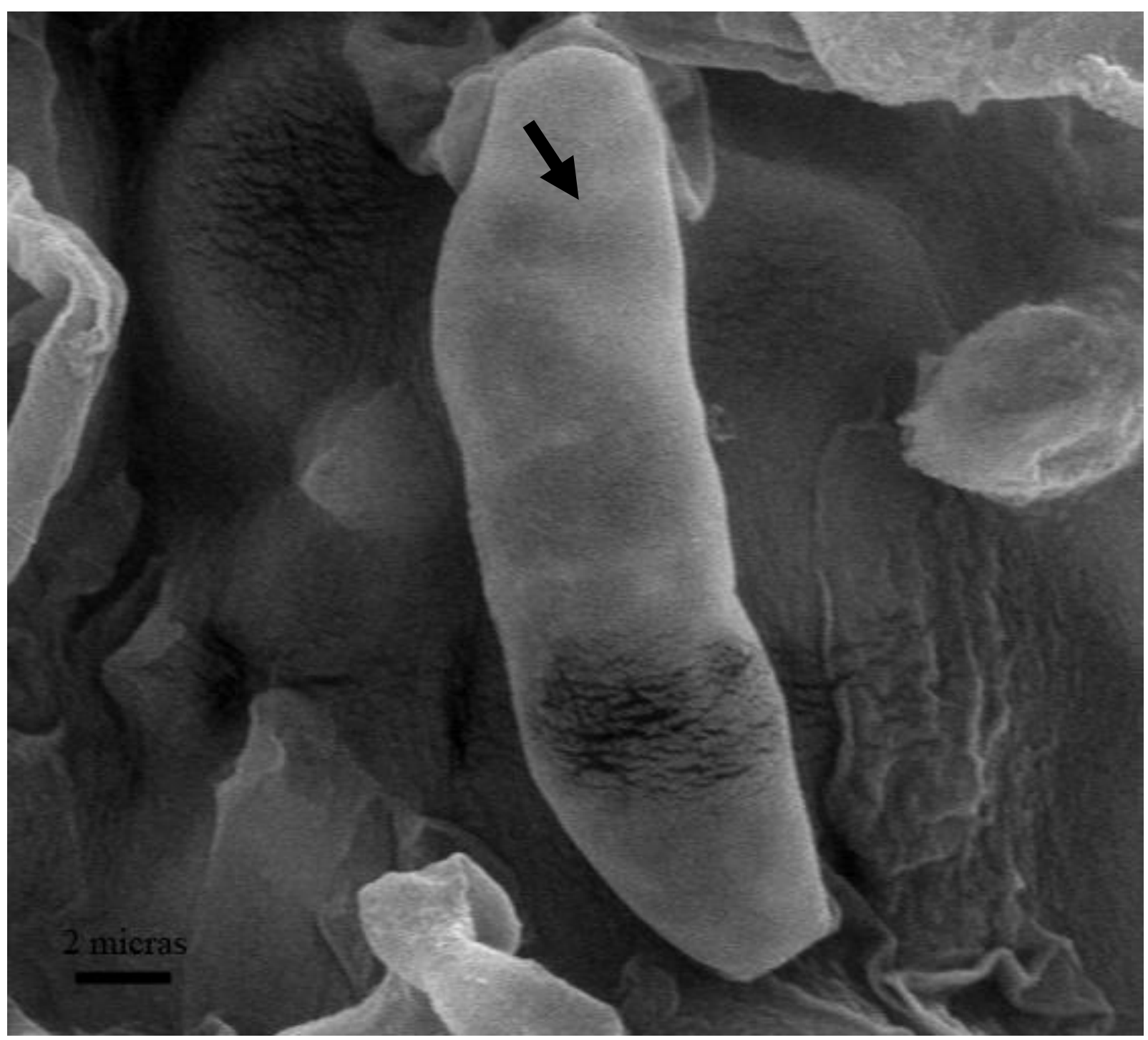




\section{Microscopía Electrónica de Transmisión}

Con el MET, en una visión panorámica del micelio reproductor se pueden observar hifas cortadas en diferentes secciones, así como microconidios (Figs. 54 y 55). Las hifas aparecen como estructuras tabicadas, con una pared en la que se pueden diferenciar dos capas, una externa, fina, desflecada y otra interna, más gruesa y menos electrondensa (Fig. 56). 
Figura 54.- T. erinacei MET; panorámica del micelio reproductor donde se observan hifas tabicadas, cortadas en diferentes secciones $(\mathrm{H})$ y microconidios aislados o unidos a la hifa, de contenido denso con vacuolas (M). 


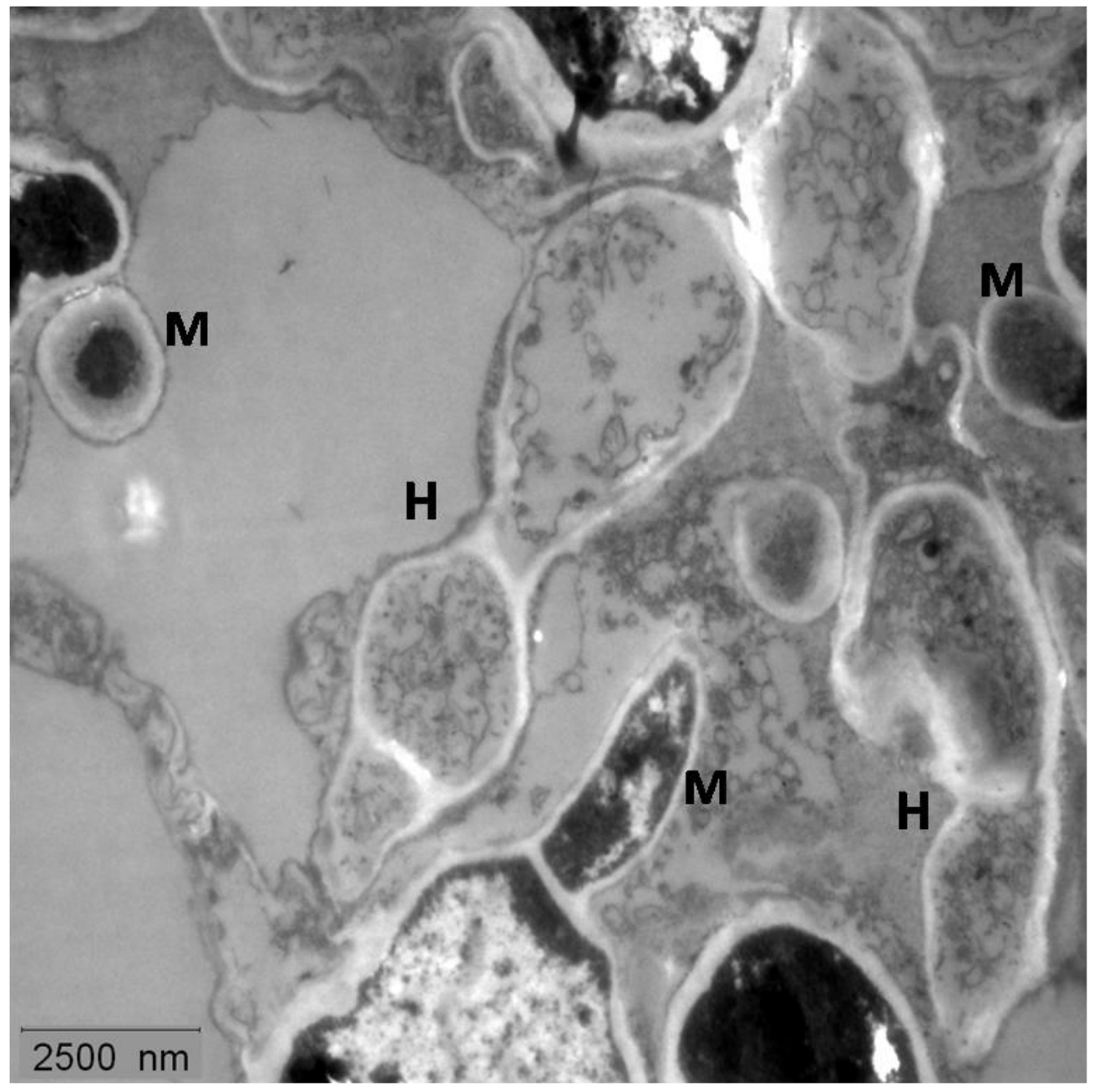


Figura 55.- T. erinacei MET. Visión panorámica del micelio reproductor con hifas tabicadas $(\mathrm{H})$, microconidos $(M)$ bien delimitados por su pared y con un contenido de material denso irregular. 


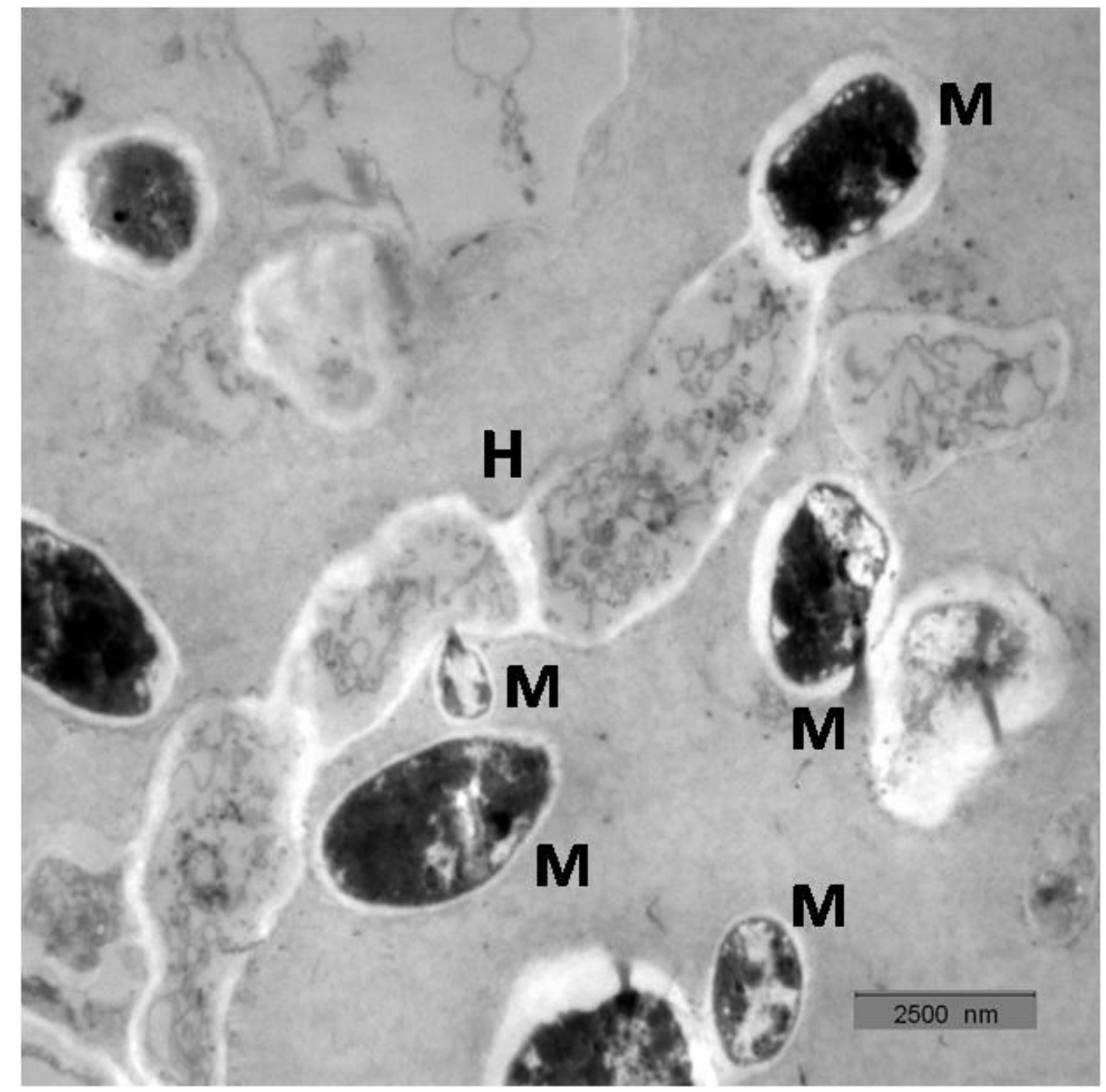


Figura 56.- T. erinacei. MET. Pared de la hifa donde podemos distinguir una capa externa (e) fina, desflecada y otra interna (i) más gruesa, que delimita el contenido citoplasmático. 


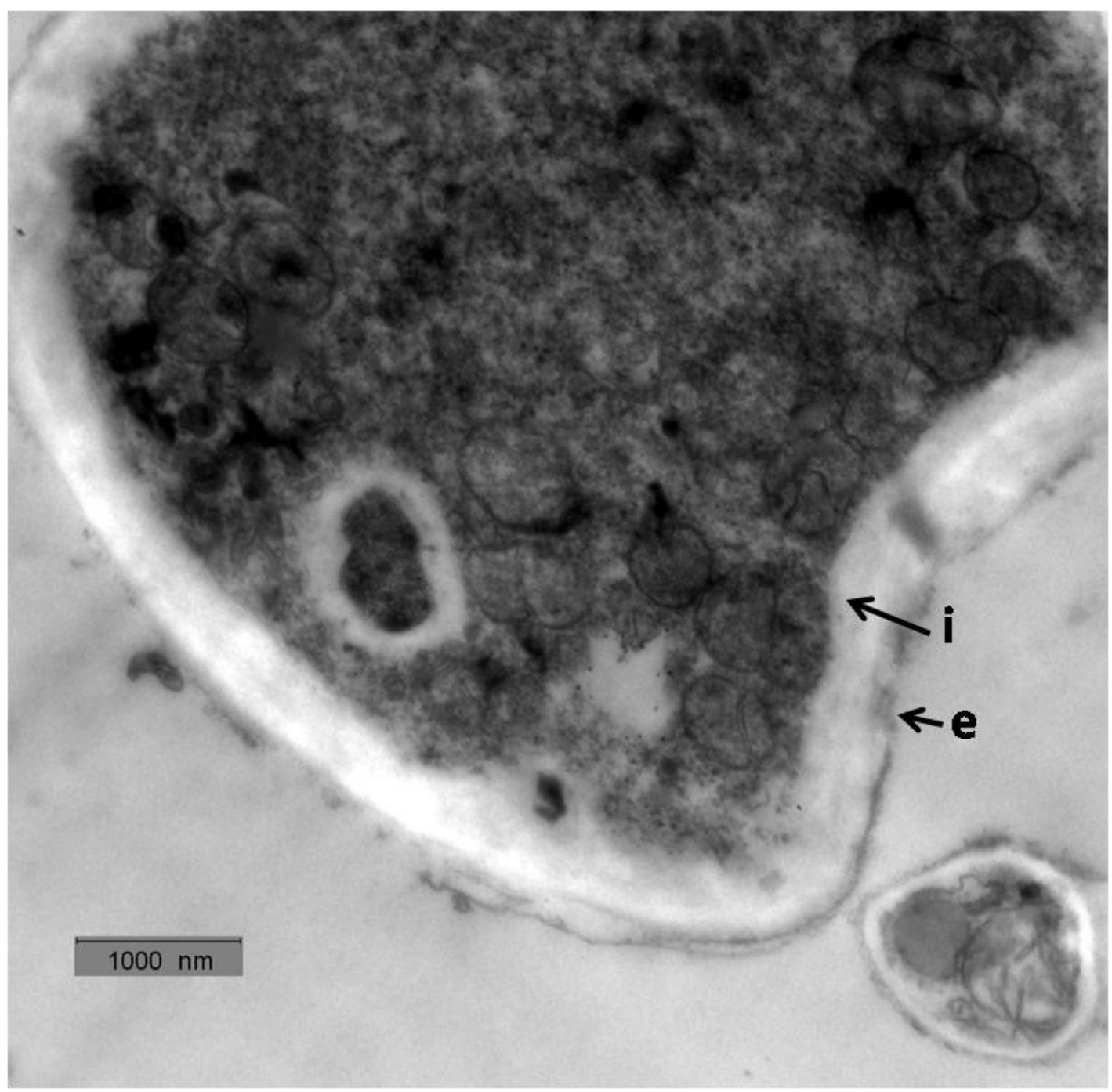


Figura 57.- T. erinacei. MET. Un detalle a mayores aumentos de la figura 55 donde se observa un microconidio unido a la pared de la hifa por un fino pedículo. 


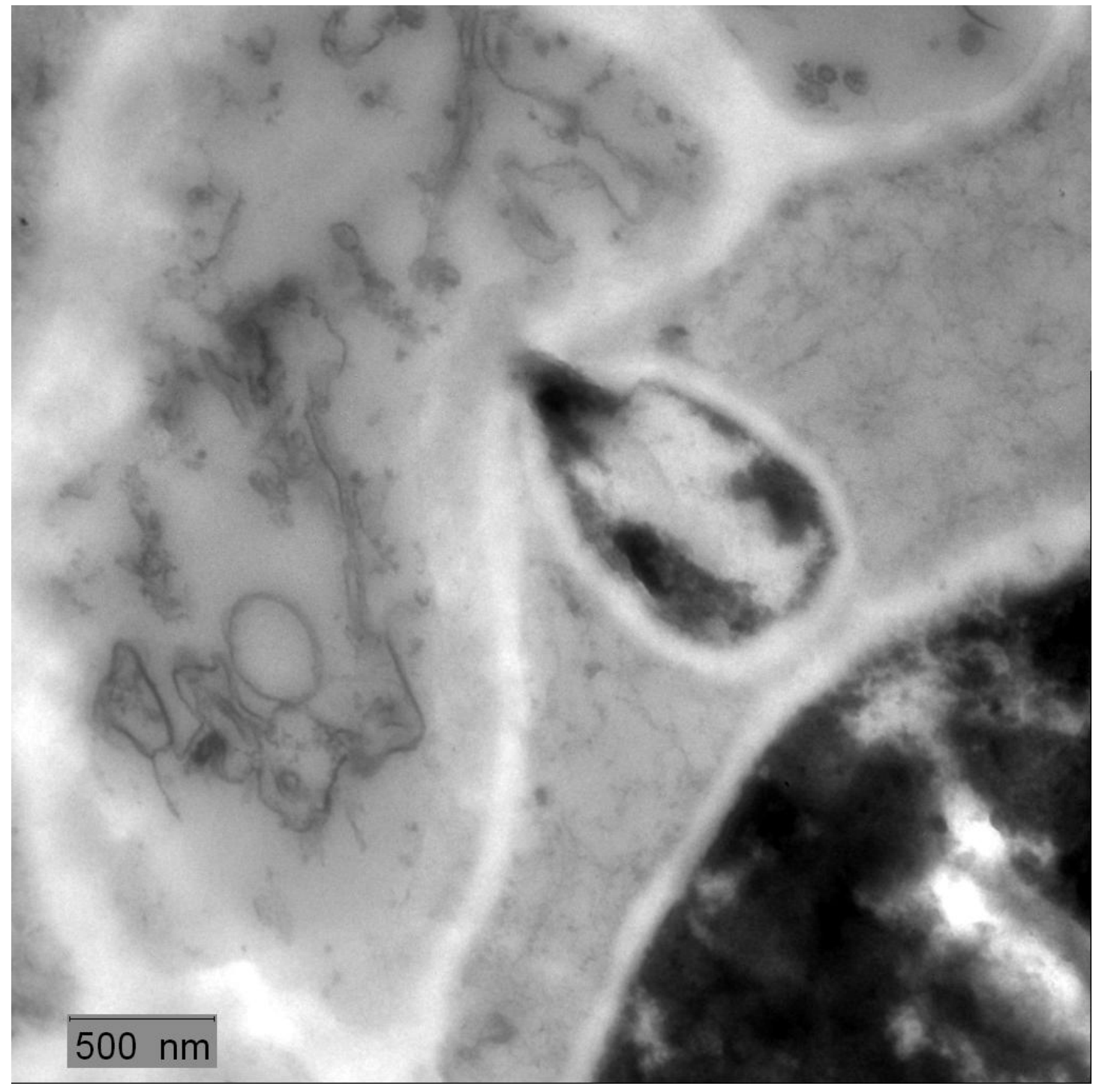


En algunas secciones podemos reconocer la formación del microconidio unido a la pared de la hifa por un fino pedículo, con pared bien definida y contenido citoplasmático con vacuolas, mitocondrias bien diferenciadas y la presencia de un material denso, esférico, que podría corresponder al núcleo (Figs. 57, 58 y 59$)$. 
Figura 58.- T. erinacei. MET. A mayores aumentos de la figura 55, observamos un microconido unido a la hifa con pared bien definida, conteniendo material denso y pequeñas vacuolas en su periferia (flecha). 


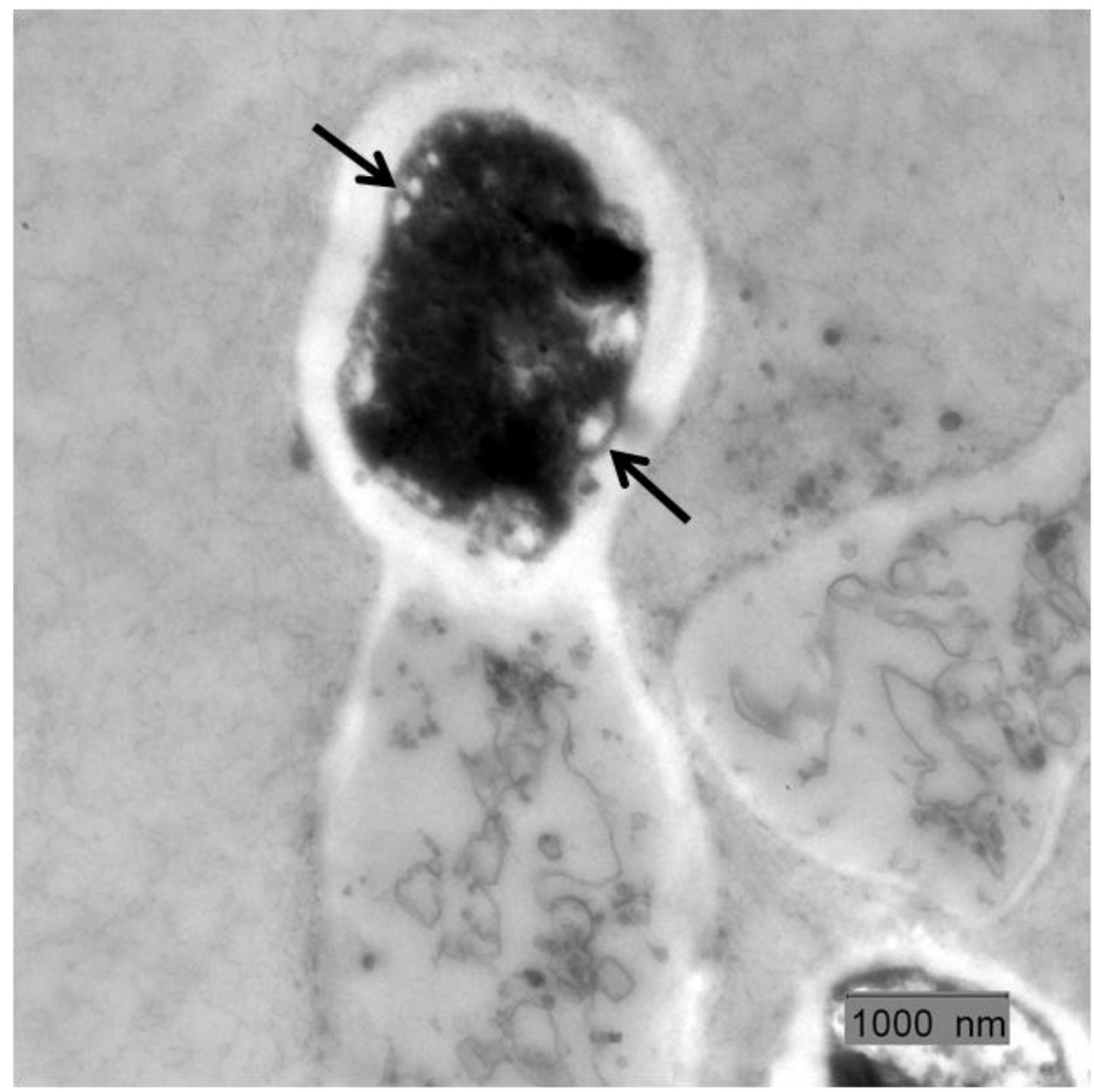


Figura 59.- T. erinacei MET. En algunos microconidios son evidentes mitocondrias $(M)$ y material denso esférico, bien delimitado (flecha). 


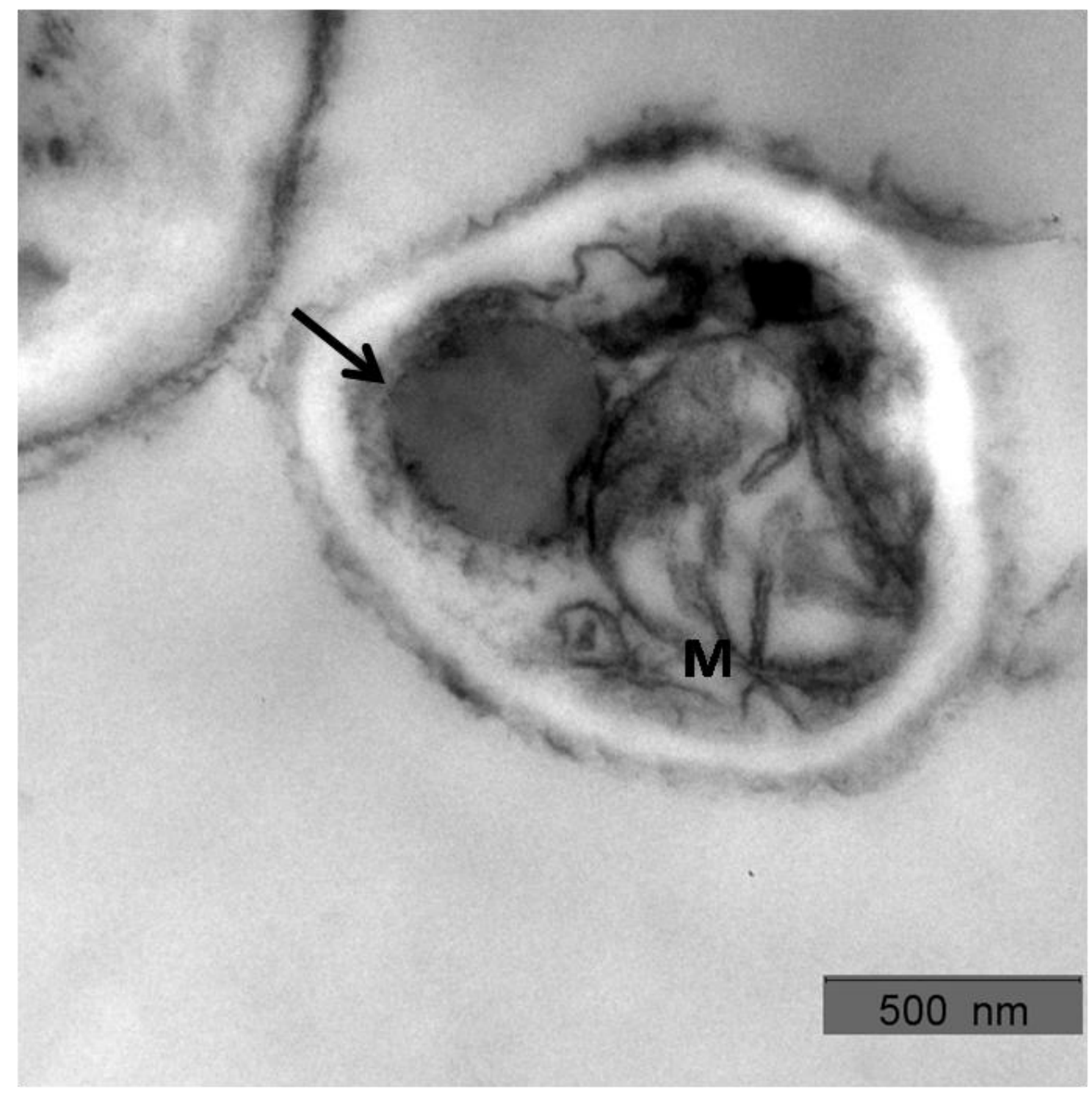


Figuras 60, A, B y C.-- T. erinacei. MET. En el contenido citoplasmáticos de las hifas, limitado por una membrana plasmática bien definida (MP), podemos observar mitocondrias $(M)$, abundantes cuerpos densos $(C D)$ y material vacuolado con restos de membranas (V) 

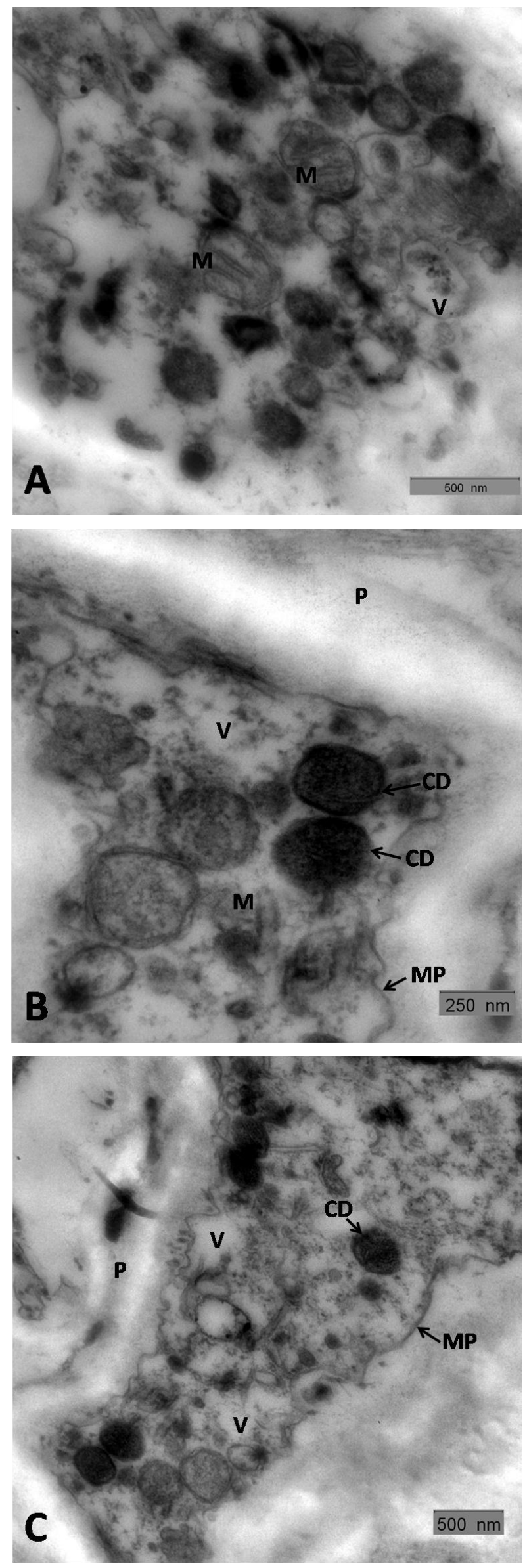
Discusión 
En general, el micelio reproductor de los tres hongos estudiados, T. mentagrophytes ( $v$. mentagrophytes), T. mentagrophytes ( $v$. erinacei) y $M$. canis, es muy complejo, con gran variedad de estructuras tanto en hifas como en las esporas asexuadas (macro y microconidios).

El estudio ultraestructural pone de manifiesto también la complejidad de estos hongos. Las hifas, aunque tabicadas, permiten a través del poro septal el paso de material citoplasmático (núcleo, mitocondrias, cuerpos lipídicos, etc.) desde un compartimiento a otro, por lo que el contenido citoplasmático de los distintos segmentos de la misma hifa es variable en los diferentes momentos del desarrollo y evolución de la misma. Estos hechos, ya señalados en estudios previos demuestran la dinámica estructural de los hongos en su desarrollo evolutivo (Martin-Pascual y Vázquez, 1979; Weitzman y Summerbell., 1995; Abdel-Rahman, 2008; Gräser y col., 2008).

El elemento más constante en la morfología es la pared que delimita la hifa y que constituye también el septo (Ito y col. 1969; Pock-Steen y col. 1970). Se trata de una estructura con gran plasticidad, que controla la permeabilidad celular, da forma a la célula y la protege de los cambios osmóticos. También constituye el lugar de interacción con el medio externo, localizándose en ella las adhesinas y un gran número de receptores que tras su activación, desencadenarán una compleja cascada de señales en el interior de la célula (Pontón, 2008). En las tres especies estudiadas hemos diferenciado dos capas o estratos de distinta densidad electrónica que se deben corresponder con los distintos elementos que constituyen la pared (polisacáridos, polipéptidos y quitina), siendo la quitina y betaglucanos los responsables de la mayor densidad electrónica de la capa interna (Casadevall y Pirofski. 1999 y Brown y Gordon. 2001).

Las proteínas generalmente están asociadas a polisacáridos formando glicoproteínas y representan el 20-30\% del peso seco de la pared de los hongos fi- 
lamentosos. Las proteínas de la pared tienen diversas funciones, participando en el mantenimiento de la forma celular, interviniendo en los procesos de adhesión, protegiendo a la célula de sustancias extrañas, participando en la absorción de moléculas, transmitiendo señales al citoplasma y sintetizando y remodelando los componentes de la pared (Bowman y Free, 2006).

La quitina se sintetiza a partir de $\mathrm{N}$-acetilglucosamina por la enzima quitin sintasa, que deposita los polímeros de quitina en el espacio extracelular próximo a la membrana citoplasmática. El contenido en quitina de la pared fúngica varía según la fase morfológica del hongo. Representa el 1-2\% del peso seco de la pared celular de las levaduras mientras que en los hongos filamentosos puede llegar al $10-20 \%$. Por su importancia en la estructura de la pared, la síntesis de la quitina es una buena diana para la acción de los antifúngicos.

El glucano es el polisacárido estructural más importante de la pared y representa el 50-60\% del peso seco de esta estructura. La mayoría de los polímeros de glucano están compuestos de unidades de glucosa con uniones B-1,3 (6590\%). El B-1,3-D-glucano se sintetiza por un complejo de enzimas denominadas glucanosintetasas, situadas en la membrana plasmática. Estas enzimas catalizan la formación de cadenas lineales de glucano compuestas por aproximadamente 1.500 residuos de glucosa unidos por enlaces $B-1,3$. En estas cadenas, cada 40-50 residuos de glucosa se unen nuevas unidades de glucosa por enlaces $\beta-1,3$ para dar lugar a una estructura ramificada. Tales ramificaciones pueden unirse a otros glucanos, a la quitina o a las manoproteínas, proporcionando una gran resistencia mecánica a la pared, esencial para mantener la integridad celular.

Estudios recientes sobre la estructura y biogénesis de la pared celular de los hongos (Alonso-Monge y col. 2008) constatan que no sólo protege de las agresiones externas sino también es la que contacta con los tejidos del huésped, jugando un papel esencial en la colonización y en la respuesta inmunológica entre el patógeno y el huésped (Aljabre y col., 1993; Chaffin y col., 1998; Pontón y col., 2001; Roman, 2004; Anderson, 2005; Nimrichter y col., 2005; Bates y col., 2006; Kaufman y col., 2007). 
Algunos componentes de la pared son muy inmunogénicos y estimulan gran número de respuestas celulares y humorales durante la infección. Componentes de la pared celular como los ß-glucanos y los mananos, así como los anticuerpos dirigidos contra ellos son de utilidad diagnóstica al detectarse en pacientes con infección fúngica invasora (Pazos y col., 2006). Otros componentes como los mananos y las manoproteínas son potentes inmunomoduladores (Pontón, 2008).

La mayoría de los estudios sobre la pared de los hongos se ha realizado en colonias desarrolladas en medio de cultivos artificiales (como nosotros) y los realizados en la fase patógena (micelios y artrosporos) sobre lesiones se han hecho, en la mayoría, en animales de experimentación y para evaluar el efecto de las sustancias antifúngicas, por lo que, en ambos casos, pueden no ser comparables ( Hutton y col., 1978; Osumi y col., 1984; Hay y col., 1988; Mares y Fasulo, 1990; Kaaman y Forslind., 2001; Ghahfarokhi y col., 2004; Dueck y col., 2004;. Por otra parte la mayoría de los estudios sobre la patogenicidad de los hongos se han realizado con levaduras (C. albicans) fundamentalmente (Alonso-Monge y col., 2008).

Otro elemento constante en los dermatofitos es el septo que separa los distintos compartimentos de la hifa y que, en todos los casos, está constituido por la membrana interna de la pared, sin solución de continuidad, dejando entre ambas capas una fina zona clara electrotransparente, que separa ambas mitades y que es más visible en los septos gruesos de los macroconidios. (Fig. 34 y 39B)

Próximos a los septos pueden observarse unos cuerpos densos, redondeados (cuerpos de Woronin, descritos por el propio Woronin en 1865), cuya función no es bien conocida pero que, en cualquier caso, regulan de algún modo la actividad del poro septal (apertura o cierre), el cual permite intercambiar material citoplasmático a uno y otro lado (Reichle y Alexander,. 1965; Werner y col. 1966). Otros piensan que actúan como obturadores de los poros para aislar los componentes cuando estos envejecen o se diferencian (Arenas, 2008). Probablemente, provoquen el taponamiento en momentos apropiados de la fisiología de las hifas o, por el contrario, con el objeto de conseguir un estado 
pseudocelular y regular selectivamente el paso de componentes citoplasmáticos entre compartimentos hifales (Markham, 1994).

En comparación con la baja frecuencia de oclusión del poro septal en micelios no dañados, es sistemática la presencia de taponamientos en los poros septales de los micelios lesionados, llegando hasta el $90 \%$ o el 100\% de la oclusión por cuerpos de Woronin en la vecindad de hifas rotas en el Penicillum chysogenum (Collinge y Markham, 1985; Markham, 1994). La función principal de los cuerpos de Woronin es el taponamiento de urgencia de los poros septales en respuesta al grave daño ocurrido en las hifas, generalmente por la aparición de brechas en sus paredes.

Los cuerpos de Woronin no son los únicos orgánulos que taponan los poros septales en los hongos filamentosos. Existen también cristales hexagonales que siendo estructuralmente distintos se piensa que sean una subclase morfológica de los cuerpos de Woronin (Markham, 1994). Se ha mostrado su presencia en un número limitado de especies de hongos filamentosos, pero no en los dermatofitos (Markham y Collinge, 1987; Markham, 1994). En la microscopía electrónica aparecen como orgánulos hexagonales aunque su forma es susceptible de variaciones (Trinci y Collinge, 1974), siendo su tamaño y estructura similares a la de los cuerpos de Woronin y aunque aparecen casi siempre ocluyendo los poros, en algunas especies, como en la Sordaria brevicollis, no parecen desarrollar esta función oclusiva del poro, sugiriendo así otro tipo de función en las hifas que los portan (Collinge y Markham, 1987).

En algunas especies de ascomicotas se han visto cuerpos cristalinos alargados, como varillas, rodeados de membrana, en asociación a los poros septales (Kimbrough, 1991; Turnau y col., 1993). Se piensa que puedan ser variantes morfológicas de los cuerpos de Woronin (Turnau y col., 1993). Probablemente los cuerpos cristalinos alargados sean, en los ascomicetas, un equivalente de las inclusiones cristalinas protináceas encontradas en tejidos especializados de basiodiomicetas, en especial rhizomorfos y basidiocarpos (Wood y col., 1985). 
Además de oclusiones completas de los poros por la presencia de cuerpos que taponan la abertura, se han descrito formaciones dentro de las hifas, en asociación con los poros de los septos fúngicos o doliporos, típicos de los hongos basiodiomicetas y que parecen ser incompletos 0 , al menos, capaces de permitir algún grado de continuidad citoplasmática o molecular ente compartimentos adyacentes (Markham, 1994). Entre estas formaciones se hallan los parentosomas como estructuras asociadas al septo y que parecen derivadas del retículo endoplasmáticos ya que se encuentran con él conectadas (Moore, 1985). En otras especies micológicas aparecen bandas electrodensas y estriaciones en el canal del doliporo (Moore, 1978). En algunos miembros de los zygomicotas, se han descrito tapones lenticulares ocluyendo los poros septales y estructuras en forma de "gorra" (pore caps); en ambos casos, tanto sus funciones como su composición están aún por dilucidar, si bien, recientemente, van Driel y col. (2008) creen que los pore caps derivarían del retículo endoplasmático y estarían implicados en la oclusión de los doliporos, contibuyendo a la homeostasis hifal de los hongos basidiomicetos.

También se ha visto, con cierta frecuencia, a núcleos y mitocondrias ocupar y tapar el poro septal. Sin embargo para que estos orgánulos puedan actuar como verdaderos tapones, tendrían que permanecer encajados en el poro durante tiempos prolongados; se desconoce si sucede de esta manera o simplemente se trata de un taponamiento transitorio durante el tiempo que dura su paso entre una y otra zona del poro septal. Una hipótesis emitida con referencia a este taponamiento del poro por núcleos o mitocondrias es que podría funcionar como oclusiones temporales durante las cuales el micelio regularía la distribución de los componentes citoplasmáticos y la variación en el metabolismo entre compartimentos hifales (Markham, 1994).

Si bien los estudios morfológicos soportan las posibles funciones de los cuerpos de Woronin, su origen celular y su composición bioquímica han permanecido desconocidos. Solo en los últimos años se ha descubierto que el gen HEX1 codifica la proteína más abundante (de $19 \mathrm{KDa}$ ) de los cuerpos de Woronin en la especie Neurospora crassa (Jedd y Chua, 2000; Maruyama y col., 2005); la delección de este gen causa la desaparición de los cuerpos de Woronin y pro- 
voca que las hifas lisadas pierdan la mayor parte del citoplasma (Jedd y Chua, 2000; Tenney y col., 2000). Además, el empleo de la microscopía confocal, utilizando proteínas fluorescentes y la reconstrucción tridimensional del hongo filamentoso Aspergillus orizae ha permitido en la actualidad visualizar in vivo el taponamiento de los poros septales de hifas por los cuerpos de Woronin (Maruyama y col., 2005).

El contenido citoplasmático en las hifas es también enormemente variable en los distintos segmentos; podemos observar el núcleo, mitocondrias (algunas parcialmente degeneradas), abundantes cuerpos lipídicos, vacuolas y restos de membranas. Otros elementos son difíciles de interpretar como cuerpos densos irregulares o redondeados, así como material grumoso.

Entre las dos especies de $T$. mentagrophytes ( $v$. mentagrophytes y $v$. erinacei) existen diferencias que, no sólo permiten su separación y reconocimiento como variedades distintas, sino también distinta constitución ultraestructural. En el micelio reproductor la $v$. mentagrophytes presenta gran variedad de hifas en "espiral" (Fig. 6-7), que no hemos observado en v. erinacei, aunque puede encontrarse alguna aislada (Rebel y Taplin 1974; Roberts y Mackenzie. 1986).

Los microconidios en ambas especies presentan una disposición distinta sobre la pared de las hifas. En la $v$. mentagrophytes se disponen formando a modo de racimos de uvas, son redondos, unidos por un fino pedículo y desprendiéndose con facilidad. En la v. erinacei aparecen unidas a la hifa por un pediculo más amplio que puede simular racimos pero con distinta disposición (comparar Fig. 3-4 con 44-45-46). En ambas especies hemos encontrado microconidios dispuestos sobre las hifas en forma de clavija, abundantes en la v. mentagrophytes escasos en la v. erinacei (comparar Fig. 5 con Fig. 47).

Otra diferencia que hemos hallado es la presencia en la v. erinacei de abundantes clamidosporos, algunos llamativamente grandes, que no hemos encontrado descritos en la bibliografía consultada (Fig. 51). 
En los macroconidios también hemos encontrado algunas diferencias: son más cortos y rechonchos en la $v$. erinacei y más largos y fusiformes en la $v$. mentagrophytes (comparar Fig. 9-10 con 52-53).

Con el MET también hemos reconocido diferencias importantes entre las dos variedades. En la v. mentagrophytes hemos podido estudiar en cortes seriados las distintas fases de apertura o cierre del poro septal, desde un pequeño orificio que apenas permite el paso a pequeñas gotas lipídicas (Fig. 13-14 y 15), hasta apertura completa, difícil de reconocer pues aparece como un segmento largo no tabicado, que permite el paso de cualquier elemento de material citoplasmático (incluyendo el núcleo) a ambos lados en los que únicamente los bordes laterales del septo permiten su identificación (Fig. 16). Estos hallazgos no los hemos podido reconocer con la misma nitidez en la variedad erinacei ni se han encontrado en otros estudios (Amer y col., 1993).

En cuanto al contenido citoplasmático de las hifas el hallazgo más significativo ha sido la presencia, en la $v$. erinacei, de abundantes cuerpos densos esféricos y menor la de los cuerpos lipídicos. La presencia de mitocondrias ha sido frecuente en ambas especies. En los microconidios también existen diferencias entre ambas variedades; en la v. mentagrophytes hemos podido secuenciar la formación del microconidio sobre la capa externa de la pared de la hifa, iniciándose como una verrucosidad de mayor densidad electrónica (Fig. 11), que posteriormente va diferenciando su pared y contenido citoplasmático (Fig. 12). En la $v$. erinacei los microconidios también se forman en la capa externa de la pared de la hifa, pero tienen un pedículo de inserción más amplio (Fig. 55-56 y 57), su pared aparece bien diferenciada con dos capas, una externa y otra interna, y en su citoplasma pueden observarse nítidamente mitocondrias y cuerpos densos redondeados y bien delimitados, que podrían corresponder al núcleo (Fig. 58).

En los macroconidios, aparte de las diferencias ya señaladas con el MEB, la estructura y contenido es muy similar en ambas variedades, con pared y septos gruesos y un contenido citoplasmático donde la diferencia más significativa ha sido la presencia, en el $T$. erinacei, de abundantes cuerpos densos. 
Las hifas del micelio reproductor de $M$. canis no presentan rasgos diferenciales significativos, como ocurre en otras especies de dermatofitos (M. andoninni con hifas "pectinadas", T. schonleinii en forma de "candelabros", etc). Con el MET puede reconocerse claramente la pared con sus dos capas, los septos formados por la capa interna de la pared y, en el citoplasma, la presencia de mitocondrias, cuerpos densos mal definidos, abundantes cuerpos lipídicos y vacuolas. A nivel del septo hemos podido estudiar y secuenciar el inicio de apertura del poro, con la presencia de cuerpos de Woronin y el paso de contenido citoplasmático a uno y otro lado (Fig. 31-32 y 33).

El rasgo diferencial más importante del micelio reproductor de $M$. canis es la presencia de grandes macroconidios tabicados (con seis o más tabiques) y superficie cubierta de "espinas", por su aspecto cuando las observamos con microscopía óptica en tomas directas de la colonia con azul de lactofenol. El estudio de los macroconidios con el MEB permite visualizar aspectos inéditos hasta 1979 (Martín Pascual y Vázquez, 1979; Vázquez y col., 1990) y que nosotros hemos confirmado. La superficie del macroconidio aparece cubierta de unas formaciones semejantes a "copos de algodón", que corresponden a las “espinas” observadas por microscopia óptica (Fig. 21 y 22).

Con el MET se analiza la gruesa pared del macroconidio cuya capa interna forma los septos (Fig. 34) y, sobre la externa, electrodensa, aparecen las formaciones algodonosas descritas constituidas por filamentos como penachos muy característicos (Fig. 35 A-B-C). El citoplasma contiene abundante material donde se reconocen mitocondrias, cuerpos densos, vacuolas y restos de membranas (Fig. 36-37 y 38).

En otros dermatofitos del género Microsporum, como el M. gypseum, especie geófila que puede parasitar el hombre y distintos animales, se han descrito rasgos ultraestructurales diferenciales con el $M$. canis, a nivel de macroconidios y menos en hifas, en ambas especies existe una importante actividad a nivel del poro septal con presencia de cuerpos de Woronin (Martín Pascual y Vázquez, 1979; Vázquez y col., 1990). 
Por todo lo expuesto en nuestros resultados, las diferencias que hemos encontrado en las especies estudiadas, vienen a confirmar los rasgos morfológicos que diferencian a cada uno de ellos, pero no aportan evidencias en relación con su distinta patogenicidad. Es evidente también que los rasgos genéticos que marcan estas diferencias son los responsables de su comportamiento patógeno. No obstante, los métodos de identificación basados en cultivos estándar son lentos ( 2 a 4 semanas) e imprecisos debido al pleomorfismo fenotípico de los hongos (Makimura y col., 1999; Grasser y col., 2000) más patente aún en el género Trichophyton, en el que la identificación se hace más compleja por el uso de sinónimos para la misma especie (Ohst y col., 2004; Grasser y col., 2006; Kong y col., 2008). Además, los dermatofitos, como la mayoría de los hongos patógenos, presentan características ambientales cambiantes dependiendo del hábitat en el que se desarrollan. Por todo ello y con el objetivo de mejorar la taxonomía y las características epidemiológicas de los hongos, se están utilizando, en las últimas décadas, diversas técnicas enmarcadas en la biología molecular, para analizar filogenéticamente a los hongos, lo que posee un gran interés taxonómico y epidemiológico.

Los estudios pioneros en analizar las relaciones evolutivas entre diferentes especies de hongos se han basado en técnicas de biología molecular, tales como el análisis RFLP o de polimorfismos de longitud de fragmentos de restricción (Kanbe y col., 2003a,b); huellas digitales de ADN mediante PCR o reacción en cadena de la polimerasa (Pounder y col., 2005); amplificación y secuenciación del gen de la subunidad mayor del RNA ribosómico o técnica LSU (Leclerc y col., 1994); técnicas ITS o de secuenciación de la región del espacio intergénico (Gräser y col., 1999, Summerbell y col., 1999, Makimura y col., 1999); estudio de los genes de la "chitin" sintasa y del DNA topoisomerasa II (Hirai y col., 2003).

En la actualidad, ha adquirido gran relevancia para el estudio de los hongos el análisis del ADN mitocondrial ya que se ha aceptado que las mitocondrias son descendientes de las alfa-protobacterias endosimbióticas (Martin y Muller, 1998; Bullerwell y Lang, 2005) y consideradas con un origen monofilético (Lang y col., 1999; Gray, 1999; Andersson y col., 2003). 
El genoma mitocondrial de los hongos contiene 14 genes que codifican para proteínas conservadas, 22-28 genes tARN y 2 genes rARN (Gray, 1999, Sideris y col., 1988; Clark-Walker, 1992; Bertrand, 2000). La divergencia del ADN mitocondrial entre diferentes especies está asociada con variaciones en las regiones intergénicas, secuencias intrónicas y ordenación de los genes (Bullerwell y Gray, 2004: Bullerwell y col., 2003). Las secuencias de ADN se utilizan cada vez más en los análisis filogenéticos debido a que unos pocos cientos de bases, con su cantidad enorme de combinaciones potenciales, bastan para hacer análisis de identificación y parentesco.

Con la técnica del ADN mitoncondrial, se ha podido observar que los dermatofitos constituyen un grupo homogéneo de especies con baja diversidad genética, lo que contrasta con la alta heterogeneidad fenotípica (Kac, 2000; Gräser y col., 2008). La composición y organización de los genes en el ADN mitocondrial de todos los dermatofitos hasta ahora analizados (Wu y col., 2009) son básicamente idénticos, reforzando así la hipótesis de que los dermatofitos están íntimamente relacionados y constituyen un linaje altamente conservado como hongos filamentosos. Además, el análisis filogenético ha confirmado que los dermatofitos tienen un origen monofilético, por lo que forman un clado (rama del árbol filogenético) distinto de otros hongos filamentosos. Comparados con otros hongos patógenos como los causantes de infecciones invasivas, los dermatofitos integran un linaje relacionado, pero a la vez divergente en el tiempo, de los hongos ascomycotas, ya que surgen de éstos en épocas muy tardías (Wu y col., 2009). Muestras fósiles han permitido datar la aparición de los ascomycota (Taylor y col., 1999). Basados en esta calibración, se puede estimar que el linaje dermatofitico se separó de otros hongos hace unos 32 millones de años (Harmsen y col., 1995). La alta conservación del genoma mitocondrial de las diferentes especies de dermatofitos sugiere que éstas divergieron de un tronco común solo en épocas recientes

La taxonomía fenotípica convencional que divide a los dermatofitos en 3 géneros (Trichophyton, Microscporum y Epidermophyton) comienza a tambalearse por los recientes estudios filogenéticos moleculares, los cuales revelan que tanto el Thichophyton como el Microsporum son parafiléticos (Gräser y 
col., 1999) por lo que urge una reevaluación de las relaciones filogenéticas entre los diferentes dermatofitos (Gräser y col., 2008). Sorprendentemente, la divergencia del $T$. ajelloi del ancestro común fue mucho más precoz que la de otras especies de dermatofitos, lo cual es consecuente con las características geofílicas del T. ajelloi: el terreno podría haber ofrecido un nicho ecológico temprano para todas las especies de dermatofitos antes de una adaptación más tardía a huéspedes especializados, incluidos los animales y el hombre. Un trabajo previo basado en las secuencias $25 \mathrm{~S}$ de rARN informó que $T$. ajelloi y T. terrestre se separaron a partir de un "dermatofito verdadero" (Leclerc y col. 1994) y sugiere, además, que Microsporum, asi como las especies de Trichophyton zoofílicas y antropofílicas procederían de un miembro geofílico de Trichophyton (Gräser y col., 1999).

El uso de técnicas moleculares augura un futuro relevante para la micología en la que se obtendrán datos que permitan conocer diferencias moleculares entre las especies de hongos y profundizar en su desarrollo filogenético (Mochizuki y col., 1996; Makimura y col., 1998; Probst y col., 2007; Sharma y col., 2007; Arenas, 2008). Con estos datos se podrán diferenciar y reconocer distintas cepas de un mismo hongo (Abdel-Rahman, 2008), incluso en lesiones múltiples en un mismo individuo, habitualmente atribuidas a autoinoculaciones por el mismo hongo, se han reconocido cepas diferentes (Cano y col., 2005). No obstante, esta "Taxonomía basada en ADN" aún adolecería de muchos de los problemas que tienen los demás enfoques, como puede ser el límite de la circunscripción de los taxones o el tener que decidir qué secuencia usar, ya que algunas secuencias no dan una información que diferencie al taxón de los demás. La causa puede estar en que un mismo gen se mantenga inalterado durante millones de generaciones después de la especiación, o debido al fenómeno de introgresión (de esa forma un gen que se había diferenciado vuelve a su estado anterior). Por tanto, de la misma forma en que no es conveniente confiar en un solo carácter morfológico para identificar una especie, tampoco es conveniente confiar en una sola secuencia de ADN (Mallet y Willmott 2003). 
Mientras llega ese futuro, creemos, sin embargo, que la descripción de caracteres visibles puede ser de uso más inmediato y definitivamente más interesantes que la lectura de las secuencias de ADN y, en este sentido, nuestro trabajo aporta conocimientos nuevos e interesantes sobre la estructura de estos hongos $y$, en cierto modo también, sobre su comportamiento biológico, como el cierre o apertura del poro septal, permitiendo el paso de material citoplasmático en ambos compartimentos de la hifa, así como la presencia de cuerpos de Woronin que, por su ubicación a ese nivel sugieren su participación en la regulación de la actividad del poro septal. 
Conclusiones 
Tras analizar los diferentes resultados obtenidos, mediante microscopía electrónica de ciertas especies de dermatofitos zoofílicos: Mentagrophytes (variedades mentagrophytes y erinacei) y Microsporum canis y después de contrastarlos con la información recogida en la bibliografía, hemos obtenido las siguientes conclusiones:

1.- Hay diferencias morfológicas estructurales entre las dos especies de $T$. mentagrophytes ( $v$. mentagrophytes y $v$. erinacei):

1.1.- La v. mentagrophytes posee abundantes hifas en espiral, no observadas en la $v$. erinacei.

1.2. - En la v. mentagrophytes los microconidios, muy abundantes, aparecen formando racimos con mínimo pedículo sobre las hifas, desprendiéndose con facilidad. En la v. erinacei, están adheridas a la superficie de la hifa, apelotonadas y con un pedículo de inserción bien diferenciado.

1.3.- Los clamidosporos, tanto terminales como intermedios, son frecuentes en ambas especies. La v. erinacei presenta clamidosporos terminales de gran tamaño, no vistos en la $v$. mentagrophytes.

1.4.- Los microconidios de la v. mentagrophytes se desarrollan a partir de verrucosidades electrodensas en la capa externa de la pared de la hifa, con escaso contenido citoplasmático, mientras que en la v. erinacei estas yemas iniciales presentan contenido con elementos citoplasmáticos bien desarrollados (núcleo, mitocondrias, vesículas, etc.). 
1.5.- Los macroconidios de la v. mentagrophytes son alargados y fusiformes. En la v. erinacei son más cortos y gruesos, con el extremo distal romo. Ultraestructuralmente no hemos encontrado diferencias significativas en los macroconidios de ambas especies.

1.6. - En la $v$. mentagrophytes es muy evidente el poro septal; en algunos sectores aparece totalmente permeable al paso de todo material citoplasmático, habiendo podido secuenciar este proceso. En cambio en la $v$. erinacei no hemos observado tanta actividad permaneciendo parcial o totalmente ocluido.

2.- Los macroconidios del M. canis tienen aspecto de "espinas" observadas como elementos algodonosos; ultraestructuralmente, son de mínimo grosor y aparecen formados por filamentos a modo de penachos.

En las hifas, el poro septal y los cuerpos de Woronin aparecen cuando el poro está parcialmente ocluido, lo que apoyaría su función en relación con la actividad del mismo.

3.- Tanto en el M. canis como en la $v$. mentagrophytes es evidente una mayor actividad a nivel del poro septal que en la $v$. erinacei, sin que este hecho nos permita asociarlo con mayor o menor patogenicidad.

Pablo Martín Clavijo 


\section{Bibliografía}


Abdel-Rahman SM. 2008. Strain differentation of dermatophytes. Mycopathologia. 166: 319-333.

Ajello L. 1968. A taxonomic review of the dermatophytes and related species. Sabourandia. 6: 147-159.

Ajello L, Cheng SL. 1967. The perfect state of trichophyten mentaprofhytes. Sabounrandia. 5: 230-234.

Ajello L, Georg LK. 1957. In Vitro hair cultures for differenciating between atypical isolates of trichophyton mentagrophytes and trichophyton rubrum. Mycopathol. Mycol. Appl. 8: 3-17.

Ajello L. 1962. Present day concepts of dermatophytes. Mycopathol. Mycol. Appl. 17: $315-324$

Ajello L. 1974. Natural history of the dermatophytes and related fungi. Mycopathol. Mycol. Appl. 53: 93-110.

Aljabre SH, Richardson MD, Scott EM, Rashid A, Shankland A. 1993. Adherence of arthroconidia and germlings of anthrophylic and zoophilic varieties of Trichopyton mentagrophytes to human corneocytes as early events in the pathogenesis of dermathophytosis. Clin. Exp. Dermatol. 18: 231:235.

Alonso-Monge R, Roman E, PlaY, Nombela E. 2008. A host view of the fungal cell wall, Chapter 11 of Evolutionary bilogy of bacterial and fungal pathogenes. Edit by F. Baquero, C. Nombela, G.H. Cassell, and J.A. Gutierrez, ASM Press, Washington, D.C.

Amer MA, Taha M, Diab NA, el Moughith A, el Harras M. 1993. Ultrastructure of Trichophyton violaceum. Int. J. Dermatol. 32: 97-99

Anderson JB. 2005. Evolution of antifungal drug resistence; mechanisms and pathogen fitness. Nat. Rev. Microbiol. 3: 547-556.

Andersson SG, Karlberg O, Canback B, Kurland CG. 2003. On the origin of mitochondria: a genomics perspective. Philos. Trans. R. Soc. Lond. B. Biol. Sci. 358: 165-177.

Arenas Guzman P. 2008. Micología Médica Ilustrada. McGraw-Hill, Madrid.

Bates S, Hughes HB, Munro CA, Thomas WP, MacCallum DM, Bertram G, Atrih A, Ferguson MA, Brown AJ, Odds FC, Gow NA. 2006. Anter chain N. Glycans are required for cell wall integrity and virulence of Candida albicans. J. Biol. Chem. 281: 90-98.

Bergmans AM, Schouls LM, van der Ent M, Klaassen A, Böhm N, Wintermans RG. 2008. Validation of PCR-reverse line blot, a method for rapid detection and identification of nine dermatophyte species in nail, skin and hair samples. Clin. Microbiol. Infect. 14: 778-788.

Bertrand H. 2000. Role of mitochondrial DNA in the senescence and hypovirulence of fungi and potential for plant disease control. Annu. Rev. Phytopathol. 38: 397422.

Blank H, Sagami S, Boyd C, Roth FJ. 1959. The pathogenesis of superficiel fungons infectionms in cultures human skin. Arch. Derm. 79: 524-535.

Bofill P, Rivas A, Ramírez W, Montañez J, Quincoses T, González L, Fustes E. Dermatomicosis. 1996. En: Manual de enfermedades Infecciosas. T. № 3. 84-100.

Bowman SM, Free SJ. 2006. The structure and synthesis of the fungal cell wall. Bio. Essays. 28: 799-808. 
Brown GD, Gordon S. 2001. Immune recognition. A new receptor for beta-glucans. Nature. 413: 36-37.

Bullerwell CE, Forget L, Lang BF. 2003. Evolution of monoblepharidalean fungi based on complete mitochondrial genome sequences. Nucleic. Acids. Res. 31: 1614-1623.

Bullerwell CE, Gray MW. 2004. Evolution of the mitochondrial genome: protist connections to animals, fungi and plants. Curr. Opin. Microbiol. 7: 528-534.

Bullerwell CE, Lang BF. 2005. Fungal evolution: the case of the vanishing mitochondrion. Curr. Opin. Microbiol. 8: 362-369.

Cabañes FJ. 2001. Identificación de hongos dermatofitos. Capítulo 12. Guía Práctica de Identificación y Diagnóstico en Micología Clínica. Revista Iberoamericana de Micología, Bilbao. ISBN: 84-607-3050-6

Calderon RA. 1989. Immunoregulation of dermatophytosis. Crit. Rev. Microbiol. 16: 338: 368.

Calvo MA, Agut M. 2001. Observations of Woronin bodies in Arthrinium aureum by scanning electron microscopy. Mycopathología. 135: 137-139.

Cano J, Rezusta A, Sole M, Gil J, Rubio MC, Revillo MJ, Guarro J. 2005. Intersingle-sequence-repeal-PCR. Typing as a new tool for identification of mycrosporum canis starins. J. Dermato. Sci. 39: 17-21.

Casadevall A, Pirofski LA. 1999. Host-pathogen interactions: redefining concepts of virulence and pathogeneticty. Infec. Immun. 67: 3703-3713.

Chaffin WL, López-Ribot JL, Casanova M, Gozalbo D, Martínez JP. 1998. Cell wall and secreted proteins of Candida albicans: identification, function, and expression. Microbiol. Mol. Biol. Rev. 62: 130-180.

Chastain MA, Reed RJ, Pankey GA. 2001. Deep dermatophytosis: report of 2 cases and review of the literature. Cutis. 67: 457-462.

Chen AWJ, Kuo JWL, Chen JS, Sun CC, Huang SF. 1993. Dermatophyte pseudomycetoma: A case report. Br. J. Dermatol. 129: 729-732.

Chmel L, Buchvald J. 1970. Ecology and transmission of Mycrosporum gypseum from soil to man. Sabourandia. 8: 149-156.

Clark-Walker GD. 1992. Evolution of mitochondrial genomes in fungi. Int. Rev. Cytol. 141: 89-127.

Collinge AJ, Markham P. 1987. Nuclei plug septal pores in severed hyphae of Sordaria brevicollis. FEMS Microbiology Letters 44: 85-90.

Collinge J, Markham P. 1985. Woronin bodies rapidly plug septal pores of severed Penicillium chrysogenum hyphae. Experimental Mycology. 9: 80-85.

Connole MD. 1965. Keratinophilic fungi on cats and dogs. Sabourandia. 4: 45-48.

Dawson Ch O, Gentles JC, Brown EM. 1964. Environmental conditions affecting sexual reproduction in species of Arthroderma and Nannizzia. Sabourandia. 3: 245250.

De Hoog GS, Queiroz-Telles F, Haase G, Fernandez-Zeppenfeldt G, Attili Angelis D, Gerrits Van Den Ende AH, Matos T, Peltroche-Llacsahuanga H, PizziraniKleiner AA, Rainer J, Richard-Yegres N, Vicente V, Yegres F. 2000a. Black fungi: clinical and pathogenic approaches. Med. Mycol. 38 Suppl 1: 243-250. 
De Hoog GS, Mayser P, Haase G, Horré R, Horrevorts AM. 2000b. A new species, Phialophora europaea, causing superficial infections in humans. Mycoses. 43: 409416.

Dueck L, Kaufman G, Ulman Y, Berdicencky I. 2004. The pathogenesis of dermathophyte infections in human skin sections. J. Infect. 48: 175-180.

Emmons CW. 1934. Dermatophytes: natural groupings based on the form of the spores and accessory organs. Arch. Dermatol. Syphilol. 30: 337-362.

English MP, Evans CD, Hewitt M, Warin RP. 1962. Hedgehog ringworm. Br. Med. J. 20: $149-151$.

English M.P. 1972. The epidemiology of animal ringworm in man. Brit. J. Derm. 86 suppl. 8: 78-87.

Erhard M, Hipler UC, Burmester A, Brakhage AA, Wöstemeyer J. 2008. Identification of dermatophyte species causing onychomycosis and tinea pedis by MALDI-TOF mass spectrometry. Exp. Dermatol. 17: 356-361.

Georg LK. 1954. The relationship between the downy and granuler forms of trichophyton mentaprofhytes. J. Invert. Dermat. 23: 123-141.

Georg LK. 1960. Epidemiology of the dermathophytoses: source of infection, moder of transmission and epidemicity. Ann. New York Acad. Sc. 89: 369-77.

Ghahfarokhi M. S., M. Goodarzi, M.. R. Abyaneh, T. Al-Tiraihi, G. Seyedipur, 2004. Morphological evidences for onion-induced growth inhibition of Tricophyton rubrum and Trichophyton mentagrophytes. Fitoterapia. 75: 645:655.

Grappel SF, Blan F. 1972. Role of keratinases in dermatophytosis. I. Immune responses of guinea pigs infected with Trichiphyton mentagrophytes and guinea pig immunized with keratinases. Dermatologica. 145: 245-255.

Gräser Y, De Hoog S, Summerbell RC. 2006. Dermatophytes:recognizing species of clonal fungi. Med. Mycol. 44: 199-209.

Gräser Y, Kuijpers AF, Presber W, de Hoog GS. 2000. Molecular taxonomy of the Trichophyton rubrum complex. J. Clin. Microbiol. 38: 3329-3336.

Gräser Y, Fari ME, Vilgalys R, Kuijpers AFA, Hoog GSD, Presber W,Tietz HJ. 1999. Phylogeny and taxonomy of the family Arthrodermataceae (dermatophytes) using sequence analysis of the ribosomal ITS region. Medical Mycology. 37: 105-114

Gräser Y, Scott J, Summerbell R. 2008. The new species concept in dermatophytes, a polyphasic approach. Mycopathologia.166: 239-256.

Gray MW. 1999. Evolution of organellar genomes. Curr. Opin. Genet. Dev. 9: 678687.

Grosshans E, Schwaab E, Samsoen M, Grange D, Koenig H, Kremer M. 1986. Clinical aspects, epidemiology and economic impact of foot epidermomycosis in an industrial milieu. Ann. Dermatol. Venereol.113: 521-533.

Gruby D. 1841. Mémorie sur une végétation qui constituent la vraie teigne. C. R. Acad. Sci. 13: 72-75.

Harmsen D, Schwinn A, Weig M, Brocker EB, Heesemann J. 1995. Phylogeny and dating of some pathogenic keratinophilic fungi using small subunit ribosomal RNA. J. Med. Vet. Mycol. 33: 299-303.

Hawksworth DL, Kirk PM, Sutton BC, Pegler DN. 1995. Ainsworth and Bisby's Dictionary of the Fungi. 8th edn. Wallingford: $C A B$ International. 
Hay RJ, Calderon RA, Mackenzie CD. 1988 Experimental dermatophytosis in mice: correlation between light and electron microscopic changes in primary, secondary and chronic infections. Br. J. Exp. Pathol. 69:703-716.

Hildick-Smith G, Blank H, Sarcany I. 1964. Fungus diseases and their treatment. Little, Brown and company. Boston.

Hirai A, Kano R, Nakamura Y, Watanabe S, Hasegawa A. 2003. Molecular taxonomy of dermatophytes and related fungi by chitin synthase 1 (CHS1) gene sequences. Antonie Van Leeuwenhoek. 83: 11-20.

Hopfer RL, Walden P, Setterquist S, Highsmith WE. 1993. Detection and differentiation of fungi in clinical specimens using polymerase chain reaction (PCR) amplification and restriction enzyme analysis. J. Med. Vet. Mycol. 31: 65-75.

Hutton RD, Kerbs S, Yee K. 1978 Scanning electron microscopy of experimental Trichophyton mentagrophytes infections in guinea pig skin. Infect. Immun. 21: 247253.

Ito Y. 1965. On the immunologicaly active sustances of dermatophytes. J. Invest. Dermat. 45: 275-294.

Ito Y, Setoguti T, Nezowa Y. 1969. Cell walls of trichophyten mentaprophytes: Isolation and fine structure. Jap. J. Med. Mycal. 9: 171-173.

Jackson CJ. 2001. Molecular identification and strain typing of dermatophyte fungi. Nippon Ishinkin Gakkai Zasshi. 42: 7-10.

Jedd G, Chua NH. 2000. A new self assembled peroxisomal vesicle required for efficient releasing of the plasma membrane. Nat. Cell. Biol. 2: 226-231.

Jones HE, Reinhardt JH, Rinaldi MG. 1974. Immunology susceptibility to cronic dermatophytosis. Arch. Derm. 110: 213-220.

Jones HE. 1993. Immune response and host resistance to human dermathophyte infection. J. Am. Acad. Dermatol. 28:12-18.

Kaaman T, Forslind B. 2001. Ultraestructural studies on experimental hair infections in vitro caused by Trichopython mentagrophytes and Trichopyton rubrum. Nippon Ishinkin Gakkai Zasshi. 42: 55-59.

Kac G. 2000. Molecular approaches to the study of dermatophytes. Med. Mycol. 38: 329-336.

Kanbe T, Suzuki Y, Kamiya A, Mochizuki T, Fujihiro M, Kikuchi A. 2003a. PCRbased identification of common dermatophyte species using primer sets specific for the DNA topoisomerase II genes. J. Dermatol. Sci. 32: 151-161.

Kanbe T, Suzuki Y, Kamiya A, Mochizuki T, Kawasaki M, Fujihiro M, Kikuchi A. 2003b. Species-identification of dermatophytes Trichophyton, Microsporum and Epidermophyton by PCR and PCR-RFLP targeting of the DNA topoisomerase II genes. J. Dermatol. Sci. 33: 41-54.

Kane J, Summerbell R, Sigler L, Krajden S, Land G. 1997. Laboratory handbook of dermatophytes and other filamentous fungi from skin, hair and nails. Belmont, Star Publishing Co.

Kaufman G, Horwitz BA, Duek L, Ullman Y, Berdicevsky I. 2007. Infection stages of the dermathophyte pathogen Trichophyton: microscopic characterization and proteolytic enzymes. Med. Mycol. 45: 149-155. 
Kawasaki M, Aoiki M, Ishizaki H. 1995. Philogenetic relationship of some Microscoporum and Arthroderma species inferred from mitochondrial DNA analysis. Micopathologia, 130: 11-21.

Kellenberger F, Rytter A, Sechaud J. 1958. Electron microscope study of DNAcontainings plasms. II. Vegetative and matute phage DNA as compared with normal bacterial nucleoids in diffetent physiological states. J. Biophys. Biochem. Cytol. 4: 671-678.

Khosravi AR, Aqhamiriam MR, Mahmoudi M. 1994. Dermatophytoses in Iran. Mycoses. 37: 43-8.

Kimbrough JW. 1991. Ultrastructural observations on Helvellaceae (Pezizales, Ascomycetes). V. Septal structures in Gyromitra. Mycological Research 95: 421-426.

King RD, Khan HA, Foyce JC, Greenberg, JH, Jones HE. 1975. Transferrin, iron, and dermatophytes. I. Serum dermatophyte inhibitory component definitively identified as unsaturated transferring. J. Clin. Med. 86: 204-212.

Kligman AM. 1956. Pathophysiology of ringworm infection in animal with skin cycles. J. Invest. Dermat. 27: 171-185.

Kohn LM. 1992. Developing new characters for fungal systematic: an experimental approach for determining the rank of resolution. Mycologia. 84: 139-153.

Kong F, Tong Z, Chen X, Sorrell T, Wang B, Wu Q, Ellis D, Chen S. 2008. Rapid identification and differentiation of Trichophyton species, based on sequence polymorphisms of the ribosomal internal transcribed spacer regions, by rollingcircle amplification. J. Clin. Microbiol. 46:1192-1199.

Kwon-Chung KJ, Bennett JE. 1992. Medical mycology. Phyladelphia, Lea \& Febiger.

Lang BF, Gray MW, Burger G. 1999. Mitochondrial genome evolution and the origin of eukaryotes. Annu. Rev. Genet. 33: 351-397.

Leclerc MC, Philippe H, Gueho E. 1994. Phylogeny of dermatophytesand dimorphic fungi based on large subunit ribosomal RNA sequence comparisons. J. Med. Vet. Mycol. 32: 331-341.

Li KN, Rouse DI, German TL. 1994. PCR primers that allow intergeneric differentiation of Ascomycetes and their application to Verticilum spp. Appl. Environ. Microbiol. 60: 4324-4331.

López R, Mason JO, Parker JS, Pappas PG. 1994. Intraocular blastomycosis: case report and review. Clin. Infect. Dis. 18: 805-807

Lorincz AL, Priestley LO, Jacobs PH. 1958. Evidence for humoral machanism wich presents growth of dermatophytes. J. Invest. Dermat. 31:15-17.

Maibach HI, Bashir SJ. McKibbon A. 2002. Evidence based dermatology. BC Decker Inc. Publising.

Makimura K, Mochizuki T, Hasegawa A, Uchida K, Saito H, Yamaguchi H. 1998. Phylogenetic classification of Trichophyton mentagrophytes complex strains based on DNA sequences of nuclear ribosomal internal transcribed spacer 1 regions. J. Clin. Microbiol. 36: 2629-2633.

Makimura K, Tamura Y, Mochizuki T, Hasegawa A, Tajiri Y, HanazawaR, Uchida K, Saito H, Yamaguchi H. 1999. Phylogenetic classification and species identification of dermatophyte strains based onDNA sequences of nuclear ribosomal internal transcribed spacer 1 regions. J. Clin. Microbiol. 37: 920-924. 
Makimura K. 2001. Species identification system for dermatophytes based on the DNA sequences of nuclear ribosomal internal transcribed spacer 1. Nippon Ishinkin Gakkai Zasshi. 42: 61-67.

Mallet J, Willmott, K. 2003. Taxonomy: Renaissance or Tower of Babel? Trends. Ecol. Evol. 18: 57-59.

Mares D, Fasulo MP. 1990. Ultrastructural alterations in Epidermophyton floccosum and Trichophyton mentagrophytes exposed in vitro to protoanemonin. Cytobios. 61: 89-95.

Markham P, Collinge AJ. 1987. Woronin bodies of filamentous fungi, FEMS Microbiology Reviews 46: 1-11.

Markham P. 1994. Occlusions of septal pores in filamentous fungi. Mycol. Res 98: 1089-1106.

Marples MJ, Smith JMB. 1960. The hedgehog as a source of human ringworm. Nature. 188: 867-868.

Martín Pascual A, Vázquez R. 1979. Dermatofitos (aspectos clínicos y morfología ultraestructural). Atlas. Ediciones Universidad de Salamanca, Salamanca.

Martin W, Muller M. 1998. The hydrogen hypothesis for the first eukaryote. Nature. 392: $37-41$.

Maruyama J, Juvvadi PR, Ishi K, Kitamoto K. 2005 . Three-dimensional image analysis of plugging at the septal pore by Woronin body during hypotonic shock inducing hyphal tip bursting in the filamentous fungus Aspergillus oryzae. Biochem. Biophys. Res. Commun. 331: 1081-1088.

Matsumoto T, Ajello L. 1987. Current Taxonimic concepts pertaining to the dermatophytes and related fungi. Int. J. Dermatol. 26: 491-499.

Mercer EH, Verma BS. 1963. An electron microscope examination. Arch. Derm 87: 357-360.

Mitchell AJ, Solomon AR, Beneke ES, Anderson TF. 1983. Subcutaneous alternariosis. J. Am. Acad. Dermatol. 8: 673-676

Mitchell TG. 1983. Dermatomicosis y otras micosis cutáneas. En: Zinsser Microbiología. Edit. Cient-Tec. №. 1291-1298

Mochizuki T, Ueara M, Ranganathan T. 1996. Minipreparation of total cellular DNA is usefull as an alternative molecular marker of mitocondrial DNA for the identification of Tricophyton mentagrophytes and T. Rubrum. Mycosis. 39: 31-35.

Moore RT. 1978. Taxonomic significance of septal ultrastructure with particular reference to the jelly fungi. Mycologia 70: 1007-1024.

Moore RT. 1985. The challenge of the dolipore/parenthesome septum. In: Developmental Biology of higher fungi (ed. D. Moore, LA Casselton, DA Woos \& JC Frankland), pp: 175-212. Cambridge University Press. Cambridge, UK.

Morris P, English MP. 1969. Trichophyten mentaprophytes ver. Erinacei in Britich hedgehops. Sabourandia 7: 122-128.

Muhsin TM, Hadi RB. 2001. Degradation of keratin substrites by fungi isolated from sewage sludge. Mycopathologic. 154: 185-189.

Nimrichter L, Rodrigues ML, Rodrigues EG, Travassos LR. 2005. The multitude of targets for the immune system and drug therapy in the fungal cell wall. Microbes Infect. 7: 789-798. 
Ogawa H, Summerbell RC, Clemons KV, Koga T, Ran YP, Rashid A, Sohnle PG, Stevens DA, Tsuboi R. 1998. Dermatophytes and host defence in cutaneous mycoses. Medical Mycology. 36: 166-173.

Ohst T, de Hoog S, Presber W, Stavrakieva V, Gräser Y. 2004. Origins of microsatellite diversity in the Trichophyton rubrum - T.violaceum clade (dermatophytes). J. Clin. Microbiol. 42: 4444-4448.

Osumi M, Yamada N, Yamada Y, Yamaguchi H. 1984. The effect of bifonazole on the structure of Trichophyton mentagrophytes. Dermatologica 169, Suppl 1: 1931.

Padhye AA, Sekhon AS, Carmichael JW. 1973. Ascocarp production by Nannizzia and Arthroderma on keratinons and non-keratinons media. Sabourandia 11: 109114.

Palumbi SR. 1996. Nucleic acids II: The polymerase chain reaction. In Hillis DM, Moritz C, Mable B (Eds). Molecular Systematics $\left(2^{\text {nd }} E d\right)$. Massachusetts, Sinauer associates Inc Pub, pp. 205-248.

Pazos C, Moragues MD, Quindós G, Pontón J, del Palacio A. 2006. Diagnostic potential of detection of (1-3)-B-D-glucan and antibodies to Candida albicans germ tubes for diagnosis and therapeutic monitoring of invasive candidiasis in neutropenic adult patients. Rev. Iberoam. Micol. 23: 209-215.

Pemán J, Martín-Mazuelos E, Rubio Calvo MC. 2001. Guía Práctica de Identificación y Diagnóstico en Micología Clínica. Revista Iberoamericana de Micología, Bilbao. ISBN: 84-607-3050-6

Pereiro M, Flórez A, Toribio J. 1999. Clasificación de dermatofitos mediante PCR. Rev. Iberoam. Micol. 16: S7-S10.

Pereiro M. 1979. Le sol. Reservoir des agents de mycoses opportunistas. Dermatología. 159: 60-69.

Pereiro M. 1982. Importancia de los dermatofitos en la patología humana y animal. J.M. Torres-Rodríguez edi. Dermatofitos y dermatofitosis. Barcelona.

Pereiro M. 1985. Aislamiento del suelo de agentes de micosis. Rev. Iber. Micol. 2: 141-157.

Pereiro MM, Pereiro M, Pereiro Y. 1991. Review of dermathophytoses in Galicia from 1951 to 1987, and comparision with other areas in Spain. Mycopathologia. 113: $65-78$.

Pock-Steen B, Kobayashi T. 1970. Ultrastucture of the Hyphal wall and septum of trichophyton mentaprophytes. J. Invest. Dermat. 55: 404-409.

Pontón J, Omaetxebarria MJ, Elguezabal N, Alvarez M, Moragues MD. 2001. Immunoreactivity of the fungal cell wall. Med Mycol, 39 (Supl. 1): 101-110.

Pontón P. 2008. La pared celular de los hongos y el mecanismo de acción de la anidulafungina. Rev. Iberoam. Micol. 25: 78-82.

Pounder JI, Williams S, Hansen D, Healy M, Reece K, Woods GL. 2005. Repetitivesequence-PCR-based DNA fingerprinting using the Diversilab system for identification of commonly encountered dermatophytes. J. Clin. Microbiol. 43: 2141-2147.

Probst S, Hoog GS, Presber W, Gräser Y. 2007. Development of DNA marker to explore host shifts in dermathophytes. Stud. Mycol. 47: 57-74.

Proença NG. 1990. Dermatophytosis in childhood: clinical and therapeutic aspects. Rev. Paul. Med. 108: 279-284. 
Quaife RA. 1966. Human infection due to the hedgehog fungus, trichophyton mentaprophytes var. erinacei. J. Clin. Path. 19: 177-178.

Rebel G, Taplin D. 1974. Dermatophytes. Their recognition and identification. University of Miami Press, $2^{\mathrm{a}}$ Edición.. Coral Gables, Florida.

Reichele RE, Alexander JV. 1965. Multiperforante septations, woroning bodies and septal plugs in fusarium. J. Cell. Biol. 24: 489-496.

Remak R. 1842. Gelungene inpfung des Favus. Med. Z. 11: 37.

Reynolds ES. 1963. The use of lead citrate at high $\mathrm{pH}$ as an electron-opaque stain in electron miscroscopy. J. Cell. Biol. 17: 208-212.

Roberts SOB, Mackenzie DWR. 1986. Mycology. Cap 25. textbook of Dermatology. Rook, A, Wilkinson, DS, Ebling, FJC, Champion, RH, Burton, JL. Blackwell Scientific.

Romani L. 2004. Immunity to fungal infections. Nat. Rev. Immunol. 4: 1-23.

Roth FJ.Jr, Boyd CC, Sagami S, Blank H. 1959. An evaluation of the fungistic activity of serum. J. Invest. Dermat. 32: 549-556.

Rothman S, Smiljanic A, Shapiro AL, Weitkamp AW. 1947. The spontaneous cure of tinea capitis in puberty. J. Invest. Dermat. 8: 81-98.

Rush-Munrd FM, Smith JMB. 1971. Furter observation on trichophyton erinacei and T. proliferans. Sabourandia 9: 61-64.

Sabouraud R. 1910. Les Teignes. Masson. Paris.

Sarkisov AK, Koromyslov G. 1983. Proposals for the prevention and control of dermatophytoses common to man and animals. Geneva; World Health Organization.

Sentamilselvi G, Janaki C, Kamalam A, Thambiah AS. 1998. Deep dermatophytosis caused by Trichophyton rubrum - A case report. Mycopathologia. 142: 9-11.

Sharma R, HoogGS, Presber, W, Gräser Y. 2007. A virulent genotype of Microsporum canis is responsible for the majority of human infection. J. Med. Microbiol. 56: 1377-1385.

Sideris EG, Charalambous SC, Tsolomyty A, Katsaros N. 1988. Mutagenesis; carcinogenesis and the metal elements DNA interaction. Prog. Clin. Biol. Res. 259: 1325.

Smith JMB, Marples MJ. 1963. Trichophyten mentagruphytes var erinacei. Sabourandia. 3: 1-10.

Smith KJ, Welsh M, Skelton H. 2001. Trichophyton rubrum showing deep dermal invasion directly from the epidermis in immunosuppressed patients. Br. J. Dermatol. 145: 344-348.

Summerbell RC, Haugland RA, Li A, Gupta AK. 1999. rRNA gene internal transcribed spacer 1 and 2 sequences of asexual, anthropophilic dermatophytes related to Trichophyton rubrum. J. Clin. Microbiol. 37: 4005-4011.

Takahashi Y, Sand A, Takizawa K. 2003. The epidermiology and mating behaviour of artheoderm benhamial var erinacei in honcehold four-toed hedgehogs (atelerix albiventris) in Japan. Jpn. J. Med. Mycol. 44: 31-38.

Takashio M. 1972. Sexual reproduction of some Arthroderma and Nannizzia of diluted Sabouraud agar with of without salts. Mykosen. 15: 11-17.

Taylor TN, Hass H, Kerp H. 1999. The oldest fossil ascomycetes. Nature. 399: 648. 
Tenney K, Hunt, Sweigard J, Pounder JI, McClain C, Bowman EJ, Bowman BJ. 2000. Hex-1, a gene unique to filamentous fungi, encodes the major protein of the Woronin body and functions as a plug for septal pores. Fungal Genet. Biol. 3: 205-217.

Trinci AP, Collinge AJ. 1974. Occlusion of the septal pores of damaged hyphae of Neurospora crassa by hexagonal crystals. Protoplasma. 80: 57-67.

Tsang P, Hopkins T, Jimenez-Lucho V. 1996. Deep dermatophytosis caused by Trichophyton rubrum in a patient with AIDS. J. Am. Acad. Dermatol. 34: 1090-1091.

Turnau K, Kottke I, Oberwinkler F. 1993. Comparative study of elongated and globose Woronin bodies using electron energy loss spectroscopy (EELS) and imaging (ESI). Mycological Research. 97:1499-1504.

Van Driel KGA, Arend F, van Peer AF, Grijpstra J, Wösten HAB, Verkleij AJ, Müller WH, Boekhout T. 2008. Septal Pore Cap Protein SPC18, Isolated from the Basidiomycetous Fungus Rhizoctonia solani, Also Resides in Pore Plugs. Eukaryotic Cell. 7: $1865-1873$.

Vanbreuseghem R. 1966. Guide practique de Mycologie Medical et Véterinarie. Masson, Paris.

Vannini GL, Mares D. 1975. Fine structural characterization of microbodies and Woronin bodies in Trichophyton mentagrophytes. Experientia. 31: 949-951.

Vázquez R, Riesco JM, Martín Pascual A. 1990. Dermatophyte morphology: A scanning electron microscopy study. Scanning Microscopy, 4: 363-374.

Velasco A, Martín Pascual A, García Pérez A. 1979. Epidemiologic study of Dermatophytoses in Salamanca (Spain). Sabourandia. 17: 113-123.

Voisard JJ, Weill FX, Beylot-Barry M, Vergier B, Dromer C, Beylot C. 1999. Dermatophytic granuloma caused by Microsporum canis in a heart-lung. Dermatology. 198: 317-319.

Weitzman I, McGinnis MR, Padhye AA, Ajello I. 1986. The Genus Arthroderma and its later synonym Nannizzia. Mycotaxon. 25: 505-518.

Weitzman I, Summerbell RC. 1995. The dermatophytes. Clinical Microbioloy reviews. 8: 240-259.

Werner HY, Jolly HW, Spurloch BO. 1966. Electron microscopie observations on the fine structure of microforum canis. J. Invest. Dermat. 46: 130-134.

Wood DA, Craig GD, Atkey PT, Newsam RJ, Gull K. 1985. Ultrastructural studies on the cultivation processes and growth and development of the cultivated mushroom Agaricus bisporus. Food Microstructure. 4:143-164.

Woronin M. 1865. Zur Entwicklungsgeschichte des Ascobolus pulcherrimus. Cr. und einiger Pezizen, Abhandlungen der Senckenbergischen Naturforschenden Gesellschaft. 5: 333-344.

Wu Y, Yang J, Yang F, Liu T, Leng W, Chu Y, Jin Q. 2009. Recent dermatophyte divergence revealed by comparative and phylogenetic analysis of mitochondrial genomes. BMC Genomics. 10: 238-252. doi: 10.1186/1471-2164/10/238. 